\title{
Macrophage Polarization and Its Role in Liver Disease
}

\author{
Cheng Wang ${ }^{\dagger}$, Cheng $\mathrm{Ma}^{\dagger}$, Lihong Gong, Yuqin Guo, Ke Fu, Yafang Zhang, \\ Honglin Zhou and Yunxia $\mathrm{Li}^{*}$
}

State Key Laboratory of Southwestern Chinese Medicine Resources, Key Laboratory of Standardization for Chinese Herbal Medicine, Ministry of Education, School of Pharmacy, Chengdu University of Traditional Chinese Medicine, Chengdu, China

\section{OPEN ACCESS}

Edited by:

Yan Shi,

Tsinghua University, China

Reviewed by:

Katsunori Yoshida,

Kansai Medical University, Japan

Yifang Gao,

The First Affiliated Hospital of

Sun Yat-sen University, China

*Correspondence:

Yunxia Li

lyxtgyxcdutcm@163.com

${ }^{\dagger}$ These authors have contributed equally to this work

Specialty section:

This article was submitted to Antigen Presenting Cell Biology, a section of the journal

Frontiers in Immunology

Received: 27 October 2021 Accepted: 29 November 2021 Published: 14 December 2021

Citation:

Wang C, Ma C, Gong L, Guo Y, Fu K,

Zhang Y, Zhou H and Li Y (2021)

Macrophage Polarization and

Its Role in Liver Disease.

Front. Immunol. 12:803037.

doi: 10.3389/fimmu.2021.803037
Macrophages are important immune cells in innate immunity, and have remarkable heterogeneity and polarization. Under pathological conditions, in addition to the resident macrophages, other macrophages are also recruited to the diseased tissues, and polarize to various phenotypes (mainly $\mathrm{M} 1$ and $\mathrm{M} 2$ ) under the stimulation of various factors in the microenvironment, thus playing different roles and functions. Liver diseases are hepatic pathological changes caused by a variety of pathogenic factors (viruses, alcohol, drugs, etc.), including acute liver injury, viral hepatitis, alcoholic liver disease, metabolic-associated fatty liver disease, liver fibrosis, and hepatocellular carcinoma. Recent studies have shown that macrophage polarization plays an important role in the initiation and development of liver diseases. However, because both macrophage polarization and the pathogenesis of liver diseases are complex, the role and mechanism of macrophage polarization in liver diseases need to be further clarified. Therefore, the origin of hepatic macrophages, and the phenotypes and mechanisms of macrophage polarization are reviewed first in this paper. It is found that macrophage polarization involves several molecular mechanisms, mainly including TLR4/NF- $\kappa B$, JAK STATs, TGF- $\beta$ /Smads, PPAR $\gamma$, Notch, and miRNA signaling pathways. In addition, this paper also expounds the role and mechanism of macrophage polarization in various liver diseases, which aims to provide references for further research of macrophage polarization in liver diseases, contributing to the therapeutic strategy of ameliorating liver diseases by modulating macrophage polarization.

Keywords: macrophage polarization, liver disease, acute liver injury, viral hepatitis, alcoholic liver disease, metabolic-associated fatty liver disease, liver fibrosis, hepatocellular carcinoma

\footnotetext{
Abbreviations: Akt, protein kinase B; ALD, alcoholic liver disease; ALI, acute liver injury; AMPK, AMP-activated protein kinase; APAP, acetaminophen; Arg1, arginase 1; AIH, autoimmune hepatitis; cAMP, cyclic adenosine monophosphate; $\mathrm{CCL}_{4}$, carbon tetrachloride; D-GalN, D-galactosamine; ECM, extracellular matrix; EVs, extracellular vesicles; HBV, hepatitis B virus; HCC, hepatocellular carcinoma; HCV, hepatitis C virus; HFD, high-fat diet; HSC, hepatic stellate cell; IFN- $\gamma$, interferon- $\gamma$; IL, interleukin; iNOS, inducible nitric oxide synthase; IRF, interferon regulatory factor; JAK, Janus kinase; LF, liver fibrosis; IncRNA, long noncoding RNA; LPS, lipopolysaccharide; MAPK, mitogen-activated protein kinase; miRNA, microRNA; MMP, matrix metalloproteinase; MSC, mesenchymal stem cell; mTOR, mechanistic target of rapamycin; MyD88, myeloid differentiation factor 88; MAFLD, metabolic-associated fatty liver disease; NASH, nonalcoholic steatohepatitis; NF- $\kappa \mathrm{B}$, nuclear factor-KB; NLRP3, NOD-like receptor protein 3; PI3K, phosphatidylinositol-3-kinase; PKA, protein kinase A; PPAR, peroxisome proliferators-activated receptor; PBC, primary biliary cholangitis; PSC, primary sclerosing cholangitis; SOCS, suppressor of cytokine signaling; STAT, signal transducer and activator of transcription; TAA, thioacetamide; TAMs, tumor associated macrophages; TGF- $\beta$, transforming growth factor- $\beta$; TLR, toll like receptor; TNF- $\alpha$, tumor necrosis factor- $\alpha$.
} 


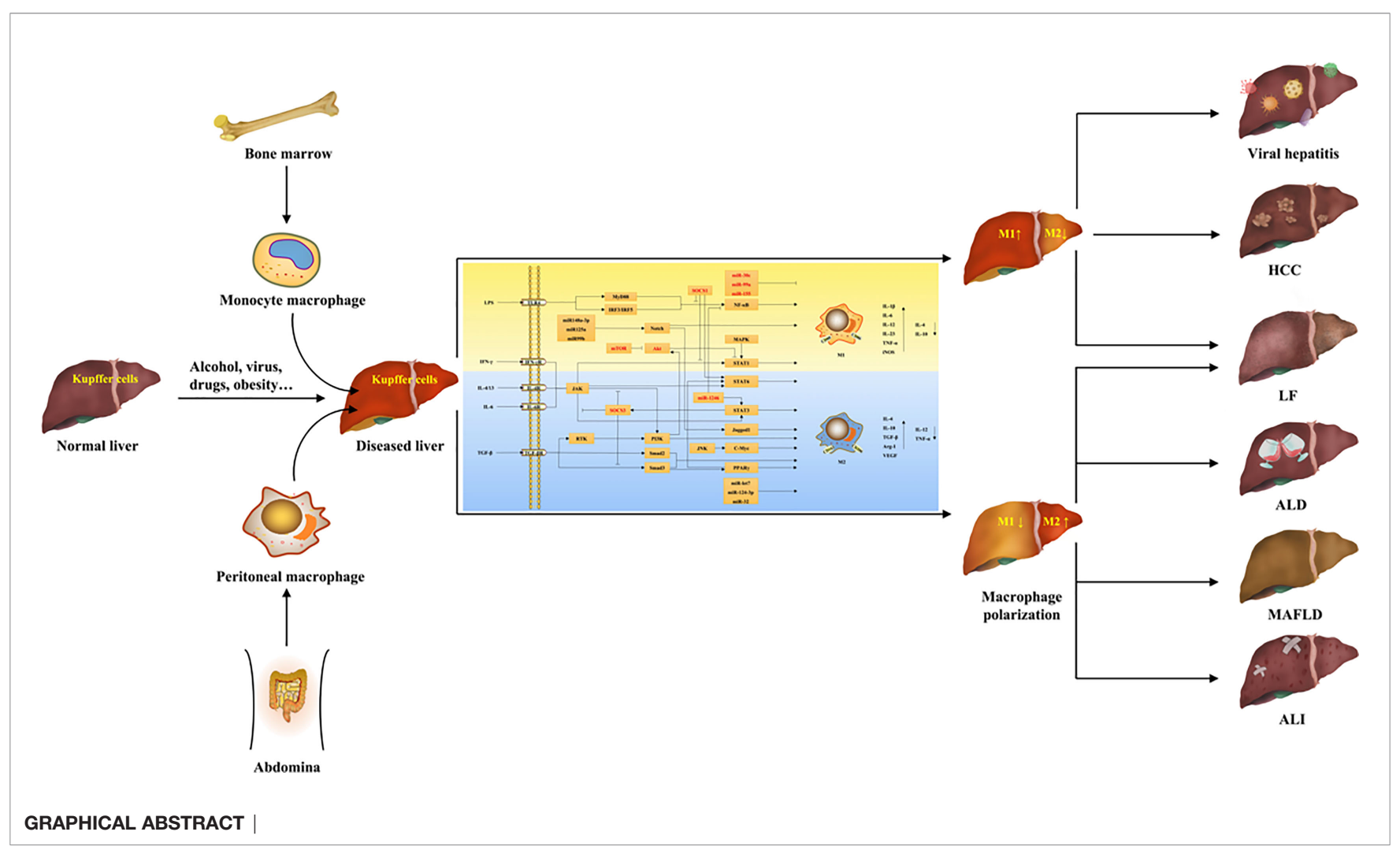

\section{INTRODUCTION}

The liver is an essential organ for maintaining normal life activities of the human body, because it not only regulates the metabolism of many nutrients and chemical drugs, but also has many functions such as synthesizing and decomposing proteins, regulating systemic blood volume, excluding body toxins, and regulating immunity (1). Liver diseases refer to hepatic pathological changes caused by a variety of pathogenic factors both inside and outside, which largely affect the normal physiological function of the human body. At present, numerous factors can trigger liver diseases, such as drugs, chemical agents, viral infection, excessive alcohol consumption, malnutrition, acid-base disorders, etc. (2-4). Based on the different etiologies and pathogenesis, liver diseases are classified as acute liver injury (ALI), viral hepatitis, alcoholic liver disease (ALD), metabolic-associated fatty liver disease (MAFLD), liver fibrosis (LF), cirrhosis, and hepatocellular carcinoma (HCC) (5). Due to the changes of living environment and the guaiac irregularity of life habits, the number of patients with liver diseases is increasing worldwide in recent years, which has gradually developed into a global public health problem. According to the epidemiological statistics, the number of global deaths caused by end-stage liver diseases such as viral hepatitis, cirrhosis and HCC is up to 2 million every year (6). Therefore, clarifying the pathogenesis of liver diseases and developing drugs for their targeted therapy are of great significance for the clinical treatment of liver diseases.
Macrophages are essential components of the innate immune system, and the activation of macrophages has been shown to be indispensable in several aspects, such as immune defense, inflammatory response, tissue remodeling, and homeostasis (7). Macrophages are distributed in nearly all tissues of the body, and are remarkably heterogeneous (8). In addition to the self-renewing resident macrophages originating in the yolk sac or embryonic hematopoietic stem cells, particularly under pathological conditions, macrophages of other origins are also continuously recruited to the tissues (8). For example, in liver tissues, in addition to Kupffer cells residing permanently within the hepatic sinuses, there are also abdomen-derived macrophages and bone marrowderived monocyte macrophages (9). More importantly, macrophages have extreme plasticity, which can exhibit different activation states due to the changes of tissue microenvironment (10). Macrophages differentiate into different phenotypes under the stimulation of various factors, and exhibit different characteristics and effects, thus exerting different regulatory functions in the body's physiological and pathological activities, which is also known as the polarizing effect of macrophages (10).

In recent years, a large body of literature has shown that macrophage polarization plays a crucial role in many pathophysiological processes, such as inflammation, tumor, tissue repair, and metabolism (11-13). Interestingly, these pathological processes are precisely also present in liver diseases, suggesting that macrophage polarization may be critically involved in the development and reversal of several liver diseases, such as fatty liver disease, hepatitis, fibrosis, and HCC (14-16). With the 
further study of macrophage polarization in liver diseases, targeting macrophage polarization to block or even reverse hepatic pathological changes has been considered as a potential strategy for the treatment of liver diseases (17). However, the origin of hepatic macrophages and the mechanism of macrophage polarization are complex, and their effects on different types of liver diseases and even on different stages of one liver disease are not the same (18). Therefore, the process of macrophage polarization and its role and mechanism on liver diseases need to be further studied and elucidated. By searching the online databases including PubMed, Web of Science, Google Scholar, and CNKI, the origin of hepatic macrophages and the diverse molecular mechanisms of macrophage polarization as well as its regulation in various liver diseases are summarized in this review. It is hoped to provide direction and basis for future research on the mechanism of macrophage polarization and on the treatment of liver diseases via regulating macrophage polarization.

\section{THE ORIGIN OF HEPATIC MACROPHAGES}

Hepatic macrophages account for $90 \%$ of the total macrophages in the human body and are remarkably heterogeneous, including liver-resident macrophages and a variety of infiltrating macrophages $(8,17)$. Liver-resident macrophages, called Kupffer cells, generally exist in the hepatic sinuses and originate from yolk sac-derived specific progenitor cells having been seeded in liver tissue during embryogenesis, which can also be replenished by differentiation of bone marrow-derived monocytes $(19,20)$. Kupffer cells are self-renewed, quiescent and non-migratory in the liver, and have functions such as clearing pathogens, phagocytosing cellular debris, and regulating iron metabolism, which are important for maintaining liver homeostasis (20). In addition, the infiltrating macrophages include bone marrow/ monocyte-derived macrophages, peritoneal macrophages, and splenic macrophages (9). Among them, bone marrow-derived monocyte macrophages are the main members of infiltrating macrophage and recruited after Kupffer cell and HSC activation, which are important contributors to the replenishment and regeneration after hepatic macrophage depletion, and have an important status in the pathological state of the liver (9). In addition to monocyte macrophages in the blood circulation, self-renewal macrophages in the peritoneal cavity also accumulate in subcapsular liver tissue when liver injury occurs and contribute to liver regeneration (17). Furthermore, the spleen has also been found to be the site of monocyte storage and distribution, and splenic macrophages are recruited to the liver during liver injury and have immunomodulatory effects (17). These macrophages have great plasticity (polarization) and usually exist with two main subsets. For example, peritoneal macrophages are divided into large peritoneal macrophages and small peritoneal macrophages (20). Interestingly, there are studies showing the presence of two monocyte macrophage subsets called ly6chigh and ly6clow in mice, and ly6chigh originates mainly from bone marrow, whereas ly6clow is derived from spleen (20).
Collectively, in normal liver, Kupffer cells, known as sentinel cells of the liver, account for the majority of hepatic macrophages and are dominant, which mainly maintain liver homeostasis (20). When the liver is invaded by external factors to develop lesions, Kupffer cells first receive the signals to differentiate into different phenotypes to produce pro- or antiinflammatory factors, and recruit a large number of other macrophages into the liver at the same time, which have similar plasticity and multiple functions as Kupffer cells, and play an important role in the progression and reversal of liver diseases $(9,17)$.

\section{MACROPHAGE POLARIZATION}

Macrophage polarization means that macrophages are activated under the stimulation of pathogenic microorganisms, inflammatory responses, cytokines, or some physicochemical factors, and differentiate into different phenotypes depending on the state and changes of the microenvironment (21). In the process of disease occurrence and regression, macrophage polarization appears to act as an intermediate process, which is activated by certain signals to generate distinct phenotypes first, thus playing a regulatory role by acting on multiple signaling pathways (22). The phenotypes, mechanisms, and functions of macrophage polarization are summarized in Table $\mathbf{1}$.

\subsection{The Phenotypes of Macrophage Polarization}

In general, the phenotypes of macrophage polarization can be divided into classically activated M1 and alternatively activated M2 (25). Nowadays, it is generally accepted that M1 macrophages are mainly induced by lipopolysaccharide (LPS) and interferon- $\gamma$ (IFN- $\gamma$ ), whereas interleukin (IL)-4 and IL-13 can activate M2 macrophages (7). M1 macrophages are also known as pro-inflammatory macrophages because they can secrete a large number of pro-inflammatory cytokines, such as IL-1 $\beta$, inducible nitric oxide synthase (iNOS), tumor necrosis factor- $\alpha$ (TNF- $\alpha)$ (10). Conversely, M2 macrophages are known as anti-inflammatory macrophages because of mainly producing anti-inflammatory factors, such as IL-10, transforming growth factor- $\beta$ (TGF- $\beta$ ), arginase 1 (Arg1) (10). M1 macrophages mainly exert antigen-presenting function, and have proinflammatory, scavenging pathogenic microorganisms, and anti-tumor effects; while M2 macrophages have the biological functions of inhibiting inflammation, promoting tissue remodeling, preventing parasitic infection, as well as involving angiogenesis, immunity regulation, and tumor progression (23). Therefore, they usually exert opposite regulatory roles in the initiation and development of many diseases. Moreover, because M2 macrophages produce complex cytokines and have various functions, they can be further divided into M2a, M2b, M2c, and M2d subtypes (30).

Although M1 and M2 are the main macrophage phenotypes which are commonly studied and applied currently, the phenotypes of macrophage polarization are not restricted to 
TABLE 1 | The phenotypes, mechanisms and functions of macrophage polarization.

\begin{tabular}{|c|c|c|c|c|c|c|c|}
\hline \multicolumn{2}{|c|}{$\begin{array}{l}\text { Macrophage } \\
\text { phenotypes }\end{array}$} & \multirow{2}{*}{$\begin{array}{l}\text { Stimulus } \\
\text { LPS, IFN- } \gamma \text {, } \\
\text { GM-CSF }\end{array}$} & \multirow{2}{*}{\begin{tabular}{l}
\multicolumn{1}{c}{$\begin{array}{c}\text { Specific } \\
\text { markers }\end{array}$} \\
CD80, CD86, \\
CD16/32, MHCIl, \\
iNOS
\end{tabular}} & \multirow{2}{*}{\begin{tabular}{l}
\multicolumn{1}{c}{ Cytokines } \\
IL-1 $\beta$, IL-6, IL-12, IL-23, TNF- $\alpha$, \\
CXCL1 3, CXCL8 10, CCL2 5, \\
CCL11
\end{tabular}} & \multirow{2}{*}{\begin{tabular}{l}
\multicolumn{1}{c}{ Mechanisms } \\
TLR4/NF-KB, \\
IRF5, JAK/STAT1, \\
Notch
\end{tabular}} & \multirow{2}{*}{$\begin{array}{l}\text { Functions } \\
\text { Antigen presentation, Th1 immune reaction, } \\
\text { proinflammation, pathogen elimination, anti- } \\
\text { tumor }\end{array}$} & \multirow{2}{*}{$\begin{array}{r}\text { References } \\
(10,23-25)\end{array}$} \\
\hline M1 & & & & & & & \\
\hline \multirow[t]{3}{*}{ M2 } & $\mathrm{M} 2 \mathrm{a}$ & $\mid \mathrm{L}-4, \mathrm{IL}-13$ & $\begin{array}{l}\text { CD206, MHCII, } \\
\text { IL-1R, Dectin-1 }\end{array}$ & $\begin{array}{l}\text { Arg1, IL-10, TGF- } \beta, \text { CCL17, } \\
\text { CCL22 }\end{array}$ & $\begin{array}{l}\text { JAK/STAT6, c- } \\
\text { Myc, IRF4 }\end{array}$ & $\begin{array}{l}\text { Anti-inflammation, wound healing, Th2 } \\
\text { immune response, anaphylaxis, fibrosis }\end{array}$ & $(26,27)$ \\
\hline & M2b & LPS, IC & $\begin{array}{l}\text { CD206, MHCII, } \\
\text { CD86 }\end{array}$ & IL-10, IL-1 $\beta$, IL-6, TNF- $\alpha$, IL-12 low & TLR4, Syk, PI3K & $\begin{array}{l}\text { Immune regulation, pro-tumor, promoting } \\
\text { infection }\end{array}$ & $(26-28)$ \\
\hline & M2d & $\begin{array}{l}\text { TLR agonist, } \\
\mathrm{A}_{2 \mathrm{~A}} \mathrm{R} \text { ligand }\end{array}$ & CD206 & IL-10, VEGF, IL-12 low, TNF- $\alpha^{\text {low }}$ & TLR4, NF-кB & Pro-tumor, angiogenesis & $(29,30)$ \\
\hline M4 & & CXCL4 & $\begin{array}{l}\mathrm{MMP}^{+} \mathrm{S} 100 \mathrm{~A} 8^{+} \\
\mathrm{CD} 206, \mathrm{CD} 163^{--}\end{array}$ & TNF- $\alpha$, CCL18 & N/A & Proinflammation, low phagocytosis & (31) \\
\hline Mox & & QxPAPC & $\begin{array}{l}\text { HO-1, Srxn1, } \\
\text { Gclc, Gclm } \\
\text { Txnrd1, Nurr1, } \\
\text { Trb3, COX-2 }\end{array}$ & IL-1 $\beta$, VEGF & $\begin{array}{l}\text { Nrf2, Keap1, } \\
\text { TLR2 }\end{array}$ & Low chemotaxis and phagocytosis & $(26,32)$ \\
\hline
\end{tabular}

them. The study by Erbel et al. (31) has shown that CXCL4 can induce a macrophage phenotype called M4, characterized by the co-expression of CD68, matrix metalloproteinase (MMP) 7, and the calcium binding protein S100A8, which has regulatory effects on diseases such as atherosclerosis. Moreover, in atherosclerosis, human hemoglobin can induce $\mathrm{M}(\mathrm{Hb})$ macrophage that highly expresses the heme scavenger receptor CD206 and CD163, and oxidized phospholipids in mice can induce Mox macrophage $(26,32)$. These macrophages have different morphological structures, gene expression, and biological functions from M1 and M2. Furthermore, Malyshev et al. (34) made a hypothesis that macrophages might achieve the interconversion of M1 and M2 by forming the M3 switching phenotype. The phenotypes and functions of macrophage polarization are shown in Figure 1.

\subsection{The Mechanism of Macrophage Polarization} 3.2.1 TLR4/NF- $\kappa B$ Signaling Pathway

Toll like receptor (TLR) 4 is an innate immune receptor expressed on the surface of macrophages that can efficiently recognize pathogen-associated molecular patterns, and is the main receptor of LPS (35). LPS binds to TLR4 to activate nuclear factor $-\kappa \mathrm{B}(\mathrm{NF}-\kappa \mathrm{B})$ through the myeloid differentiation factor 88 (MyD88)-dependent pathways or interferon regulatory factor (IRF) 3, thereby promoting the expression of inflammatory factors (36). Recently, a variety of drugs have been shown to inhibit M1 macrophage polarization by inhibiting the TLR4/NF- $\kappa \mathrm{B}$ signaling pathway. For example, berberine could competitively inhibit the combination of TLR4 and MyD88 to

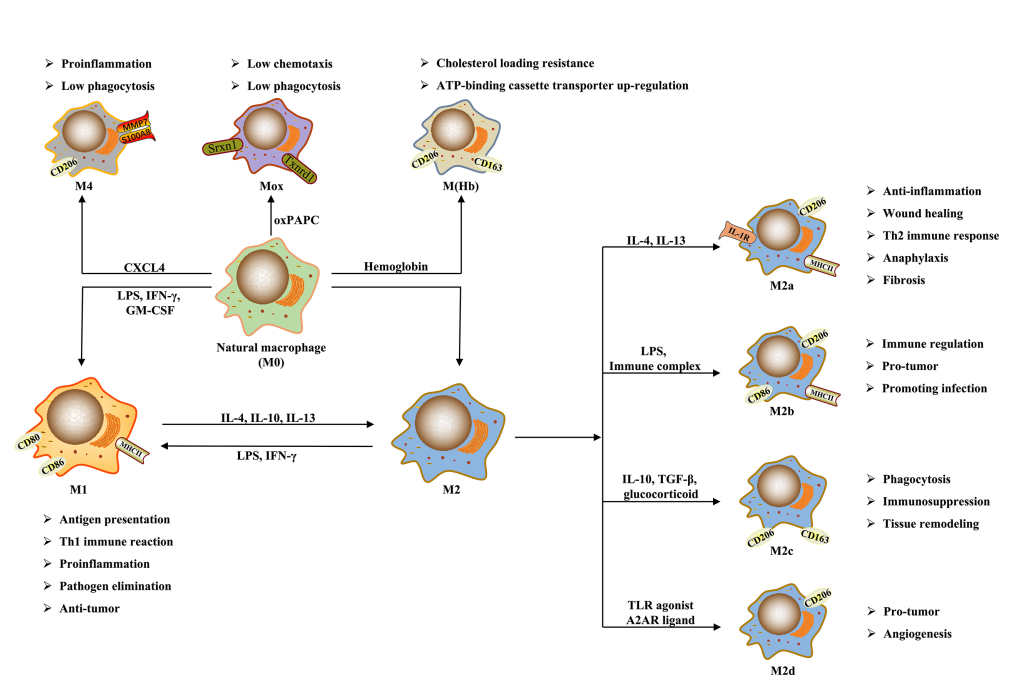

FIGURE 1 | The phenotypes and functions of macrophage polarization. 
inhibit the TLR4/MyD88/NF- $\mathrm{KB}$ signaling pathway, thus inhibiting M1 macrophage polarization (37). Similarly, quercetin downregulated the expression of NF- $\mathrm{KB}$ and IRF5, and then inhibited the activity of upstream TLR4/MyD88 to inhibit M1 polarization $(38,39)$. In addition, the chemical compounds NZ, meisoindigo, and others can inhibit M1 macrophage polarization, which is associated with the downregulation of the TLR4/NF- $\kappa \mathrm{B}$ signaling pathway $(38,40)$. These findings sufficiently indicate the critical role of TLR4/NF- $\kappa B$ signaling pathway in M1 macrophage polarization.

\subsubsection{JAK/STAT Signaling Pathway}

The Janus kinase (JAK)/signal transducer and activator of transcription (STAT) pathway mainly mediates the signaling of cytokine receptors (41). IFN- $\gamma$ binds to its receptor and activates JAK, thus inducing the phosphorylation of STAT1, which leads to the polarization of macrophages to M1 (42). Moreover, IFN- $\gamma$ can enhance the sensitivity of macrophages to inflammatory mediators, and exert a synergistic effect by blocking the feedback inhibition to TLR signaling; meanwhile, NF- $\kappa B$ and mitogenactivated protein kinase (MAPK) can also enhance the transcriptional activity of JAK/STAT1 $(42,43)$. Research found that azithromycin promoted M2 polarization by inhibiting the transcription of STAT1 and NF- $\kappa B$ (44). In addition, IFN- $\gamma$ can also promote the metabolic switch of M1 macrophages, which in turn enhances their cell viability and pro-inflammatory activity through the JAK/STAT1 pathway (45). JAK/STAT6 is an important pathway by which IL-4 inhibits M1 and induces M2 polarization (46). For example, curcumin up-regulated STAT6 expression by secreting IL- 4 and IL-13, thereby inducing M0 and M1 macrophages to polarize to M2 (47).

In addition, STAT3 is important for M2 macrophage polarization. Studies have shown that the inhibition of IL-6/ STAT3 and JAK3/STAT3 signaling pathways results in the polarization of macrophages from M2 to M1 phenotype (48, 49). Suppressor of cytokine signaling (SOCS) is a feedback inhibitor of JAK/STAT signaling. It was found that the deficiency of SOCS1 and SOCS3 promoted M1 macrophage polarization by activating the JAK1/STAT1 signaling pathway $(50,51)$. The study by Yu et al. (52) further showed that increased phosphorylation of STAT3 could feedback inhibit the expression of STAT1 by upregulating the expression of SOCS3, thereby inhibiting macrophage polarization mediated by the JAK/STAT1 signaling pathway. In summary, M1 macrophage polarization is closely related to the phosphorylation of STAT1, whereas M2 polarization mainly depends on the increased expression of STAT3, STAT6, and SOCS.

\subsubsection{TGF- $\beta /$ Smads Signaling Pathway}

TGF- $\beta$ acts on type II receptors first, and then binds to type I receptors to form a receptor complex, which leads to the phosphorylation of type I receptor domain, thus regulating the expression of the related genes by activating their downstream signaling molecules (Smad2 and Smad3) (53). The study by Wang et al. (54) found that growth differentiation factor 3 from the TGF- $\beta$ superfamily suppressed M1 and promoted M2 polarization by promoting the phosphorylation of Smad 2 and
Smad3. Similarly, there have been multiple studies showing the role of TGF- $\beta /$ Smads signaling pathway in promoting M2 macrophage polarization. For example, quercetin was found to inhibit M2 polarization through inhibiting TGF- $\beta 1$-smad2/3 pathway (39). In addition, both TGF- $\beta$ and Smads signaling can individually mediate macrophage polarization. For example, under hypoxia, TGF- $\beta$ expression was upregulated, which might increase M2 polarization through the receptor tyrosine kinase/ phosphatidylinositol-3-kinase (PI3K) pathway (55). Chen et al. (56) experimentally demonstrated that Smad3 could be directly activated by macrophage phagocytosis independently of TGF- $\beta$, which might promote macrophage polarization toward the antiinflammatory phenotype via peroxisome proliferators-activated receptors (PPARs).

\subsubsection{PPAR $\gamma$ Signaling Pathway}

PPAR $\gamma$ is an important transcription factor for cell differentiation and has many functions, such as regulating glucose and lipid metabolism, anti-inflammation, reducing oxidative stress, and so on (57). PPAR $\gamma$ usually regulates the polarization of macrophages by interacting with other signaling pathways. The study by Luo et al. (58) showed that PPAR $\gamma$ interacted with NF- $\kappa B$ to regulate the balance of $\mathrm{M} 1 / \mathrm{M} 2$ macrophages. Gao et al. (47) found PPAR $\gamma$ was involved in the process of M2 macrophage polarization induced by IL-4/IL-13. This suggests that PPAR $\gamma$ plays an important role in M2 macrophage polarization. For example, HuoxueTongfu formula activated PPAR $\gamma$ to up-regulate the expression of SOCS1/STAT6 signaling pathway and inhibit SOCS3/JAK2/STAT1 pathway, thereby promoting M2 polarization (59). In addition, insulin and $\alpha$-ketoglutarate can also increase the expression of PPAR $\gamma$ signaling to promote M2 polarization, thus slowing down the development of various inflammatory diseases $(60,61)$.

\subsubsection{MicroRNAs}

According to the current research, the role of microRNAs (miRNAs) on macrophage polarization has been gradually highlighted, mainly relying on their regulation of other signaling pathways. For example, miR-221-3p promotes M2 macrophage polarization toward M1 phenotype by inhibiting JAK3/STAT3 signaling pathway (49). MiR-1246 induces M2 polarization by targeting TERF2IP to activate STAT3 and inhibit NF- $\mathrm{KB}$ (62). In recent years, exosomes have been extensively studied and applied, and have been shown to be important carriers of miRNA signaling (63). Adipocyte-derived exosomes carry miR-34a, which can suppress Krüppel like factor 4 expression and inhibit M2 polarization (64). Conversely, mesenchymal stem cell (MSC)-derived exosomal miR-124-3p can promote M2 macrophage polarization (65). Meanwhile, macrophage-derived exosomes can also exert their biological effects via miRNAs. M2 macrophage-derived exosomes led to the exacerbation of pancreatic ductal adenocarcinoma through the inhibitory effect of miR-501-3p on TGFBR3, and down-regulated TXNIP expression as well as inhibited the TLR4/NF- $\mathrm{KB} / \mathrm{NOD}$ like receptor protein 3 (NLRP3) inflammasome signaling pathway via miR-148a, thus attenuating myocardial ischemia/ reperfusion injury $(66,67)$. Moreover, miR-30c, miR-99a and 
miR-155 have all been shown to inhibit M1 macrophage polarization, while miR-let7 and miR-32 contribute to M2 polarization (68-72).

\subsubsection{Notch Signaling Pathway}

Notch signaling pathway includes a series of highly conserved surface receptors, and is involved in cell proliferation and apoptosis, affecting the development of various biological organs and tissues (73). A study has found that M1 macrophages have a marked increase in Notch1 receptor expression, and Notch1 receptor inhibition leads to decreased M1 polarization and increased M2 polarization (74). In recent years, much literature has reported that many drugs can regulate macrophage polarization by targeting the Notch signaling pathway. For example, astragalus polysaccharide activates the Notch signaling pathway to induce M1 polarization (75). Capsaicin inhibits M1 polarization by inhibiting the Notch signaling pathway (76). In addition, Zheng et al. (77) found that Notch1/Jagged1 signaling inhibition could suppress schistosome infection-induced M2 polarization. Meanwhile, the study by Tao et al. (78) also showed that Linc00514 promoted M2 polarization through STAT3 and Notch/Jagged1 signaling pathway, leading to the development of breast cancer. Therefore, these suggest that the Notch/Jagged1 pathway may be a therapeutic target for some diseases associated with M2 macrophage polarization.

Interestingly, the current studies have shown that Notch signaling regulating macrophage polarization is closely associated with miRNAs. Li et al. (79) found that the mechanism by which Notch signaling promotes M1 polarization involved increased expression of miR-125a/miR-99b. Similarly, miR-148a-3p was shown to be a mediator by which Notch promotes M1 polarization (80). Moreover, adipose stem cell-derived extracellular vesicles (EVs) could inhibit the Notch signaling pathway and M1 polarization to exert anti-inflammatory effects, which was associated with decreased expression of miR148a-3p (81).

\subsubsection{Other Mechanisms}

In addition to the pathways described above, multiple other signals and targets have been included in the underlying mechanisms of macrophage polarization. Mammalian target of rapamycin signaling pathway was shown to be involved in regulating M1/M2 polarization, mainly relying on the feedback effect between mechanistic target of rapamycin (mTOR) complex 1 and protein kinase B (Akt) signaling (82). Insulin suppressed NF- $\mathrm{KB}$ and STAT1 expression through the PI3K/Akt signaling pathway, thus reducing pro-inflammatory M1 macrophage activation (60). The study by Zhang et al. (83) showed that MCP-induced protein 1 promoted macrophage polarization from M1 to M2 by inhibiting the JNK/c-Myc signaling pathway. $\omega$-alkynyl arachidonic acid promoted M2 polarization by regulating the crosstalk of pyruvate kinase M2, hypoxia inducible factor- $1 \alpha$ (HIF-1 $\alpha)$ and iNOS, thus contributing to the attenuation of the inflammatory responses in acute myocardial infarction (84). Furthermore, Gu et al. (85) found that the effects of the N6 methyladenosine demethylase FTO on macrophage polarization were complex. On the one hand, FTO could mediate the phosphorylation of $\mathrm{IKK} \beta, \operatorname{I\kappa B} \alpha$, and p65 to activate NF- $\kappa B$ signaling pathway and up-regulate STAT1 expression, thereby inducing M1 polarization (85). On the other hand, FTO deficiency not only inhibited M1 polarization, but also inhibited M2 polarization, which was related to the downregulation of STAT6 and PPAR $\gamma(85)$.

In fact, the mechanism associated with macrophage polarization is very extensive, and the induction of macrophage polarization by most factors involves the co-regulation of multiple signaling pathways, which is perhaps an important factor for macrophage polarization to have multiple roles in liver diseases. The detailed mechanisms of macrophage polarization are shown in Figure 2.

\section{THE ROLE OF MACROPHAGE POLARIZATION IN LIVER DISEASES}

\subsection{Acute Liver Injury}

ALI is the acute hepatic inflammation and hepatocyte necrosis caused by endotoxin, certain drugs and their metabolites, or other physicochemical factors, which may cause liver

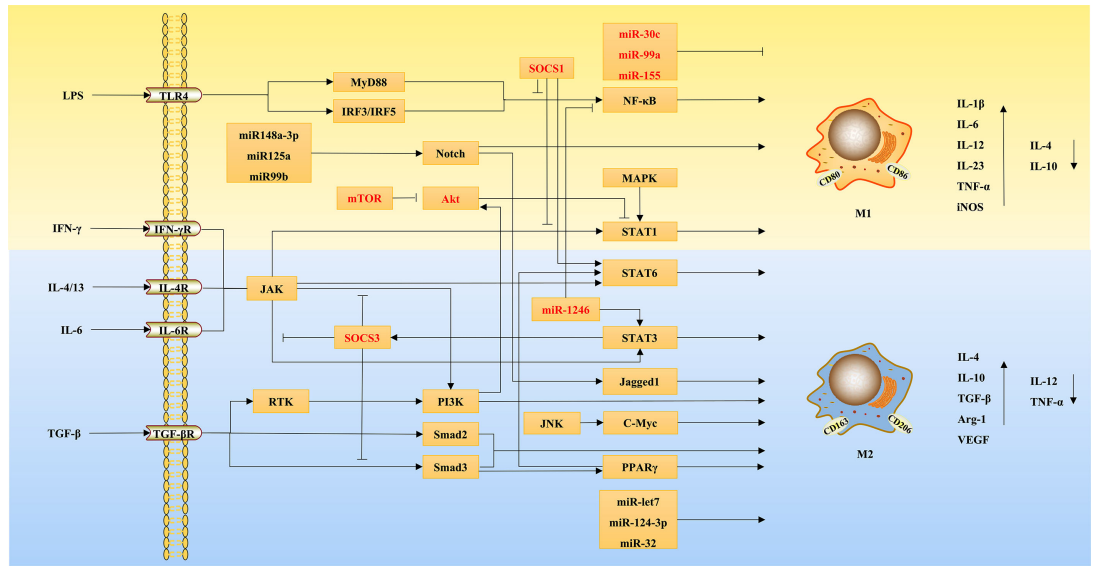

FIGURE 2 | The mechanisms of macrophage polarization. 
dysfunction or even acute liver failure (86). Empirically, LPS, D-galactosamine (D-GalN), thioacetamide (TAA), and acetaminophen (APAP) can cause ALI and have mostly been used to establish experimental ALI models $(87,88)$. Through a study in the TAA-treated rats, Golbar et al. (87) demonstrated that the depletion of hepatic macrophages obviously aggravated liver injury. Zigmond et al. (89) further found that the macrophages of different origins differentiated into different subpopulations and had different functions in the APAPinduced ALI mouse model. In addition, the study by Rahman et al. (90) showed that M1 and M2 macrophages together contributed to D-GalN-induced ALI in rats and interconverted during the lesion progression. These findings provided ample evidence that macrophages played an important role in ALI, and indicated that it was possible to control the disease progression by regulating macrophage polarization.

JAK/STAT1 and TLR4/NF- $\mathrm{KB}$ pathways are important mechanisms of M1 macrophage polarization, while STAT6 is mainly related to $\mathrm{M} 2(45,46,91)$. Through the in vivo and in vitro experiments, Xie et al. (92) demonstrated that protein interacting with $\mathrm{C}$ kinase 1 up-regulated the expression of STAT6 and $\mathrm{p} 38 \alpha$ as well as inhibited the NF- $\mathrm{\kappa B}$ signaling pathway, promoting M2 and inhibiting M1 polarization, which reduced the liver injury. MSC-derived prostaglandin E2 acted on EP4 receptor, and then alleviated hepatic inflammation by reducing the release of inflammatory factors as well as promoted M2 polarization by up-regulating the expression of STAT6 and mTOR signaling, thus alleviating ALI (93). Cannabinoid receptor 2 can down-regulate the expression of TLR4 signaling via miR145 and promote macrophage polarization from $\mathrm{M} 1$ to $\mathrm{M} 2$, thus playing a protective role in mice with acute liver failure (94). Conversely, Wang et al. (95) found that hyperglycemia promoted M1 and inhibited M2 polarization by up-regulating STAT1 and down-regulating STAT6 expression, and aggravated APAP-induced ALI in mice through the PI3K/Akt signaling pathway. Similarly, SMA/ CORM2, a CO donor designed by Song et al. (96) for colitis, attenuated liver injury by reducing oxidative stress and modulating M1/M2 polarization, which was associated with the down-regulation of HIF-1 $\alpha$ expression and the activation of the PI3K/Akt/mTOR signaling pathway. However, Gong et al. (97) conducted in vivo and in vitro experiments and demonstrated that the mechanism by which phenylenediamine analogue FC-99 attenuated liver injury was mainly through the M2 macrophage polarization mediated by PPAR- $\gamma$ rather than STAT6.

CCL5 can act on CCR1/CCR5 receptor and up-regulate the expression of MAPK and NF- $\kappa \mathrm{B}$ signaling pathways, which promotes M1 and inhibits M2 macrophage polarization (98). Peng et al. (99) and Liu et al. (100) demonstrated that the p300/ CBP inhibitor and $\mathrm{p} 38 \alpha$ deletion could contribute to liver injury amelioration by reducing CCL 5 expression and inhibiting NF- $\kappa B$ signaling to regulate macrophage polarization []. In addition, Tsuji et al. (101) demonstrated the close relationship between M1/M2 macrophage polarization and autophagy by a study on the pathogenesis of ALI induced by APAP in rats. Further research by Zhou et al. (102) and Hua et al. (103) showed that both spermine and human amniotic mesenchymal stromal cells could inhibit M1 and promote M2 polarization by promoting autophagy, thus alleviating liver injury in different ALI mouse models.

M1 macrophages aggravate liver tissue injury because of promoting inflammatory responses; conversely, M2 macrophages can attenuate liver injury through their effects of anti-inflammation and tissue repairing (23). Therefore, in theory, the increase of M2 macrophage polarization or the inhibition of M1 polarization is good for ALI alleviation. In fact, the promoting or slowing effects of most internal and external factors on ALI are achieved by regulating macrophage polarization, as shown in Table 2.

\subsection{Viral Hepatitis}

Viral hepatitis is a class of infectious diseases caused by hepatitis virus with hepatocyte degeneration, necrosis and apoptosis as the main lesions, including five types: $\mathrm{A}, \mathrm{B}, \mathrm{C}, \mathrm{D}$, and $\mathrm{E}$ (105). It is very likely to form chronic hepatitis after hepatitis virus infection, and then progress to liver fibrosis, ultimately leading to cirrhosis and even HCC (105). Currently, inhibiting the replication and spread of hepatitis virus by regulating the body's immune system is the key to the treatment of viral hepatitis (106). Macrophage, as an important immune cell, is considered to be an important player in the development and resolution of chronic viral hepatitis (107). When viral infection occurs in the liver, Kupffer cells will recognize danger signals first, and trigger the recruitment of circulating monocytes to the liver and subsequent differentiation to macrophages, together exerting immunoregulatory function as well as having pathogen elimination and anti-viral effects (18).

Hepatitis B, mainly caused by hepatitis B virus (HBV) infection, is one of the leading causes of chronic hepatitis worldwide (105). It is generally believed that HBV-related liver damage is associated with the killing of infected-hepatocytes by $\mathrm{CD}^{+} \mathrm{T}$ lymphocytes. Meanwhile, the anti-viral function of $\mathrm{CD}^{+} \mathrm{T}$ lymphocytes is regulated by hepatic regulatory $\mathrm{T}$ cells. Dai et al. (108) found that CD206-positive macrophages were predominant in $\mathrm{HBV}$-infected mice and produced amphiregulin to up-regulate the immunosuppressive activity of regulatory $\mathrm{T}$ cells, impairing the anti-viral effect of $\mathrm{CD}^{+} \mathrm{T}$ cells, which was associated with rapamycin signaling activation. Similarly, Yi et al. (109) found that hepatitis B core antigen significantly inhibited M2 polarization and the production of anti-inflammatory factors by activating the TLR2-NF- $\kappa \mathrm{B}$ signaling pathway, which exerted therapeutic potential against chronic hepatitis B. In addition, studies have shown that miRNAs are also involved in regulating the occurrence and resolution of hepatitis B. Zhao et al. (110) have proved that $\mathrm{HBV}$-encoded miR-3 can promote M1 macrophage polarization to exert anti-HBV effects, which may be through suppressing SOCS5 expression to activate the JAK/ STAT signaling pathway (110).

Hepatitis $C$ is a viral hepatitis caused by hepatitis $C$ virus (HCV) infection with a worldwide prevalence of approximately $3 \%$ and an increasing trend (111). G. Dultz et al. (112) found that the serum level of soluble CD163, a marker of M2 macrophage 
TABLE 2 | The role and mechanisms of macrophage polarization in ALI.

\begin{tabular}{|c|c|c|c|c|c|}
\hline Regulation Factor & Research objects & $\begin{array}{l}\text { Macrophage } \\
\text { polarization }\end{array}$ & Mechanisms & $\begin{array}{l}\text { Year and } \\
\text { Country }\end{array}$ & Reference \\
\hline \multicolumn{6}{|l|}{ Alleviating ALI } \\
\hline Protein interacting with $\mathrm{C}$ kinase 1 & Mice, cells & $\mathrm{M} 1 \downarrow ; \mathrm{M} 2 \uparrow$ & NF-кB signaling $\downarrow ;$ STAT6 signaling $\uparrow$ & 2016, China & (92) \\
\hline P38 $\alpha$ deficiency & Mice, cells & $\mathrm{M} 1 \rightarrow \mathrm{M} 2$ & CCL2, CCL5 $\downarrow ; p 38 \alpha-C R E B-C / E B P \beta \downarrow$ & 2017, China & $(100)$ \\
\hline Spermine & Mice, cells & $\mathrm{M} 1 \downarrow ; \mathrm{M} 2 \uparrow$ & 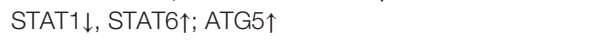 & 2018, China & (102) \\
\hline Homeobox Containing 1 & Cells, mice & 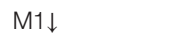 & $\mathrm{NF}-\kappa \mathrm{B}$ signaling $\downarrow ; \mathrm{MHCll} \downarrow$ & 2018, China & $(104)$ \\
\hline $\begin{array}{l}\text { Human amniotic mesenchymal } \\
\text { stromal cells }\end{array}$ & Mice, cells & 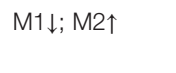 & LC3B- $-1 \uparrow$ & 2019, China & (103) \\
\hline Carbon monoxide & Mice, cells & $\mathrm{M} 1 \downarrow ; \mathrm{M} 2 \uparrow$ & HIF-1 $\alpha \downarrow ;$ PI3K/Akt/mTOR signaling $\uparrow$ & 2021, China & (96) \\
\hline Msc-secreted prostaglandin $E_{2}$ & Mice, cells & $\mathrm{M} 2 \uparrow$ & STAT6 and mTOR signaling $\uparrow$ & 2021, China & (93) \\
\hline \multicolumn{6}{|l|}{ Aggravating ALI } \\
\hline
\end{tabular}

activation, was significantly increased in $\mathrm{HCV}$-infected patients, but decreased after the anti-viral therapy, confirming the crucial role of M2 polarization in the progression of hepatitis C. Moreover, a recent study showed that the M1 macrophages from the livers of $\mathrm{HCV}$-infected patients exhibited M2 phenotypic features, and the M2 macrophages exhibited M1 phenotypic features (113). Similarly, a study by Saha et al. (114) found that HCV-infected HCC cells induced monocytes to differentiate into macrophages and polarize to M2 phenotype. Moreover, a previous study showed that exogenous HCV core protein promoted macrophages to secrete pro-inflammatory and anti-inflammatory factors, and mediated the pro-proliferative effect of macrophages on human normal hepatocyte line LO2, which was accompanied by increased expression of M2associated STAT3 and CD206 (115). Subsequently, further research showed that $\mathrm{HCV}$ core protein inhibited M1 and M2 macrophage polarization through the TLR2/STATs pathway, and impaired their phagocytic activity and functions (116).

Vaccine is an important means to prevent and control viral hepatitis, and the development of an effective vaccine against $\mathrm{HCV}$ infection is of great importance. Ohtsuki et al. (117) showed that the number of M2 macrophages in the liver of $\mathrm{HCV}$-infected mice was significantly increased, accompanied by high expression of IL- 6 and TNF- $\alpha$, whereas the recombinant vaccinia virus expressed $\mathrm{HCV}$ nonstructural protein $\mathrm{rVV}-\mathrm{N} 25$ and inhibited the number and activation of M2 macrophages, thus preventing the development of chronic hepatitis. Taken together, M2 macrophages have an important role during HBV and HCV infection, and are mostly accompanied by a complex cytokine profile, not only including increased M2-related antiinflammatory cytokines but also involving M1. These results suggest that M2 macrophage polarization inhibition and M1related inflammatory factor secretion may contribute to the inhibition of virus replication and infection, thus alleviating viral hepatitis and inhibiting related fibrosis. The role and mechanisms of macrophage polarization in viral hepatitis are shown in Table 3.

\subsection{Alcoholic Liver Disease}

ALD mainly refers to the hepatic inflammatory responses induced directly or indirectly by ethanol and its derivatives during their metabolism, which is the result of the interaction of various factors including oxidative stress, gut-derived endotoxin, inflammatory mediators, and nutritional imbalance (122). In particular, the activation of Kupffer cells by endotoxins due to impaired intestinal barrier function plays an important role in the initiation and progression of ALD (123). When ALD occurs, Kupffer cell activation plays a central role; meanwhile, monocyte macrophages are recruited to the liver and polarized to M1 or M2 phenotype according to the state of the liver microenvironment (19). Voican et al. (124) found that macrophage infiltration in subcutaneous adipose tissue was reduced, and M2 macrophage polarization was increased in the ALD patients with alcohol withdrawal. Moreover, M2 macrophages were shown to induce hepatocyte senescence via IL-6 and resist alcohol-induced hepatocyte apoptosis and hepatic steatosis (125). Therefore, the pathogenesis of ALD involves macrophage polarization, and M2 macrophages seem to be beneficial for ALD resolution.

Ethanol can significantly induce the expression of telomerase reverse transcriptase in vitro and in vivo, thereby promoting M1 macrophage polarization through the NF- $\mathrm{KB}$ signaling pathway, which has an important role in the pathogenesis of ALD (126). Cannabinoid CB2 receptor activation attenuates alcohol-induced hepatic steatosis and inflammation by inhibiting M1 polarization of Kupffer cells, and partially by promoting M2 polarization (127). $\beta$-caryophyllene, a food additive, can reduce M1 activation of Kupffer cells and contribute to the amelioration of ALD, which is partially dependent on CB2 (127). TLRs are widely expressed in ALD. Research has shown that the inhibition of TLR2 expression and the promotion of TLR3 expression in Kupffer cells can activate STAT3 and produce IL-10, which is beneficial to promote M1 to M2 polarization and then alleviate ALD (128). In addition, Fas, an apoptosis-related receptor, has a dual role in the development of ALD. On the one hand, Fas receptor favored 
TABLE 3 | The role and mechanisms of macrophage polarization in viral hepatitis.

\begin{tabular}{|c|c|c|c|c|c|}
\hline Regulation Factor & Research objects & $\begin{array}{l}\text { Macrophage } \\
\text { polarization }\end{array}$ & Mechanisms & $\begin{array}{l}\text { Year and } \\
\text { Country }\end{array}$ & Reference \\
\hline \multicolumn{6}{|c|}{ Alleviating hepatotropic virus infection } \\
\hline \multicolumn{6}{|c|}{ Alleviating HBV infection } \\
\hline Hepatitis B Core Antigen & $\begin{array}{l}\text { Patient samples, } \\
\text { cells }\end{array}$ & 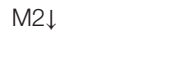 & TLR2/NF-кB pathway $\uparrow ;$ STAT6 $\downarrow$ & 2020, China & (109) \\
\hline HBV-miR-3 & $\begin{array}{l}\text { Patient samples, } \\
\text { cells }\end{array}$ & $\mathrm{M} 1 \uparrow$ & SOCS5 $\downarrow ;$ JAK/STA T signaling pathway $\uparrow$ & 2020, China & (110) \\
\hline HCV antigens & $\begin{array}{l}\text { Patient samples, } \\
\text { cells }\end{array}$ & 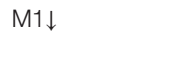 & 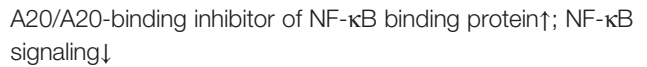 & 2015, China & (119) \\
\hline HCV core protein & $\begin{array}{l}\text { Patient samples, } \\
\text { cells }\end{array}$ & 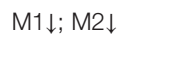 & 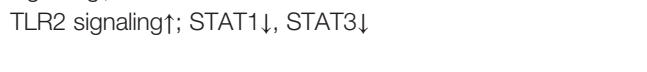 & 2016, China & (116) \\
\hline HCV single-stranded RNA & $\begin{array}{l}\text { Patient samples, } \\
\text { cells }\end{array}$ & $\mathrm{M} 2 \uparrow$ & TLR7/8 signaling $\uparrow$ & 2017, America & (120) \\
\hline
\end{tabular}

early ethanol-induced M1 macrophage polarization and inflammatory responses (129). On the other hand, it reduced TGF- $\beta$ production by inhibiting M2 polarization, and subsequently inhibited the pro-fibrotic responses in chronic ALD (129). Moreover, in the ethanol-induced in vitro and in vivo models, the overexpression of brain and muscle Arnt-like protein-1 could inhibit M1 and promote M2 polarization through glycolysis pathway, thus alleviating ALD (130).

Saha et al. (131) conducted in-depth studies on ALD, and found that both M1 and M2 polarization of hepatic macrophages were increased in the mouse model of chronic alcohol exposure, which was significantly associated with the modulation of Krüppel-like factor 4 expression by ethanol and its metabolite acetaldehyde. EVs carry a large number of proteins and miRNAs, which have been shown to be important mediators of intercellular signaling (132). Saha et al. (133) further found that the mice with ALD had an increased number of EVs, which carried specific proteins such as Hsp90 and increased the number of M1 macrophages as well as the infiltration of monocytes/macrophages. In addition, their findings showed that miR-27a from alcohol-exposed monocyte-derived EVs could induce naïve monocytes to differentiate into M2 macrophages (134). During alcoholic hepatitis, the regulation of miRNAs associated with macrophage polarization is disordered, and hepatic macrophages become less sensitive to LPS and undergo M1/M2 hyperpolarization (135).

Currently, endoplasmic reticulum stress has been shown to contribute to M2 macrophage polarization (136). Park et al. (137) found that NOGO-B, a protein that maintains the structure of endoplasmic reticulum, could promote M1 polarization of Kupffer cells and then aggravate alcoholic liver injury. Conversely, its absence contributed to increased endoplasmic reticulum stress and M2 polarization (137). More importantly, according to recent studies, pharmacological intervention targeting M2 macrophage polarization may be an effective approach for the treatment of ALD during the early inflammatory phase. For example, inulin can inhibit short chain fatty acid-induced M1 polarization, and promote M2 polarization, attenuating the inflammation of ALD mice (138). Furthermore, the study by Patel et al. (139) has shown that probiotics and metformin, as well as their combination, can promote M2 polarization and inhibit M1 polarization, contributing to the alleviation of alcoholic liver injury. The role and mechanisms of macrophage polarization in ALD are shown in Table 4.

\subsection{Metabolic-Associated Fatty Liver Disease}

MAFLD is a clinicopathological syndrome closely related to obesity, inflammation, and insulin resistance, which is mainly characterized by excessive lipid deposition in hepatocytes (144, 145). It was found that in the MAFLD mouse model induced by fructose rich and high-fat diet (HFD), the expression of M1 macrophage-related genes and signal pathways in the liver was increased significantly, while the expression of M2 markers was decreased $(146,147)$. Further research found that M1 macrophages could induce p62-positive inclusion body accumulation and chronic inflammation in the liver, thus leading to the exacerbation of MAFLD patients (148). In addition, Yoshii et al. (149) first used micromini pigs as animal models to explore the phenotypic changes of macrophages in HFD-induced MAFLD. The results showed that hepatic fat accumulation induced macrophage accumulation, and M2 macrophages were increased in the early stage of MAFLD, whereas M1 macrophages were increased in the late stage (149). These findings fully indicate that the occurrence and development of MAFLD are closely related to the M1/M2 polarization of macrophages, and regulating macrophage polarization may be an important strategy for the treatment of MAFLD.

Macrophage polarization involves various mechanisms, and similarly, the pathogenesis of MAFLD also includes various signaling molecules $(24,150)$. Targeting these signaling molecules to modulate macrophage polarization may be a potential avenue against MAFLD. For example, the activation of nuclear factor like 2 has been shown to improve obesity and 
TABLE 4 | The role and mechanisms of macrophage polarization in ALD.

\begin{tabular}{|c|c|c|c|c|c|}
\hline Regulation Factor & Research Objects & $\begin{array}{c}\text { Macrophage } \\
\text { polarization }\end{array}$ & Mechanisms & $\begin{array}{l}\text { Year and } \\
\text { Country }\end{array}$ & Reference \\
\hline \multicolumn{6}{|l|}{ Alleviating ALD } \\
\hline EV-miR-27a & Patient samples, cells & 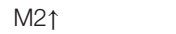 & IL-10, TGF- $\beta \uparrow$ & 2016, America & (134) \\
\hline$\beta$-caryophyllene & Mice & M1 $\downarrow$ & Cannabinoid 2 receptors $\uparrow ;$ PPAR $\alpha \uparrow$ & 2018, America & $(140)$ \\
\hline$\beta$-hydroxybutyrate & $\begin{array}{l}\text { Patient samples, mice, } \\
\text { cells }\end{array}$ & $\mathrm{M} 2 \uparrow$ & Hcar2-cAMP pathway $\uparrow$ & 2018, America & (141) \\
\hline $\begin{array}{l}\text { Brain and Muscle Arnt-Like } \\
\text { Protein-1 }\end{array}$ & Mice, cells & $\mathrm{M} 1 \downarrow ; \mathrm{M} 2 \uparrow$ & S100A9 protein $\uparrow$; glycolytic pathway $\downarrow$ & 2021, China & $(130)$ \\
\hline Metformin and Probiotics & Cells, rats & $\mathrm{M} 1 \downarrow ; \mathrm{M} 2 \uparrow$ & MAPK/Nrf-2/HO-1 signaling pathway $\uparrow$ & 2021, India & (139) \\
\hline \multicolumn{6}{|l|}{ Aggravating ALD } \\
\hline Telomerase reverse transcriptase & Mice, cells & $\mathrm{M} 1 \uparrow$ & NF-кB pathway $\uparrow$ & 2016, China & (126) \\
\hline
\end{tabular}

insulin resistance in mice. Nagata et al. (151) showed that Glucoraphanin, a stable precursor of the nuclear factor like 2 inducer sulforaphane, reduced M1 macrophage activation and increased the number of M2 macrophages, which alleviated HFD-induced MAFLD. In addition, PPAR $\gamma$ is also a key pathway for M2 macrophage polarization. A study found that the up-regulation of PPAR $\gamma$ could promote Kupffer cells to convert from M1 to M2 phenotype in HFD-fed mice (58). In addition, long noncoding RNAs (lncRNAs) have also been found to be widely involved in MAFLD. For example, lncRNA SNHG20 silencing could attenuate inflammatory responses in MAFLD by inhibiting M1 polarization (152). However, its overexpression up-regulated STAT6, thus promoting M2 polarization and accelerating the progression of MAFLD to HCC (152). Similarly, diverse intestinal flora also promotes or reverses MAFLD/nonalcoholic steatohepatitis (NASH) by inducing macrophage polarization, such as Escherichia coli, Lactobacillus paracasei, etc. $(153,154)$.

Diabetic patients are usually accompanied by MAFLD, and many anti-diabetic drugs can improve MAFLD by inducing macrophage polarization. For example, rosiglitazone can attenuate hepatic steatosis and insulin resistance in MAFLD mice by promoting M2 and reducing M1 polarization (155). The mechanism involves the down-regulation of NF- $\kappa B$ signaling that interacts with $\operatorname{PPAR} \gamma$ (155). In addition, liraglutide, a first-line drug for the treatment of type 2 diabetes, can induce anti-inflammatory M2 polarization of Kupffer cells via the cyclic adenosine monophosphate (cAMP)/protein kinase A (PKA)/STAT3 signaling pathway, and attenuate HFD-induced inflammation, which improves MAFLD (156). Similarly, saxagliptin, a novel anti-diabetic drug, was shown to promote M2 polarization by activating CaMKK $\beta / A M P$-activated protein kinase (AMPK) signaling pathway and inhibit M1 polarization by decreasing NF- $\mathrm{KB}$ activity, which alleviated inflammatory responses in diabetic rats, thus ameliorating MAFLD (157). It is worth mentioning that metformin is also a common drug used in the clinical treatment of type 2 diabetes (158). Zamani-Garmsiri et al. (159, 160) found that, in HFD-fed mice, metformin combined with genistein or chlorogenic acid significantly reduced macrophage infiltration in the liver and induced macrophage polarization to M2 phenotype, thereby attenuating hepatic inflammation and MAFLD. The mechanism was associated with the inhibition of the NF- $\mathrm{KB}$ signaling pathway and the increase of AMPK expression $(159,160)$.

$\mathrm{NASH}$, the hepatocyte inflammation based on hepatocyte steatosis, is a more severe stage of MAFLD (161). Through in vitro and in vivo experiments, Zhong et al. (162) demonstrated that honokiol promoted M2 polarization by activating PPAR $\gamma$ signaling, and attenuated high-cholesterol and high-fat dietinduced NASH. Similarly, cactus seed extract could attenuate hepatic steatosis and NASH in mice by modulating macrophage polarization (163). The mechanism might be related to the inhibition of the TLR4/NF- $\mathrm{KB}$ pathway and the promotion of PPAR $\alpha$ expression (163). In addition, Yao et al. (164) found that myricetin suppressed M1 and promoted M2 polarization by inhibiting the TREM-1-TLR2/4-MyD88 signaling pathway and the phosphorylation of STAT3, thus attenuating the NASH induced by choline-deficient, L-amino acid-defined, and highfat diet. $\beta$-cryptoxanthin and astaxanthin, two carotenoids with anti-oxidant effects, could inhibit M1 macrophage polarization to improve insulin resistance and NASH induced by a highcholesterol and high-fat diet in mice $(165,166)$. Tyrosine kinase is important for NF- $\kappa \mathrm{B}$ activation (167). Dasatinib is a tyrosine kinase inhibitor that prevents $\mathrm{NF}-\kappa \mathrm{B}$ activation, which can inhibit M1 and induce M2 polarization to alleviate western diet-induced NASH in mice (167). The role and mechanisms of macrophage polarization in MAFLD/NASH are shown in Table 5.

\subsection{Liver Fibrosis}

LF refers to the abnormal proliferation of intrahepatic connective tissue caused by various pathogenic agents, characterized by 
TABLE 5 | The role and mechanisms of macrophage polarization in MAFLD/NASH.

\begin{tabular}{|c|c|c|c|c|c|}
\hline Regulation Factor & Research Objects & $\begin{array}{l}\text { Macrophage } \\
\text { polarization }\end{array}$ & Mechanisms & $\begin{array}{l}\text { Year and } \\
\text { Country }\end{array}$ & Reference \\
\hline \multicolumn{6}{|l|}{ Alleviating MAFLD/NASH } \\
\hline$\beta$-Cryptoxanthin & Mice, cells & 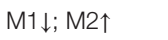 & 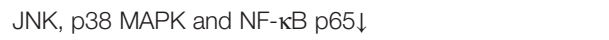 & 2015, Japan & $(165)$ \\
\hline Lactobacillus Paracasei & Mice & $\mathrm{M} 2 \uparrow$ & TLR-4, NOX-4 $\downarrow$; MCP-1, PPAR- $\gamma \downarrow$ & 2015, Korea & (153) \\
\hline Astaxanthin & $\begin{array}{l}\text { Patient samples, mice, } \\
\text { cells }\end{array}$ & $\mathrm{M} 1 \downarrow ; \mathrm{M} 2 \uparrow$ & p38 MAPK $\downarrow, N F-\kappa B \downarrow, J N K \downarrow$ & 2015, Japan & $(166)$ \\
\hline Opuntia ficus indica seed & Mice & $\mathrm{M} 2 \uparrow$ & PPAR- $\alpha \uparrow ;$ PPAR- $\gamma \downarrow ;$ TLR4/NF-кB pathway $\downarrow$ & $\begin{array}{l}\text { 2016, South } \\
\text { Korea }\end{array}$ & $(163)$ \\
\hline Glucoraphanin & Mice, cells & $\mathrm{M} 1 \downarrow ; \mathrm{M} 2 \uparrow$ & 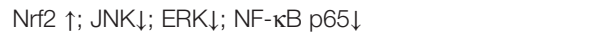 & 2017, Japan & $(151)$ \\
\hline Honokiol & Mice & $\mathrm{M} 2 \uparrow$ & PPAR- $\gamma$ signaling $\uparrow$ & 2018, China & (162) \\
\hline $\begin{array}{l}\text { Retinoic-acid-related orphan } \\
\text { receptor } \alpha\end{array}$ & Mice, cells & $\mathrm{M} 2 \uparrow$ & Kruppel-like factor $4 \uparrow$ & 2017, Korea & $(168)$ \\
\hline Saxagliptin & Rats, cells & $\mathrm{M} 1 \downarrow ; \mathrm{M} 2 \uparrow$ & CaMKKß/AMPK pathway ; NF-кB $\downarrow$ & 2018, China & $(157)$ \\
\hline $\begin{array}{l}\text { Mucosal-associated invariant } \mathrm{T} \\
\text { cells }\end{array}$ & $\begin{array}{l}\text { Patient samples, mice, } \\
\text { cells }\end{array}$ & $\mathrm{M} 2 \uparrow$ & MHCl-related molecule $\uparrow ; \mathrm{IL}-4 \uparrow$ & 2018, China & $(169)$ \\
\hline IL-25 & Mice, cells & $\mathrm{M} 2 \mathrm{a} \uparrow$ & IL-13/STAT6 pathway $\uparrow$ & 2019, China & $(170)$ \\
\hline Raptor & $\begin{array}{l}\text { Patient samples, mice, } \\
\text { cells }\end{array}$ & $\mathrm{M} 2 \uparrow$ & Dynamin-related protein $1 \uparrow$ & 2019, China & $(171)$ \\
\hline Ribes nigrum & Mice & 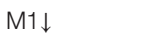 & IL-1 $\beta$, TNF- $\alpha \downarrow ;$ miR-122-5p, miR-192-5p $\downarrow$ & 2019, America & $(172)$ \\
\hline Liraglutide & Mice, cells & $\mathrm{M} 2 \uparrow$ & CAMP-PKA-STAT3 signaling pathway $\uparrow$ & 2019, China & $(156)$ \\
\hline Fermented Korean red ginseng & Mice, cells & $\mathrm{M} 2 \uparrow$ & mTOR complex 1 signaling $\downarrow$ & 2019, Korea & $(173)$ \\
\hline Rosiglitazone & Cells, mice & $\mathrm{M} 1 \rightarrow \mathrm{M} 2$ & PPAR $\gamma \uparrow ;$ TLR4/NF- $\kappa B$ signaling pathway $\downarrow$ & 2020, China & $(155)$ \\
\hline Myricetin & Mice, cells & $\mathrm{M} 1 \downarrow ; \mathrm{M} 2 \uparrow$ & TREM-1-TLR2/4-MyD88 signaling $\downarrow ;$ NF-кB $\downarrow ;$ p-STAT3 $\downarrow$ & 2020, China & (164) \\
\hline $\begin{array}{l}\text { Eccentric exercise and Caloric } \\
\text { restriction }\end{array}$ & Mice & $\mathrm{M} 1 \downarrow ; \mathrm{M} 2 \uparrow$ & MCP1, TNF- $\alpha, I L-1 \beta, I L-6 \downarrow ;$ IL-10个 & 2020, China & (174) \\
\hline Anagliptin & Mice, cells & $\mathrm{M} 1 \downarrow ; \mathrm{M} 2 \uparrow$ & 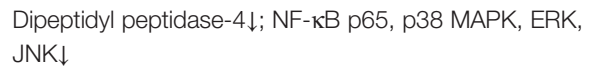 & 2020, Japan & $(175)$ \\
\hline Annexin A5 & Mice, cells & $\mathrm{M} 1 \rightarrow \mathrm{M} 2$ & 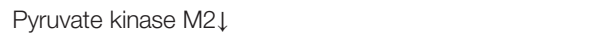 & 2020, China & $(12)$ \\
\hline Amlexanox & Cells & $\mathrm{M} 2 \uparrow$ & TBK1/IKKe-NF-кB signaling pathway $\downarrow$; IRF3 pathway $\downarrow$ & 2020, Korea & $(176)$ \\
\hline $\begin{array}{l}\text { Metformin and Genistein/ } \\
\text { Chlorogenic }\end{array}$ & Mice & $\mathrm{M} 2 \uparrow$ & $\mathrm{NF}-\kappa \mathrm{B} \downarrow ; p-\mathrm{AMPK} \uparrow$ & 2020, Iran & $(159,160)$ \\
\hline Dasatinib & Mice & $\mathrm{M} 2 \uparrow$ & COX2, SREBP-1, p-PDGFR $\downarrow ; N F-\kappa B \downarrow$ & 2021, Egypt & $(167)$ \\
\hline $\begin{array}{l}\text { CD4 derived double negative } T \\
\text { cells }\end{array}$ & Mice, cells & $M 1 \downarrow$ & TLR4, CCR2, TNF- $\alpha \downarrow$ & 2021, China & $(177)$ \\
\hline $\begin{array}{l}\text { G protein-coupled bile acid } \\
\text { receptor } 1\end{array}$ & $\begin{array}{l}\text { Patient samples, mice, } \\
\text { cells }\end{array}$ & 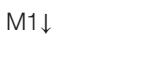 & NLRP3 inflammasome activation $\downarrow$ & 2020, China & $(178)$ \\
\hline \multicolumn{6}{|l|}{ Aggravating MAFLD/NASH } \\
\hline Histone methyltransferase Suv39h2 & $\begin{array}{l}\text { Patient samples, mice, } \\
\text { cells }\end{array}$ & $\mathrm{M} 1 \uparrow$ & Sirt1 $\downarrow ; N F-\kappa B \uparrow ; P P A R-\gamma \downarrow$ & 2017, China & $(179)$ \\
\hline CD44 & Patient samples, mice & $\mathrm{M} 1 \uparrow ; \mathrm{M} 2 \downarrow$ & MCP-1/CCL2/CCR2 $\uparrow$ & 2017, France & $(180)$ \\
\hline MiR-141/200C & $\begin{array}{l}\text { Patient samples, mice, } \\
\text { cells }\end{array}$ & $\mathrm{M} 1 \uparrow ; \mathrm{M} 2 \downarrow$ & 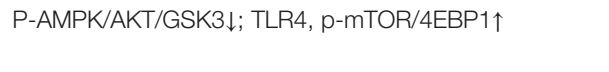 & 2017, America & $(181)$ \\
\hline P62-positive inclusion body & Patient samples & $\mathrm{M} 1 \uparrow$ & Nrf2 $\uparrow$ & 2018, Japan & $(148)$ \\
\hline HSPA12A & $\begin{array}{l}\text { Patient samples, mice, } \\
\text { cells }\end{array}$ & $\mathrm{M} 1 \uparrow$ & Nuclear M2 isoform of pyruvate kinase $\uparrow$ & 2019, China & $(182)$ \\
\hline Iron overload & Mice, cells & $\mathrm{M} 1 \uparrow ; \mathrm{M} 2 \downarrow$ & 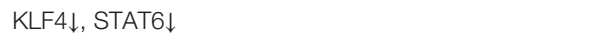 & 2019, America & $(183)$ \\
\hline $\mathrm{P} 38 \alpha$ & Patient samples, mice & $\mathrm{M} 1 \uparrow$ & 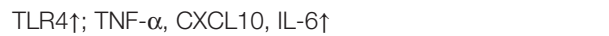 & 2019, China & (184) \\
\hline Cholesterol & Patient samples, cells & $\mathrm{M} 1 \uparrow$ & Exosomal miR-122-5p $\uparrow$ & 2020, China & $(185)$ \\
\hline $\begin{array}{l}\text { Hepatocyte-derived exosomal miR- } \\
192-5 p\end{array}$ & Patient samples, rats & $\mathrm{M} 1 \uparrow$ & 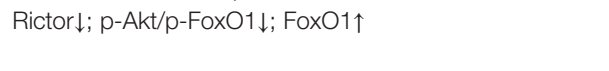 & 2020, China & (186) \\
\hline E. coli NF73-1 & $\begin{array}{l}\text { Patient samples, mice, } \\
\text { cells }\end{array}$ & $\mathrm{M} 1 \uparrow$ & $\begin{array}{l}\text { TLR2/NLRP3 pathway } \uparrow ; \text { mTOR-S6K1-SREBP-1/PPAR- } \\
\alpha \text { signaling } \uparrow\end{array}$ & 2020, China & (154) \\
\hline
\end{tabular}

excessive deposition of extracellular matrix (ECM) (187). LF is essentially an excessive reparative response of the liver against chronic injury, and the formation mechanism is quite complex, which involves not only multiple cells, but also the complex cytokine network constituted by cellular autocrine and paracrine components (188). The activation of hepatic stellate cells (HSCs) is the major source of ECM as well as the central link of LF formation (189). The initiation and persistence of HSC activation is directly regulated by hepatic macrophages. On the one hand, macrophages activate HSCs and promote the progression of LF (190). On the other hand, during the reversal of LF, macrophages can drive HSC apoptosis and ECM degradation (191). Beljaars et al. (192) localized and quantified the macrophages with different phenotypes in the liver of humans and mice with LF. The results demonstrated that the numbers of both M1 and M2 macrophages were significantly increased during 
LF formation phase (192). However, compared with M2 macrophages, M1 macrophages may play a more important role in the regression of LF (192). In addition, Xi et al. (193) found that activated HSCs could promote hepatic macrophage infiltration through the CCL2/CCR2 pathway and induce M2 polarization to aggravate liver fibrosis. These studies amply suggest that macrophage polarization occupies an important role in LF progression.

Because there are various factors causing LF, and the pathogenesis and pathological process of different types of LF are different, the effects of macrophage polarization also vary. A study has shown that M1 macrophages and related proinflammatory cytokines are markedly increased in carbon tetrachloride $\left(\mathrm{CCl}_{4}\right)$-induced $\mathrm{LF}$, whereas M2 macrophage polarization seems to predominate in schistosome infectioninduced LF (194). Therefore, the inhibition of M1 and M2 macrophage polarization may respectively alleviate $\mathrm{CCl}_{4}$ - and schistosome infection-induced LF. For example, margatoxin reduced $\mathrm{M} 1$ and increased $\mathrm{M} 2$ macrophage polarization by inhibiting STAT1 and promoting the phosphorylation of STAT6, which down-regulated pro-inflammatory cytokines and increased IL-10 expression, alleviating $\mathrm{CCl}_{4}$-induced LF in mice (195). Corilagin inhibited M2 polarization by inhibiting IL-13R $\alpha 1$ signaling pathway, which alleviated schistosome egg-induced LF (196). However, this is not a completely uniform law. Ma et al. (14) showed that M1 polarization rather than M2 polarization contributed to the reduced activation and number of HSCs in the $\mathrm{CCl}_{4}$ and bile duct ligation-induced LF mouse model. Similarly, 2methoxyestradiol alleviated $\mathrm{CCl}_{4}$-induced $\mathrm{LF}$ in mice by reducing macrophage infiltration and M2 polarization (197). These findings sufficiently indicate the complex association between LF and macrophage polarization.

The mechanisms by which macrophage polarization regulates LF are complex, involving multiple pathways and signaling molecules. Among them, Notch signaling pathway is closely related to multiple cellular activities, and has an important role in LF by regulating HSC activation and macrophage polarization (198). Bansal et al. (199) experimentally demonstrated that Notch pathway inhibition contributed to reducing M1 and promoting M2 macrophage polarization, as well as reducing the activation of HSCs and fibroblasts. Similarly, capsaicin and quercetin could also attenuate $\mathrm{CCl}_{4}$-induced hepatic inflammation and fibrosis in mice by inhibiting M1 polarization via the inhibition of the Notch signaling pathway $(76,200)$. However, in schistosome infection-induced LF, Notch inhibition also suppressed M2 macrophage polarization, thus ameliorating LF (77). Furthermore, IL-4R $\alpha$ plays a dual role in LF. On the one hand, IL- $4 \mathrm{R} \alpha$ activation induced M2 macrophage polarization to accelerate the process of LF (201). On the other hand, IL-4R $\alpha$-mediated STAT6 phosphorylation induced the production of MMP-12, contributing to hepatic fibrinolysis (201).

Currently, MSC transplantation is a promising anti-fibrotic strategy (202). Watanabe et al. (203) showed that MSCs could induce the M2 polarization of bone marrow-derived macrophages to play a synergistic role in the reversal of LF. Similarly, Luo et al. (204) showed that MSC transplantation could promote M2 and inhibit M1 macrophage polarization, as well as increase MMP13 expression and inhibit HSC activation, which exerted a synergistic anti-LF effect. Subsequently, further research has found that TNF-stimulated gene 6 is a major cytokine by which MSCs exert anti-fibrotic effects (205). Specifically, its liver-targeted delivery through calcium phosphate nanoparticles contributed to LF treatment, which was related to promoting M2 macrophage polarization and increasing MMP12 expression (205). Furthermore, in the development of LF, increased NKp $46^{+}$cells produced IFN- $\gamma$ to induce M1 macrophage polarization, and limited M2 polarization and the production of pro-fibrotic factors, which inhibited the occurrence of metabolism-related LF (206). The role and mechanisms of macrophage polarization in LF are shown in Table 6.

\subsection{Hepatocellular Carcinoma}

Chronic liver diseases and the related inflammation may lead to ECM deposition to form LF, which if left unchecked, fibrous scars will continuously accumulate to form cirrhosis, ultimately causing HCC (220). HCC is the end stage of chronic liver diseases, and accounts for more than $80 \%$ of primary liver cancers worldwide, which is the fourth leading cause of cancerrelated death (221). Although there are FDA-approved drugs for the clinical treatment of HCC currently, their therapeutic effects are quite limited. Therefore, it is still of great interest to explore the pathological mechanism of HCC and develop effective therapeutic drugs. Tumor growth, metastasis, and regression are influenced by the microenvironment in which it resides. Tumor-associated macrophages (TAMs) are major components of tumor microenvironment, and can differentiate into M1 and M2 phenotypes because of their plasticity, having an important role in the progression of HCC (222).

Autophagy is a key physiological and pathological process of the body, which is particularly important in tumor research (223). The study of Chang et al. (224) found that TLR2 ligands in HCC decreased NF- $\kappa \mathrm{B}$ activity and promoted M2 macrophage polarization. Further research showed that HCC-derived high mobility group box 1 protein induced M2 polarization via the TLR2/NOX2/autophagy axis, promoting HCC development (225). These are perhaps potential targets for the treatment of HCC. Moreover, autophagy may influence the therapeutic effects of drugs on HCC. Tan et al. (226) found that baicalin promoted M2-TAMs to repolarize to M1 phenotype via autophagyinduced RelB/p52 activation, thus suppressing HCC. Sorafenib is currently an important option for the clinical treatment of HCC (227). However, Wei et al. (228) found that M2-TAMs could promote the autophagy of HCC cells and decrease the inhibitory effect of sorafenib on the proliferation of HCC cells, ultimately leading to sorafenib resistance in HCC treatment.

The latest evidence has suggest that lncRNAs play a crucial role in the occurrence and development of HCC (229). LncRNA TP73AS1 down-regulates miR539 to promote MMP8 expression, thus activating TGF- $\beta 1$ signaling, which promotes 
TABLE 6 | The role and mechanisms of macrophage polarization in LF.

\begin{tabular}{|c|c|c|c|c|c|}
\hline Regulation Factor & Research Objects & $\begin{array}{l}\text { Macrophage } \\
\text { polarization }\end{array}$ & Mechanisms & $\begin{array}{l}\text { Year and } \\
\text { Country }\end{array}$ & Reference \\
\hline \multicolumn{6}{|l|}{ Alleviating LF } \\
\hline \multirow[t]{2}{*}{$\gamma$-secretase inhibitor } & $\begin{array}{l}\text { Patient samples, cells, } \\
\mathrm{CCl}_{4} \text {-treated mice }\end{array}$ & 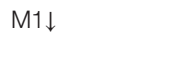 & Notch signaling $\downarrow$ & $\begin{array}{l}2015, \\
\text { Netherlands }\end{array}$ & $(199)$ \\
\hline & $\begin{array}{l}\text { Cells, schistosome-infected } \\
\text { mice }\end{array}$ & $\mathrm{M} 2 \downarrow$ & & 2016, China & $(77)$ \\
\hline $\mathrm{NKp} 46^{+}$cells & MCD-fed mice, cells & $\mathrm{M} 1 \uparrow$ & $\mid \mathrm{FN}-\gamma \uparrow$ & $\begin{array}{l}\text { 2016, } \\
\text { America }\end{array}$ & $(206)$ \\
\hline Toxoplasma gondii GRA15॥ & Cells, schistosome-infected & $\mathrm{M} 1 \uparrow$ & 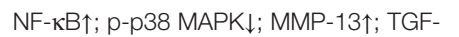 & 2018, China & $(207)$ \\
\hline Lentiviral GRA15॥ & mice & & $\beta 1 \downarrow$ & 2018, China & $(208)$ \\
\hline Corilagin & Schistosome-infected mice & $\mathrm{M} 2 \downarrow$ & 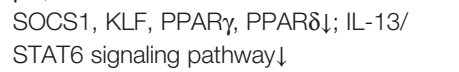 & 2016, China & $(209)$ \\
\hline $\begin{array}{l}\text { Phosphatase and tensin homolog deleted } \\
\text { on chromosome } 10\end{array}$ & $\mathrm{CCl}_{4}$-treated mice, cells & $\mathrm{M} 2 \uparrow$ & PI3K/Akt/STA T6 signaling $\uparrow$ & 2017, China & $(210)$ \\
\hline S-allyl-glutathione & $\begin{array}{l}\mathrm{CCl}_{4} \text {-treated rats, cells } \\
\text { DMN-treated rats, cells }\end{array}$ & 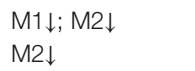 & heat shock protein $47 \downarrow$ & 2018, Japan & $(211)$ \\
\hline Quercetin & $\mathrm{CCl}_{4}$-treated mice, cells & $\mathrm{M} 1 \downarrow$ & Notch1 pathway $\downarrow$ & 2018, China & $(200)$ \\
\hline $\begin{array}{l}\text { Proline-serine-threonine-phosphatase- } \\
\text { interacting protein2 }\end{array}$ & $\mathrm{CCl}_{4}$-treated mice, cells & $\mathrm{M} 1 \downarrow ; \mathrm{M} 2 \uparrow$ & STAT1 $\downarrow ;$ STAT6 $\uparrow$ & 2018, China & $(212)$ \\
\hline Bone marrow MSC transplantation & $\mathrm{CCl}_{4}$-treated mice, cells & 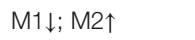 & 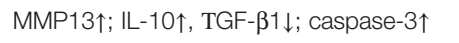 & 2019, China & $(204)$ \\
\hline Splenectomy & ConA-treated mice & $\mathrm{M} 2 \uparrow$ & $N F-\kappa B$ p65/p50 & 2019, China & (213) \\
\hline Recombinant Sj16 protein & $\begin{array}{l}\text { Schistosome-infected mice, } \\
\text { cells }\end{array}$ & $\mathrm{M} 2 \uparrow$ & Arg-1, IL-10个; Th1 response $\downarrow$ & 2019, China & $(214)$ \\
\hline Margatoxin & $\mathrm{CCl}_{4}$-treated mice, cells & $\mathrm{M} 1 \downarrow ; \mathrm{M} 2 \uparrow$ & 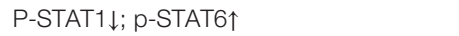 & 2020, China & $(195)$ \\
\hline TNF-stimulated gene 6 & $\mathrm{CCl}_{4}$-treated mice & $\mathrm{M} 2 \uparrow$ & P-STAT1/3, p-p65, p-Akt $\downarrow ; N F-\kappa B \downarrow$ & 2020, China & $(205)$ \\
\hline Endoplasmic reticulum stress & $\mathrm{CCl}_{4}$-treated rats, cells & $\mathrm{M} 1 \uparrow$ & TNF- $\alpha \uparrow ;$ TNF-R1/caspase $8 \uparrow$ & 2020, China & $(215)$ \\
\hline Capsaicin & $\mathrm{CCl}_{4}$-treated rats, cells & $\mathrm{M} 1 \downarrow$ & Notch signaling $\downarrow ;$ TNF- $\alpha \downarrow$ & 2020, China & $(76)$ \\
\hline IL-22 & $\mathrm{CCl}_{4}$-treated mice, cells & $\mathrm{M} 1 \rightarrow \mathrm{M} 2$ & $\begin{array}{l}\text { Erk1/2 and Akt pathways } \downarrow \text {; STAT3 } \\
\text { pathway } \uparrow\end{array}$ & 2021, China & $(216)$ \\
\hline \multicolumn{6}{|l|}{ Aggravating LF } \\
\hline Cytochrome P450 2E1 & $\begin{array}{l}\text { Patient samples, DEN- } \\
\text { treated mice }\end{array}$ & $\mathrm{M} 2 \downarrow$ & CD163/CD68 ratio $\downarrow$ & 2019, China & $(217)$ \\
\hline PC3-secreted microprotein & $\begin{array}{l}\text { Patient samples, } \mathrm{CCl} 4 \text { - } \\
\text { treated mice }\end{array}$ & $\mathrm{M} 1 \uparrow$ & $\mathrm{CCR} 2 \uparrow$ & 2020, China & $(218)$ \\
\hline LncRNA Lfar1 & $\begin{array}{l}\text { Cells, } \mathrm{CCl}_{4} \text { and } \mathrm{BDL}- \\
\text { treated mice }\end{array}$ & $\mathrm{M} 1 \uparrow$ & NLRP3 inflammasome ; NF-кB pathway & 2020, China & $(219)$ \\
\hline Activated HSCs & Patient samples, cells & $\mathrm{M} 2 \uparrow$ & CCL2/CCR2 pathway $\uparrow$ & 2021, China & (193) \\
\hline
\end{tabular}

M2 macrophage polarization and HCC progression (230). Similarly, lncRNA LINC00662 activates Wnt/ $\beta$-catenin signaling to promote M2 polarization and HCC (231). In addition, angiogenesis is a prominent feature of tumor development (232). The study by Han et al. (233) showed that lncRNA-CRNDE could induce M2 polarization and promote angiogenesis, and the mechanism was associated with upregulating the expression of JAK1, STAT6, AKT1, and angiogenesis-related proteins. Hou et al. (234) found that IncRNA MALAT1 expression was increased in HCC cells, which inhibited miR140 expression, ultimately promoting angiogenesis and M2 polarization, and enhancing immunosuppressive capacity.

Exosomes, the main members of EVs, have an important role in tumor initiation and development because of carrying and transmitting multiple biological signals (235). On the one hand, tumor-derived exosomes mostly accelerate tumor development. For example, lncRNA TUC339 of HCC-derived exosomes can promote M2 polarization, and its inhibition can promote the expression and phagocytic activity of M1 macrophage-related inflammatory factors (236). The transcription factor Sal like protein-4 can up-regulate miR-146a-5p expression of HCC- derived exosomes, promoting M2 macrophage polarization and the expression of the inhibitory receptor PD1 on the surface of $\mathrm{T}$ cells, which accelerates HCC progression (237). On the other hand, macrophage-derived exosomes can also regulate HCC progression. Wu et al. (238) showed that M2 macrophageproduced exosomes expressed specific CD11b/CD18 proteins, which up-regulated MMP-9 expression after entering HCC cells, thus promoting HCC migration. M1 macrophage-derived exosomal miR-326 inhibits NF- $\mathrm{KB}$ signaling pathway to inhibit the proliferation and migration of HCC cells (239).

The recurrence of HCC after tumor resection is a major hidden danger in HCC treatment. HCC prognosis contributes to the survival prediction of HCC patients, but there are limitations to traditional prognostic methods. Therefore, searching for HCC prognosis-related biomarkers is beneficial not only for better prognosis but also for the targeted therapy of HCC. Shu et al. (240) and Dong et al. (241) showed that M1/M2 macrophage polarization can be used as an independent prognostic factor for HCC, and the markers CD86 and CD206 can be used as the biomarkers for HCC prognosis. A subsequent study showed that $\mathrm{GdCl} 3$ could inhibit HCC progression in mice by down-regulating 
CD206 expression (242). In HBV-related HCC, T-UCR uc.306 expression is increased in M1 but down-regulated in M2 macrophages, which may serve as a HCC prognostic marker and a potential therapeutic target (243). Moreover, both neuromedin $U$ and transmembrane 205 can serve as the biomarkers for macrophage polarization-related HCC prognosis, which contributes to the targeted therapy of $\operatorname{HCC}(244,245)$.

In conclusion, it is currently generally accepted that M2 macrophages induce tumor cell proliferation and metastasis to promote tumor development, whereas M1 macrophages have anti-tumor effects. In the HCC microenvironment, besides the role of HCC cells and macrophages, multiple internal factors and external interventions may also induce macrophage polarization to influence the development of HCC. For example, IL-37 inhibits M2 macrophage polarization mediated by the IL-6/STAT3 signaling pathway, thereby preventing HCC development (246). 4-methylumbelliferone can induce M1 macrophage polarization in the tumor microenvironment and inhibit the invasion of HCC cells (247). However, the study by Wang et al. (248) found that M1 macrophages could activate $\mathrm{NF}-\kappa \mathrm{B} /$ focal adhesion kinase signaling to contribute to HCC metastasis. In addition, the study by Zong et al. (249) demonstrated that M1 macrophages induced the high expression of the programmed cell death-ligand 1 in HCC cells by up-regulating IL-1 $\beta$. Their findings support the pro-HCC effect of M1 macrophages. Therefore, the role of macrophage polarization in HCC is not as simple as it appears, and more indepth studies are needed in the future. The role and mechanisms of macrophage polarization in HCC are shown in Table 7.

\section{DISCUSSION AND CONCLUSION}

Liver diseases are a major public health problem worldwide with high morbidity and mortality (5). At present, in-deep research on the pathogenesis of liver diseases and the development of effective drugs are important means for the treatment of liver diseases, as well as an important task and difficulty for scientific researchers. It is worth mentioning that recent studies have revealed that macrophage polarization plays an important role in the initiation and progression of liver diseases, and has a dual regulatory role on various liver diseases (273). This suggests that macrophages can influence the progression of multiple liver diseases through their polarization. Figure 3 clearly shows the ameliorative effects of macrophage polarization on various liver diseases.

Hepatic macrophages have significant heterogeneity, which are composed of macrophages from multiple origins. Current studies have shown that macrophages mainly polarize to two phenotypes, pro-inflammatory M1 and anti-inflammatory M2 (25). Specifically, after being induced by their respective activators, M1 and M2 macrophages produce a large number of pro-inflammatory or anti-inflammatory cytokines and chemokines, thus acting on different targets to activate the signaling pathways associated with multiple pathological processes, which exert their regulatory functions (25).
According to the data, macrophage polarization is mainly associated with TLR4/NF- $\kappa B$, JAK/STATs, TGF- $\beta /$ Smads, $\operatorname{PPAR} \gamma$, Notch, and miRNA signaling pathways. In addition, other signaling pathways, such as MAPK, mTOR, and so on, may be also involved. Therefore, targeting these signaling pathways may modulate macrophage polarization to alter the role of macrophages in liver diseases.

ALI refers to hepatic acute injury and hepatocellular necrosis mostly resulting from chemical drugs and poisons (86). Current studies generally show that M1 macrophagesecreted pro-inflammatory cytokines aggravate ALI, whereas M2 macrophages have the function of promoting tissue injury repair and secrete anti-inflammatory cytokines, which is beneficial for inflammation resolution and ALI alleviation. Therefore, promoting macrophage polarization to M2 phenotype and inhibiting M1 phenotype are important mechanisms to ameliorate ALI.

M1 and M2 macrophages in viral hepatitis have a complex cytokine profile (113). Specifically, after HBV and HCV infection, M2 macrophage polarization and IL-10 secretion are increased, and the pro-inflammatory factors produced by M1 macrophages are decreased, while some of them contribute to the alleviation of viral infection (274). Therefore, the inhibition of M2 macrophage polarization and the promotion of M1associated cytokine production contribute to the alleviation of HBV - and HCV-related hepatitis. Differently, Labonte et al. (118) infected the mice with recombinant adenovirus expressing ovalbumin and performed an in vitro study of macrophage polarization, which showed that liver resident Kupffer cells polarized to M2 phenotype through up-regulating the expression of scavenger receptor AI, contributing to the reversal of chronic inflammation and tissue damage caused by viral infection. This suggests that the polarization of macrophages of different origins in the liver under the background of virus infection may have different effects on the disease development.

Ethanol leads to M1 macrophage polarization by acting on multiple receptors and targets in the body, thus aggravating inflammatory responses, which is one of the important pathogenesis of ALD (126). Current studies generally agree that M1 macrophages promote inflammation and aggravate ALD, whereas M2 macrophages have anti-inflammatory effects and attenuate alcohol-caused liver injury. Therefore, the development of targeted agents that induce macrophage polarization from M1 to M2 is of great significance for the clinical treatment of ALD. However, a study showed that TGF- $\beta$, a M2-associated profibrotic factor, was highly expressed in the liver of alcoholic hepatitis patients, which involved the interaction of M1 and multiple subtypes of M2 macrophages (M2a, M2b, and M2c) (275). Therefore, the role of macrophage polarization in ALD warrants further in-depth investigation.

MAFLD is a kind of liver injury closely related to metabolism and genetics with multiple complications, initially characterized by fat accumulation and degeneration, and probably develops into NASH with massive inflammatory responses $(144,145)$. Research showed that M1 macrophage polarization increased 
TABLE 7 | The role and mechanisms of macrophage polarization in HCC.

\begin{tabular}{|c|c|c|c|c|c|}
\hline Regulation Factor & Research Objects & $\begin{array}{l}\text { Macrophage } \\
\text { polarization }\end{array}$ & Mechanisms & $\begin{array}{l}\text { Year and } \\
\text { Country }\end{array}$ & Reference \\
\hline \multicolumn{6}{|l|}{ Alleviating HCC } \\
\hline Cantharidin & Cells, mice & $\mathrm{M} 2 \rightarrow \mathrm{M} 1$ & 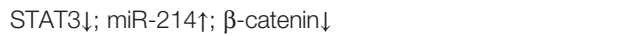 & 2014, China & $(250)$ \\
\hline Baicalin & Cells, mice & $\mathrm{M} 2 \rightarrow \mathrm{M} 1$ & RelB/p52 pathway $\uparrow$ & 2015, China & $(226)$ \\
\hline $\mathrm{GdCl}_{3}$ & $\begin{array}{l}\text { Patient samples, } \\
\text { mice, cells }\end{array}$ & $\mathrm{M} 2 \downarrow$ & 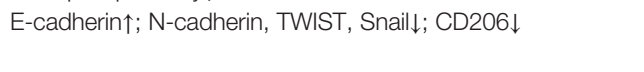 & 2015, China & $(242)$ \\
\hline $\mathrm{IL}-12$ & Cells, mice & $\mathrm{M} 1 \uparrow$ & STAT3/C-Myc pathway $\downarrow$ & 2016, China & $(251)$ \\
\hline ToxoGRA15 & Cells, mice & $\mathrm{M} 1 \uparrow$ & 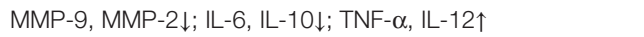 & 2017, China & $(252)$ \\
\hline LncRNA cox-2 & Cells, mice & $\mathrm{M} 1 \uparrow ; \mathrm{M} 2 \downarrow$ & $\mathrm{p} 50 / \mathrm{p} 65 \uparrow ; \mathrm{COX}-2 \uparrow$ & 2018, China & $(253)$ \\
\hline MiR-98 & Cells & $\mathrm{M} 2 \rightarrow \mathrm{M} 1$ & 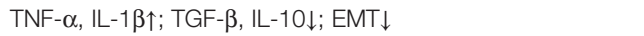 & 2018, China & $(254)$ \\
\hline SPON2 & $\begin{array}{l}\text { Patient samples, } \\
\text { mice, cells }\end{array}$ & $\mathrm{M} 1 \uparrow$ & Integrin-Rho GTPase-Hippo pathways $\uparrow$ & 2018, China & $(255)$ \\
\hline Cryptotanshinone & Cells, mice & $\mathrm{M} 1 \uparrow$ & TLR7/MyD88/NF-кB signaling pathway $\uparrow$ & $\begin{array}{l}2019, \\
\text { America }\end{array}$ & $(256)$ \\
\hline Sirtuin 1 & $\begin{array}{l}\text { Patient samples, } \\
\text { cells }\end{array}$ & $\mathrm{M} 1 \uparrow$ & NF-кB pathway $\uparrow$ & 2019, China & $(257)$ \\
\hline Sirtuin 4 & $\begin{array}{l}\text { Patient samples, } \\
\text { cells, mice }\end{array}$ & $\mathrm{M} 2 \downarrow$ & FAO-PPAR $\delta$-STAT3 signaling pathway $\downarrow$ & 2019, China & $(258)$ \\
\hline IL-37 & $\begin{array}{l}\text { Patient samples, } \\
\text { cells, mice }\end{array}$ & $\mathrm{M} 2 \rightarrow \mathrm{M} 1$ & IL-6/STAT3 pathway $\downarrow$ & 2020, China & $(246)$ \\
\hline Retinoic acid-inducible gene I & $\begin{array}{l}\text { Patient samples, } \\
\text { cells, mice }\end{array}$ & $\mathrm{M} 1 \uparrow$ & MAVS/TRAF2/NF-кB pathway $\uparrow$ & 2020, China & $(259)$ \\
\hline 4-methylumbelliferone & Mice, cells & $\mathrm{M} 1 \uparrow$ & 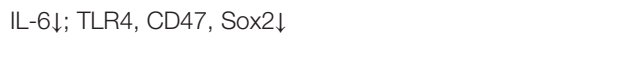 & $\begin{array}{l}2021 \\
\text { Australia }\end{array}$ & $(247)$ \\
\hline $\begin{array}{l}\text { G. lucidum spore } \\
\text { polysaccharide }\end{array}$ & Cells, mice & $\mathrm{M} 1 \uparrow$ & TNF- $\alpha$, IL-1 $\beta$, IL-6, TGF- $\beta 1 \uparrow ;$ PI3K/AKT pathway $\uparrow$ & 2021, China & $(260)$ \\
\hline MiR-144/451a cluster & $\begin{array}{l}\text { Patient samples, } \\
\text { mice, cells }\end{array}$ & $\mathrm{M} 1 \uparrow$ & $\begin{array}{l}\text { hepatocyte growth factor (HGF) } \downarrow \text {; migration inhibitory factor } \\
\text { (MIF) } \downarrow\end{array}$ & 2021, China & $(261)$ \\
\hline \multicolumn{6}{|l|}{ Aggravating HCC } \\
\hline $\begin{array}{l}\text { Oxidored-nitro domain- } \\
\text { containing protein } 1\end{array}$ & $\begin{array}{l}\text { Patient samples, } \\
\text { mice, cells }\end{array}$ & $\mathrm{M} 2 \uparrow$ & 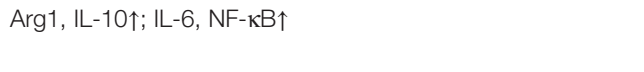 & 2018, China & $(262)$ \\
\hline $\begin{array}{l}\text { N-myc downstream-regulated } \\
\text { gene } 2\end{array}$ & Cells, mice & $\mathrm{M} 1 \downarrow$ & $N F-\kappa B$ signaling pathway $\downarrow$ & 2018, China & $(263)$ \\
\hline Wnt ligands & $\begin{array}{l}\text { Patient samples, } \\
\text { mice, cells }\end{array}$ & $\mathrm{M} 2 \uparrow$ & Wnt/ $\beta$-catenin signaling $\uparrow$ & 2018, China & $(15)$ \\
\hline Neurotensin & $\begin{array}{l}\text { Patient samples, } \\
\text { cells, mice }\end{array}$ & $\mathrm{M} 2 \uparrow$ & 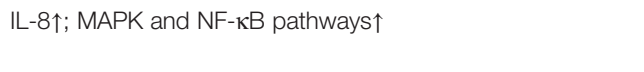 & 2018, China & $(264)$ \\
\hline Sal-like protein-4 & $\begin{array}{l}\text { Patient samples, } \\
\text { cells, mice }\end{array}$ & $\mathrm{M} 2 \uparrow$ & Exosomal miR-146a-5p $\uparrow$ & 2019, China & $(237)$ \\
\hline Intestinal dysbacteriosis & $\begin{array}{l}\text { Patient samples, } \\
\text { cells, mice }\end{array}$ & $\mathrm{M} 2 \uparrow$ & 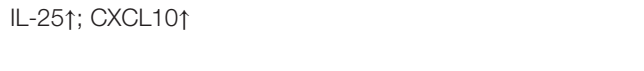 & 2019, China & $(265)$ \\
\hline LncRNA LINC00662 & $\begin{array}{l}\text { Patient samples, } \\
\text { cells, mice }\end{array}$ & $\mathrm{M} 2 \uparrow$ & Wnt/ $\beta$-catenin signaling $\uparrow$ & 2020, China & $(231)$ \\
\hline LncRNA MALAT1 & $\begin{array}{l}\text { Patient samples, } \\
\text { cells, mice }\end{array}$ & $\mathrm{M} 2 \uparrow$ & 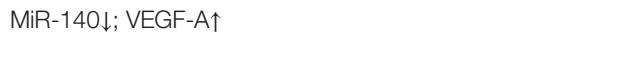 & 2020, China & $(234)$ \\
\hline Extracellular ubiquitin & $\begin{array}{l}\text { Patient samples, } \\
\text { cells, mice }\end{array}$ & $\mathrm{M} 2 \uparrow$ & CXCR4/ERK signaling pathway $\uparrow$ & 2020, China & $(266)$ \\
\hline LncRNA TP73-AS1 & $\begin{array}{l}\text { Patient samples, } \\
\text { cells, mice }\end{array}$ & $\mathrm{M} 2 \uparrow$ & 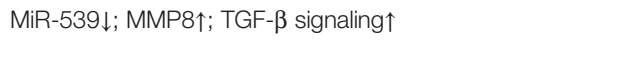 & 2020, China & $(230)$ \\
\hline Nogo-B & $\begin{array}{l}\text { Patient samples, } \\
\text { cells, mice }\end{array}$ & $\mathrm{M} 2 \uparrow$ & $\begin{array}{l}\text { Yes-associated protein (Yap)/transcriptional coactivator with } \\
\text { PDZ-binding motif (Taz) } \uparrow\end{array}$ & 2020, China & $(267)$ \\
\hline High-mobility group box 1 & Cells, mice & $\mathrm{M} 2 \uparrow$ & TLR2/NOX2/autophagy axis $\uparrow$ & 2020, China & $(225)$ \\
\hline Arsenite & Cells, mice & $\mathrm{M} 2 \uparrow$ & $\begin{array}{l}\text { MiR-15b } \uparrow \text {; large tumor suppressor kinase } 1 \downarrow \text {; Hippo } \\
\text { pathway }\end{array}$ & 2021, China & (268) \\
\hline IncRNA-CRNDE & Cells, mice & $\mathrm{M} 2 \uparrow$ & 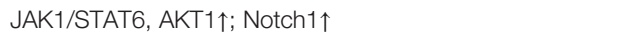 & 2021, China & $(233)$ \\
\hline Cancer-associated fibroblast & Cells & $\mathrm{M} 2 \uparrow$ & 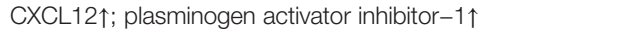 & 2021, Japan & $(269)$ \\
\hline Cyclooxygenase-2 & $\begin{array}{l}\text { Patient samples, } \\
\text { mice, cells }\end{array}$ & $\mathrm{M} 2 \uparrow$ & 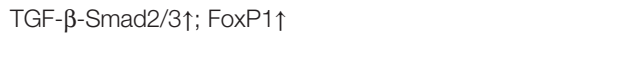 & 2021, China & $(270)$ \\
\hline Epithelial cell transforming 2 & $\begin{array}{l}\text { Patient samples, } \\
\text { cells, mice }\end{array}$ & $\mathrm{M} 2 \uparrow$ & PLK1/PTEN pathway $\uparrow$ & 2021, China & $(271)$ \\
\hline $\begin{array}{l}\text { Distal-less homeobox } 6 \\
\text { antisense } 1\end{array}$ & $\begin{array}{l}\text { Patient samples, } \\
\text { cells, mice }\end{array}$ & $\mathrm{M} 2 \uparrow$ & 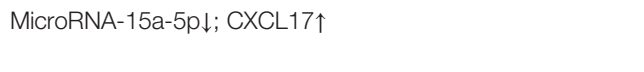 & 2021, China & $(272)$ \\
\hline
\end{tabular}




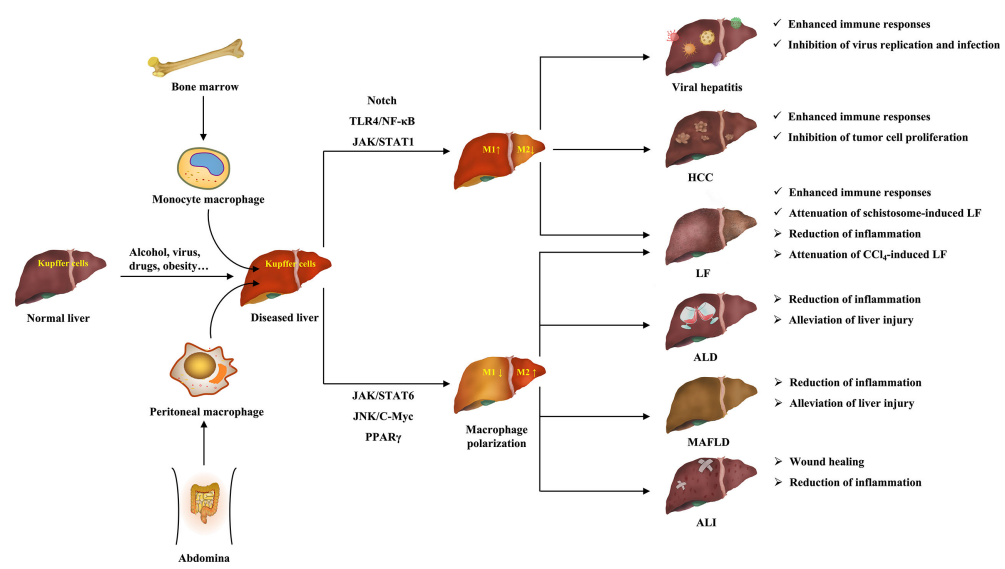

FIGURE 3 | The ameliorative effects of macrophage polarization on various liver diseases.

markedly during the development of MAFLD and NASH (146, 276). In addition to the body's genes and receptors, many drugs can target relevant signaling pathways to inhibit M1 and promote M2 macrophage polarization, thus attenuating hepatic steatosis and inflammation in MAFLD/NASH. Interestingly, based on clinical studies and life experience, daily exercise and a controlled diet contribute to the improvement of MAFLD, which was shown to be related to the regulation of macrophage polarization (174). In addition, the study by Wan et al. (277) found that Kupffer cells with M2 phenotype could promote the apoptosis of M1 macrophages, inhibiting alcohol and high-fat diet-induced liver injury and inflammation. This is perhaps a potential mechanism by which M2 macrophages ameliorate ALD and MAFLD.

LF is a chronic liver disease resulting from the excessive repair of liver tissue injury, characterized by excessive deposition of ECM in the liver, which manifests as intrahepatic connective tissue dysplasia (278). Due to extensive etiologies, such as common $\mathrm{CCl}_{4}$ and schistosome infection in research, the pathogenesis of LF is not consistent (279). Therefore, different phenotypes of macrophages have different effects in different types of LF. In general, $\mathrm{M} 1$ macrophages promote $\mathrm{CCl}_{4}$-induced LF but inhibit schistosome infection-induced LF, but the effect of M2 macrophages is reversed. However, an increase in M1 polarization or a decrease in M2 polarization sometimes contributes to the alleviation of $\mathrm{CCl}_{4}$-induced $\mathrm{LF}(14,197)$. Multiple mechanisms are involved in macrophage polarization in LF. Research proved that Notch signaling inhibition could alleviate $\mathrm{CCl}_{4^{-}}$and schistosome-induced LF by inhibiting M1 and M2 polarization, respectively. More importantly, MSC transplantation, commonly used in LF treatment, also relies on the regulation of macrophage polarization. Furthermore, the study by Takemura et al. (211) found that s-allyl-glutathione reduced HSC activation in the rats with $\mathrm{CCl}_{4}$-induced LF by regulating macrophage polarization, rather than directly acting on HSCs. Therefore, macrophage polarization may have an indispensable role in LF.
HCC, the end stage of various chronic liver diseases, is a major cause of cancer-related death worldwide (221). Macrophages in the tumor microenvironment have a dominant role in cancer development and prognosis (280). The effect of macrophage polarization on HCC progression involves multiple cytokines and signaling pathways, including autophagy, IncRNAs, miRNAs, and the classical pathways of macrophage polarization. Exosomes serve as important vehicles for the signal transduction of HCC cells and macrophages. In general, M2 macrophages promote the proliferation and migration of HCC cells, whereas M1 macrophages can inhibit HCC development. However, some studies have shown that M1 macrophages may also have pro-tumor effects, indicating that the macrophage polarization in HCC is not restricted to protumor M2 and anti-tumor M1 $(248,249)$.

In addition to the liver diseases discussed above, autoimmune liver disease is a group of special chronic liver diseases caused by immune dysfunction in the body, including autoimmune hepatitis $(\mathrm{AIH})$, primary biliary cholangitis $(\mathrm{PBC})$, primary sclerosing cholangitis (PSC) and their overlap syndrome (281). Interestingly, soluble CD163, a marker of macrophage activation, is closely associated with the severity of AIH, PBC and PSC, which can be used as a prognostic marker for them (282-284). Guicciardi et al. (285) further experimented to directly demonstrated that M1 and M2 macrophages were involved in the pathogenesis of PSC. These suggest us that it is worthy and necessary to pay more attention to the role of macrophage polarization in autoimmune liver disease. Li et al. (286) found that M1 macrophage polarization and the self-renewal of hepatic progenitor cells were increased in the livers of patients with PSC, associated with enhanced expression of Notch signaling pathway. Consistently, Jiang et al. (287) used 3,5diethoxycarbonyl-1,4-dihydrocollidine to induce a liver disease similar to sclerosing cholangitis, and found that M1 polarization of macrophages led to decreased Wnt secretion and aggravated liver injury. A later study further found that cholangiocytederived exosomal lncRNA H19 exacerbated the inflammatory 
responses in patients with $\mathrm{PBC}$ and PSC by promoting Kupffer cell activation and M1 polarization of bone marrow-derived macrophage (288). Moreover, in a Con A-induced AIH mouse model, IL-34 and splenectomy were shown to inhibit inflammation and fibrosis, both of which were related to promoting M2 macrophage polarization $(213,289)$. From these findings, it is concluded that M1 macrophage polarization aggravates autoimmune liver disease and inflammation, while increased M2 polarization contributes to their remission. This can also be understood from the fact that M2 macrophages have immunoregulatory functions.

In addition, the pathogenesis of liver disease is complex, at least partly due to the crosstalk between the liver and peripheral tissues. Especially in fatty liver, the crosstalk of the liver with peripheral organs through the adipose tissue-liver axis, gut-liver axis, bone marrow-liver axis and brain-liver axis significantly influences the disease progression (290, 291). Altered gene expression in liver cells (hepatocytes and hepatic nonparenchymal cells) affects lipogenesis, lipolysis and inflammation in other tissues, and the metabolic and genetic changes in adipocytes and enterocytes also affect hepatic steatosis and inflammation (291). The growing of adipose tissue is accompanied by macrophage infiltration as well as the production of adipokines (leptin, adiponectin, resistin, etc.) and multiple cytokines, leading to inflammation, ECM accumulation and even insulin resistance, which in turn induces lipolysis and excessive free fatty acids release into the circulation, thus together contributing to hepatic steatosis after entering the liver (292). For example, adiponectin, an adipokine, promotes fatty acid oxidation in hepatocytes as well as reduces TNF- $\alpha$ and IL-10 production in Kupffer cells, contributing to the attenuation of hepatic steatosis and inflammation (293). Gut-liver crosstalk mainly results from increased intestinal permeability causing PAMPs to enter the liver via the portal circulation, also involving the changes of gut microbiota and the secretion of auxins, hormones, and bile acids (292). The interaction of bone marrow and the liver is mainly manifested by the recruitment of bone marrow-derived macrophages by activated Kupffer cells and HSCs in the liver, which have a regulatory role (291). In addition, the hypothalamic arcuate nucleus is the first-order neuron of the action of peripheral metabolic hormones (leptin, insulin, etc.), and the central nervous system controls energy balance to regulate obesity and fatty liver (290). Moreover, in other liver diseases such as ALI, viral hepatitis, and HCC, the presence of crosstalk between the liver and peripheral organs has been demonstrated (294-296). These suggest that the crosstalk between the liver and other organs plays a key role in the pathogenesis of liver disease. Furthermore, it is not difficult to see the critical role of macrophages. Therefore, we speculate that targeting the polarization of macrophages in multiple organs rather than just in the liver may contribute to treating liver disease by modulating the crosstalk between the liver and peripheral tissues.

Taken together, macrophage polarization plays an important role in a variety of liver diseases. In general, M1 macrophages have antigen presentation, pathogen clearance, and anti-tumor functions, having a protective effect in viral hepatitis, parasitic infection-induced LF, and HCC. In contrast, M2 macrophages have an anti-inflammatory effect and promote wound healing, which can effectively ameliorate the liver diseases mainly characterized by inflammatory injury, such as ALI, ALD, MAFLD, and $\mathrm{CCl}_{4}$-induced LF. However, in some cases (e.g., different targets or species), the effects of M1 and M2 macrophages in liver diseases may be opposite to the above. It is worth mentioning that current research is almost exclusively focusing on the M1 and M2 phenotypes of macrophages, so more macrophage phenotypes closely associated with disease progression are expected to be uncovered and studied. Therefore, due to the dual complexity of macrophage polarization and liver disease pathogenesis, more in-depth research on the role and mechanism of macrophage polarization in different liver diseases are worthwhile and necessary.

\section{AUTHOR CONTRIBUTIONS}

CW, CM, and YL designed the paper and recommended a structure for the review. CW, CM, YG, YZ, and HZ wrote the initial draft and prepared figures. LG, KF, and YL helped to revise the manuscript. All authors contributed to the article and approved the submitted version.

\section{FUNDING}

The work was supported by National Natural Science Foundation of China (No: 81891012, 81630101, and U19A2010), Sichuan Province Science and Technology Program (No: 2021JDRC0041), and Xinglin Scholar Research Premotion Project of Chengdu University of Traditional Chinese Medicine (No: CXTD2018019).

\section{REFERENCES}

1. Trefts E, Gannon M, Wasserman D. The Liver. Curr Biol CB (2017) 27(21): R1147-51. doi: 10.1016/j.cub.2017.09.019

2. Liang T. Hepatitis B: The Virus and Disease. Hepatol (Baltimore Md.) (2009) 49:S13-21. doi: 10.1002/hep.22881

3. Mandato C, Di Nuzzi A, Vajro P. Nutrition and Liver Disease. Nutrients (2017) 10(1):9. doi: 10.3390/nu10010009

4. Bajaj J. Alcohol, Liver Disease and the Gut Microbiota. Nat Rev Gastroenterol Hepatol (2019) 16(4):235-46. doi: 10.1038/s41575-018-0099-1

5. Xiao J, Wang F, Wong N, He J, Zhang R, Sun R, et al. Global Liver Disease Burdens and Research Trends: Analysis From a Chinese Perspective. J Hepatol (2019) 71(1):212-21. doi: 10.1016/j.jhep.2019.03.004

6. Asrani S, Devarbhavi H, Eaton J, Kamath P. Burden of Liver Diseases in the World. J Hepatol (2019) 70(1):151-71. doi: 10.1016/ j.jhep.2018.09.014

7. Sica A, Mantovani A. Macrophage Plasticity and Polarization: In Vivo Veritas. J Clin Invest (2012) 122(3):787-95. doi: 10.1172/jci59643

8. Gentek R, Molawi K, Sieweke M. Tissue Macrophage Identity and SelfRenewal. Immunol Rev (2014) 262(1):56-73. doi: 10.1111/imr.12224 
9. Guillot A, Tacke F. Liver Macrophages: Old Dogmas and New Insights. Hepatol Commun (2019) 3(6):730-43. doi: 10.1002/hep4.1356

10. Shapouri-Moghaddam A, Mohammadian S, Vazini H, Taghadosi M, Esmaeili S, Mardani F, et al. Macrophage Plasticity, Polarization, and Function in Health and Disease. J Cell Physiol (2018) 233(9):6425-40. doi: 10.1002/ jcp. 26429

11. Wang L, Zhang H, Sun L, Gao W, Xiong Y, Ma A, et al. Manipulation of Macrophage Polarization by Peptide-Coated Gold Nanoparticles and Its Protective Effects on Acute Lung Injury. J Nanobiotechnol (2020) 18(1):38. doi: 10.1186/s12951-020-00593-7

12. Xu F, Guo M, Huang W, Feng L, Zhu J, Luo K, et al. Annexin A5 Regulates Hepatic Macrophage Polarization via Directly Targeting PKM2 and Ameliorates NASH. Redox Biol (2020) 36:101634. doi: 10.1016/ j.redox.2020.101634

13. Zhao S, Mi Y, Guan B, Zheng B, Wei P, Gu Y, et al. Tumor-Derived Exosomal miR-934 Induces Macrophage M2 Polarization to Promote Liver Metastasis of Colorectal Cancer. J Hematol Oncol (2020) 13(1):156. doi: 10.1186/s13045020-00991-2

14. Ma P, Gao C, Yi J, Zhao J, Liang S, Zhao Y, et al. Cytotherapy With M1Polarized Macrophages Ameliorates Liver Fibrosis by Modulating Immune Microenvironment in Mice. J Hepatol (2017) 67(4):770-9. doi: 10.1016/ j.jhep.2017.05.022

15. Yang Y, Ye Y, Chen Y, Zhao J, Gao C, Han H, et al. Crosstalk Between Hepatic Tumor Cells and Macrophages via Wnt/ $\beta$-Catenin Signaling Promotes M2-Like Macrophage Polarization and Reinforces Tumor Malignant Behaviors. Cell Death Dis (2018) 9(8):793. doi: 10.1038/s41419018-0818-0

16. Kazankov K, Jørgensen S, Thomsen K, Møller H, Vilstrup H, George J, et al. The Role of Macrophages in Nonalcoholic Fatty Liver Disease and Nonalcoholic Steatohepatitis. Nat Rev Gastroenterol Hepatol (2019) 16 (3):145-59. doi: 10.1038/s41575-018-0082-x

17. van der Heide D, Weiskirchen R, Bansal R. Therapeutic Targeting of Hepatic Macrophages for the Treatment of Liver Diseases. Front Immunol (2019) 10:2852. doi: 10.3389/fimmu.2019.02852

18. Krenkel O, Tacke F. Liver Macrophages in Tissue Homeostasis and Disease. Nat Rev Immunol (2017) 17(5):306-21. doi: 10.1038/nri.2017.11

19. Li P, He K, Li J, Liu Z, Gong J. The Role of Kupffer Cells in Hepatic Diseases. Mol Immunol (2017) 85:222-9. doi: 10.1016/j.molimm.2017.02.018

20. Tacke F. Targeting Hepatic Macrophages to Treat Liver Diseases. J Hepatol (2017) 66(6):1300-12. doi: 10.1016/j.jhep.2017.02.026

21. Atri C, Guerfali F, Laouini D. Role of Human Macrophage Polarization in Inflammation During Infectious Diseases. Int J Mol Sci (2018) 19(6):1801. doi: $10.3390 / \mathrm{ijms} 19061801$

22. Sica A, Erreni M, Allavena P, Porta C. Macrophage Polarization in Pathology. Cell Mol Life Sci CMLS (2015) 72(21):4111-26. doi: 10.1007/s00018-0151995-y

23. Mantovani A, Biswas S, Galdiero M, Sica A, Locati M. Macrophage Plasticity and Polarization in Tissue Repair and Remodelling. J Pathol (2013) 229 (2):176-85. doi: 10.1002/path.4133

24. Wang N, Liang H, Zen K. Molecular Mechanisms That Influence the Macrophage M1-M2 Polarization Balance. Front Immunol (2014) 5:614. doi: 10.3389/fimmu.2014.00614

25. Yunna C, Mengru H, Lei W, Weidong C. Macrophage M1/M2 Polarization. Eur J Pharmacol (2020) 877:173090. doi: 10.1016/j.ejphar.2020.173090

26. Colin S, Chinetti-Gbaguidi G, Staels B. Macrophage Phenotypes in Atherosclerosis. Immunol Rev (2014) 262(1):153-66. doi: 10.1111/imr.12218

27. Funes S, Rios M, Escobar-Vera J, Kalergis A. Implications of Macrophage Polarization in Autoimmunity. Immunology (2018) 154(2):186-95. doi: $10.1111 / \mathrm{imm} .12910$

28. Wang L, Zhang S, Wu H, Rong X, Guo J. M2b Macrophage Polarization and Its Roles in Diseases. J Leukoc Biol (2019) 106(2):345-58. doi: 10.1002/ jlb.3ru1018-378rr

29. Grinberg S, Hasko G, Wu D, Leibovich S. Suppression of PLCbeta2 by Endotoxin Plays a Role in the Adenosine A(2A) Receptor-Mediated Switch of Macrophages From an Inflammatory to an Angiogenic Phenotype. Am J Pathol (2009) 175(6):2439-53. doi: 10.2353/ajpath.2009.090290

30. Ferrante $\mathrm{C}$, Leibovich S. Regulation of Macrophage Polarization and Wound Healing. Adv Wound Care (2012) 1(1):10-6. doi: 10.1089/wound.2011.0307
31. Erbel C, Tyka M, Helmes C, Akhavanpoor M, Rupp G, Domschke G, et al. CXCL4-Induced Plaque Macrophages can be Specifically Identified by CoExpression of MMP7+S100A8+ In Vitro and In Vivo. Innate Immun (2015) 21(3):255-65. doi: 10.1177/1753425914526461

32. Kadl A, Meher A, Sharma P, Lee M, Doran A, Johnstone S, et al. Identification of a Novel Macrophage Phenotype That Develops in Response to Atherogenic Phospholipids via Nrf2. Circ Res (2010) 107(6):737-46. doi: 10.1161/ circresaha.109.215715

33. Finn A, Nakano M, Polavarapu R, Karmali V, Saeed O, Zhao X, et al. Hemoglobin Directs Macrophage Differentiation and Prevents Foam Cell Formation in Human Atherosclerotic Plaques. J Am Coll Cardiol (2012) 59 (2):166-77. doi: 10.1016/j.jacc.2011.10.852

34. Malyshev I, Malyshev Y. Current Concept and Update of the Macrophage Plasticity Concept: Intracellular Mechanisms of Reprogramming and M3 Macrophage "Switch" Phenotype. BioMed Res Int (2015) 2015:341308. doi: $10.1155 / 2015 / 341308$

35. Ciesielska A, Matyjek M, Kwiatkowska K. TLR4 and CD14 Trafficking and Its Influence on LPS-Induced Pro-Inflammatory Signaling. Cell Mol Life Sci CMLS (2021) 78(4):1233-61. doi: 10.1007/s00018-020-03656-y

36. Chen X, Tang L, Fu Y, Wang Y, Han Z, Meng J. Paralemmin-3 Contributes to Lipopolysaccharide-Induced Inflammatory Response and Is Involved in Lipopolysaccharide-Toll-Like Receptor-4 Signaling in Alveolar Macrophages. Int J Mol Med (2017) 40(6):1921-31. doi: 10.3892/ ijmm.2017.3161

37. Gong J, Li J, Dong H, Chen G, Qin X, Hu M, et al. Inhibitory Effects of Berberine on Proinflammatory M1 Macrophage Polarization Through Interfering With the Interaction Between TLR4 and Myd88. BMC Complement Altern Med (2019) 19(1):314. doi: 10.1186/s12906-019-2710-6

38. Xiang P, Chen T, Mou Y, Wu H, Xie P, Lu G, et al. NZ Suppresses TLR4/NF$\kappa \mathrm{b}$ Signalings and NLRP3 Inflammasome Activation in LPS-Induced RAW264.7 Macrophages. Inflamm Res (2015) 64(10):799-808. doi: 10.1007/ s00011-015-0863-4

39. Lu H, Wu L, Liu L, Ruan Q, Zhang X, Hong W, et al. Quercetin Ameliorates Kidney Injury and Fibrosis by Modulating M1/M2 Macrophage Polarization. Biochem Pharmacol (2018) 154:203-12. doi: 10.1016/j.bcp.2018.05.007

40. Ye Y, Jin T, Zhang X, Zeng Z, Ye B, Wang J, et al. Meisoindigo Protects Against Focal Cerebral Ischemia-Reperfusion Injury by Inhibiting NLRP3 Inflammasome Activation and Regulating Microglia/Macrophage Polarization via TLR4/NF-kb Signaling Pathway. Front Cell Neurosci (2019) 13:553. doi: 10.3389/fncel.2019.00553

41. Xin P, Xu X, Deng C, Liu S, Wang Y, Zhou X, et al. The Role of JAK/STAT Signaling Pathway and Its Inhibitors in Diseases. Int Immunopharmacol (2020) 80:106210. doi: 10.1016/j.intimp.2020.106210

42. Wang F, Zhang S, Jeon R, Vuckovic I, Jiang X, Lerman A, et al. Interferon Gamma Induces Reversible Metabolic Reprogramming of M1 Macrophages to Sustain Cell Viability and Pro-Inflammatory Activity. EBioMedicine (2018) 30:303-16. doi: 10.1016/j.ebiom.2018.02.009

43. Ivashkiv L. Ifn $\gamma$ : Signalling, Epigenetics and Roles in Immunity, Metabolism, Disease and Cancer Immunotherapy. Nat Rev Immunol (2018) 18(9):545-58. doi: 10.1038/s41577-018-0029-z

44. Haydar D, Cory T, Birket S, Murphy B, Pennypacker K, Sinai A, et al. Azithromycin Polarizes Macrophages to an M2 Phenotype via Inhibition of the STAT1 and NF- kb Signaling Pathways. J Immunol (Baltimore Md. 1950) (2019) 203(4):1021-30. doi: 10.4049/jimmunol.1801228

45. Hu X, Chen J, Wang L, Ivashkiv L. Crosstalk Among Jak-STAT, Toll-Like Receptor, and ITAM-Dependent Pathways in Macrophage Activation. J Leukoc Biol (2007) 82(2):237-43. doi: 10.1189/jlb.1206763

46. He Y, Gao Y, Zhang Q, Zhou G, Cao F, Yao S. IL-4 Switches Microglia/ macrophage M1/M2 Polarization and Alleviates Neurological Damage by Modulating the JAK1/STAT6 Pathway Following ICH. Neuroscience (2020) 437:161-71. doi: 10.1016/j.neuroscience.2020.03.008

47. Gao S, Zhou J, Liu N, Wang L, Gao Q, Wu Y, et al. Curcumin Induces M2 Macrophage Polarization by Secretion IL-4 and/or IL-13. J Mol Cell Cardiol (2015) 85:131-9. doi: 10.1016/j.yjmcc.2015.04.025

48. Yin Z, Ma T, Lin Y, Lu X, Zhang C, Chen S, et al. IL-6/STAT3 Pathway Intermediates M1/M2 Macrophage Polarization During the Development of Hepatocellular Carcinoma. J Cell Biochem (2018) 119(11):9419-32. doi: $10.1002 /$ jcb.27259 
49. Quero L, Tiaden A, Hanser E, Roux J, Laski A, Hall J, et al. miR-221-3p Drives the Shift of M2-Macrophages to a Pro-Inflammatory Function by Suppressing JAK3/STAT3 Activation. Front Immunol (2019) 10:3087. doi: 10.3389/ fimmu.2019.03087

50. Qin H, Holdbrooks A, Liu Y, Reynolds S, Yanagisawa L, Benveniste E. SOCS3 Deficiency Promotes M1 Macrophage Polarization and Inflammation. J Immunol (Baltimore Md. 1950) (2012) 189(7):3439-48. doi: 10.4049/ jimmunol.1201168

51. Liang $\mathrm{Y}$, Tang H, Chen Z, Zeng L, Wu J, Yang W, et al. Downregulated SOCS1 Expression Activates the JAK1/STAT1 Pathway and Promotes Polarization of Macrophages Into M1 Type. Mol Med Rep (2017) 16(5):6405-11. doi: 10.3892/mmr.2017.7384

52. Yu T, Zuo Y, Cai R, Huang X, Wu S, Zhang C, et al. SENP1 Regulates IFN- $\gamma$ STAT1 Signaling Through STAT3-SOCS3 Negative Feedback Loop. J Mol Cell Biol (2017) 9(2):144-53. doi: 10.1093/jmcb/mjw042

53. Travis M, Sheppard D. TGF- $\beta$ Activation and Function in Immunity. Annu Rev Immunol (2014) 32:51-82. doi: 10.1146/annurev-immunol-032713120257

54. Wang L, Li Y, Wang X, Wang P, Essandoh K, Cui S, et al. GDF3 Protects Mice Against Sepsis-Induced Cardiac Dysfunction and Mortality by Suppression of Macrophage Pro-Inflammatory Phenotype. Cells (2020) 9(1):120. doi: $10.3390 /$ cells 9010120

55. Guo X, Xue H, Shao Q, Wang J, Guo X, Chen X, et al. Hypoxia Promotes Glioma-Associated Macrophage Infiltration via Periostin and Subsequent M2 Polarization by Upregulating TGF-Beta and M-CSFR. Oncotarget (2016) 7 (49):80521-42. doi: 10.18632/oncotarget.11825

56. Chen B, Huang S, Su Y, Wu Y, Hanna A, Brickshawana A, et al. Macrophage Smad3 Protects the Infarcted Heart, Stimulating Phagocytosis and Regulating Inflammation. Circ Res (2019) 125(1):55-70. doi: 10.1161/circresaha. 119.315069

57. Marion-Letellier R, Savoye G, Ghosh S. Fatty Acids, Eicosanoids and PPAR Gamma. Eur J Pharmacol (2016) 785:44-9. doi: 10.1016/j.ejphar.2015.11.004

58. Luo W, Xu Q, Wang Q, Wu H, Hua J. Effect of Modulation of PPAR- $\gamma$ Activity on Kupffer Cells M1/M2 Polarization in the Development of Non-Alcoholic Fatty Liver Disease. Sci Rep (2017) 7:44612. doi: 10.1038/srep44612

59. Zhao M, Bian Y, Yang L, Chen Y, Wang Y, Ma Y, et al. \}huoxuetongfu Formula Alleviates Intraperitoneal Adhesion by Regulating Macrophage Polarization and the SOCS/JAK2/STAT/PPAR- Signalling Pathway. Mediators Inflamm (2019) 2019:1769374. doi: 10.1155/2019/1769374

60. Yu T, Gao M, Yang P, Liu D, Wang D, Song F, et al. Insulin Promotes Macrophage Phenotype Transition Through PI3K/Akt and PPAR- $\gamma$ Signaling During Diabetic Wound Healing. J Cell Physiol (2019) 234(4):4217-31. doi: $10.1002 / j c p .27185$

61. Liu M, Chen Y, Wang S, Zhou H, Feng D, Wei J, et al. $\alpha$-Ketoglutarate Modulates Macrophage Polarization Through Regulation of Ppar $\gamma$ Transcription and Mtorc1/P70s6k Pathway to Ameliorate ALI/ARDS. Shock (Augusta Ga.) (2020) 53(1):103-13. doi: 10.1097/shk.0000000000001333

62. Qian M, Wang S, Guo X, Wang J, Zhang Z, Qiu W, et al. Hypoxic GliomaDerived Exosomes Deliver microRNA-1246 to Induce M2 Macrophage Polarization by Targeting TERF2IP via the STAT3 and NF-kb Pathways. Oncogene (2020) 39(2):428-42. doi: 10.1038/s41388-019-0996-y

63. Yu X, Odenthal M, Fries J. Exosomes as miRNA Carriers: FormationFunction-Future. Int J Mol Sci (2016) 17(12):2028. doi: 10.3390/ijms17122028

64. Pan Y, Hui X, Hoo R, Ye D, Chan C, Feng T, et al. Adipocyte-Secreted Exosomal microRNA-34a Inhibits M2 Macrophage Polarization to Promote Obesity-Induced Adipose Inflammation. J Clin Invest (2019) 129(2):834-49. doi: $10.1172 /$ jci123069

65. Li R, Zhao K, Ruan Q, Meng C, Yin F. Bone Marrow Mesenchymal Stem CellDerived Exosomal microRNA-124-3p Attenuates Neurological Damage in Spinal Cord Ischemia-Reperfusion Injury by Downregulating Ern1 and Promoting M2 Macrophage Polarization. Arthritis Res Ther (2020) 22(1):75. doi: 10.1186/s13075-020-2146-x

66. Yin Z, Ma T, Huang B, Lin L, Zhou Y, Yan J, et al. Macrophage-Derived Exosomal microRNA-501-3p Promotes Progression of Pancreatic Ductal Adenocarcinoma Through the TGFBR3-Mediated TGF- $\beta$ Signaling Pathway. J Exp Clin Cancer Res CR (2019) 38(1):310. doi: 10.1186/s13046019-1313-x
67. Dai Y, Wang S, Chang S, Ren D, Shali S, Li C, et al. M2 Macrophage-Derived Exosomes Carry microRNA-148a to Alleviate Myocardial Ischemia/ Reperfusion Injury via Inhibiting TXNIP and the TLR4/NF- $\mathrm{kb} / \mathrm{NLRP} 3$ Inflammasome Signaling Pathway. J Mol Cell Cardiol (2020) 142:65-79. doi: 10.1016/j.yjmcc.2020.02.007

68. Bao L, Li X. MicroRNA-32 Targeting PTEN Enhances M2 Macrophage Polarization in the Glioma Microenvironment and Further Promotes the Progression of Glioma. Mol Cell Biochem (2019) 460:67-79. doi: 10.1007/ s11010-019-03571-2

69. Hu J, Huang C, Rao P, Zhou J, Wang X, Tang L, et al. Inhibition of microRNA-155 Attenuates Sympathetic Neural Remodeling Following Myocardial Infarction via Reducing M1 Macrophage Polarization and Inflammatory Responses in Mice. Eur J Pharmacol (2019) 851:122-32. doi: 10.1016/j.ejphar.2019.02.001

70. Jaiswal A, Reddy S, Maurya M, Maurya P, Barthwal M. MicroRNA-99a Mimics Inhibit M1 Macrophage Phenotype and Adipose Tissue Inflammation by Targeting Tnfo. Cell Mol Immunol (2019) 16(5):495-507. doi: 10.1038/ s41423-018-0038-7

71. Li J, Xue H, Li T, Chu X, Xin D, Xiong Y, et al. Exosomes Derived From Mesenchymal Stem Cells Attenuate the Progression of Atherosclerosis in ApoE Mice via miR-Let7 Mediated Infiltration and Polarization of M2 Macrophage. Biochem Biophys Res Commun (2019) 510(4):565-72. doi: 10.1016/j.bbrc.2019.02.005

72. Zhihua Y, Yulin T, Yibo W, Wei D, Yin C, Jiahao X, et al. Hypoxia Decreases Macrophage Glycolysis and M1 Percentage by Targeting microRNA-30c and mTOR in Human Gastric Cancer. Cancer Sci (2019) 110(8):2368-77. doi: $10.1111 /$ cas. 14110

73. Bai J, Wei M, Li J, Zhang G. Notch Signaling Pathway and Endocrine Resistance in Breast Cancer. Front Pharmacol (2020) 11:924. doi: 10.3389/ fphar.2020.00924

74. Singla R, Wang J, Singla D. Regulation of Notch 1 Signaling in THP-1 Cells Enhances M2 Macrophage Differentiation. Am J Physiol Heart Circulatory Physiol (2014) 307(11):H1634-1642. doi: 10.1152/ajpheart.00896.2013

75. Wei W, Li Z, Bian Z, Han Q. Astragalus Polysaccharide RAP Induces Macrophage Phenotype Polarization to M1 via the Notch Signaling Pathway. Molecules (Basel Switzerland) (2019) 24(10):2016. doi: 10.3390/ molecules 24102016

76. Sheng J, Zhang B, Chen Y, Yu F. Capsaicin Attenuates Liver Fibrosis by Targeting Notch Signaling to Inhibit TNF- $\alpha$ Secretion From M1 Macrophages. Immunopharmacol Immunotoxicol (2020) 42(6):556-63. doi: 10.1080/08923973.2020.1811308

77. Zheng S, Zhang P, Chen Y, Zheng S, Zheng L, Weng Z. Inhibition of Notch Signaling Attenuates Schistosomiasis Hepatic Fibrosis via Blocking Macrophage M2 Polarization. PLoS One (2016) 11(11):e0166808. doi: 10.1371/journal.pone. 0166808

78. Tao S, Chen Q, Lin C, Dong H. Linc00514 Promotes Breast Cancer Metastasis and M2 Polarization of Tumor-Associated Macrophages via Jagged1Mediated Notch Signaling Pathway. J Exp Clin Cancer Res CR (2020) 39 (1):191. doi: 10.1186/s13046-020-01676-x

79. Li Q, He X, Yu Q, Wu Y, Du M, Chen J, et al. The Notch Signal Mediates Macrophage Polarization by Regulating miR-125a/miR-99b Expression. Artif Cells Nanomed Biotechnol (2019) 47(1):833-43. doi: 10.1080/21691401. 2019.1576711

80. Huang F, Zhao J, Wang L, Gao C, Liang S, An D, et al. miR-148a-3p Mediates Notch Signaling to Promote the Differentiation and M1 Activation of Macrophages. Front Immunol (2017) 8:1327. doi: 10.3389/fimmu.2017.01327

81. Bai X, Li J, Li L, Liu M, Liu Y, Cao M, et al. Extracellular Vesicles From Adipose Tissue-Derived Stem Cells Affect Notch-Mir148a-3p Axis to Regulate Polarization of Macrophages and Alleviate Sepsis in Mice. Front Immunol (2020) 11:1391. doi: 10.3389/fimmu.2020.01391

82. Byles V, Covarrubias A, Ben-Sahra I, Lamming D, Sabatini D, Manning B, et al. The TSC-mTOR Pathway Regulates Macrophage Polarization. Nat Commun (2013) 4:2834. doi: 10.1038/ncomms3834

83. Zhang Y, Huang T, Jiang L, Gao J, Yu D, Ge Y, et al. MCP-Induced Protein 1 Attenuates Sepsis-Induced Acute Lung Injury by Modulating Macrophage Polarization via the JNK/c-Myc Pathway. Int Immunopharmacol (2019) 75:105741. doi: 10.1016/j.intimp.2019.105741 
84. Cheng Y, Feng Y, Xia Z, Li X, Rong J. $\omega$-Alkynyl Arachidonic Acid Promotes Anti-Inflammatory Macrophage M2 Polarization Against Acute Myocardial Infarction via Regulating the Cross-Talk Between PKM2, HIF-1 $\alpha$ and iNOS. Biochim Biophys Acta Mol Cell Biol Lipids (2017) 1862(12):1595-605. doi: 10.1016/j.bbalip.2017.09.009

85. Gu X, Zhang Y, Li D, Cai H, Cai L, Xu Q. N6-Methyladenosine Demethylase FTO Promotes M1 and M2 Macrophage Activation. Cell Signal (2020) 69:109553. doi: 10.1016/j.cellsig.2020.109553

86. Chen T, Li R, Chen P. Gut Microbiota and Chemical-Induced Acute Liver Injury. Front Physiol (2021) 12:688780. doi: 10.3389/fphys.2021.688780

87. Golbar H, Izawa T, Wijesundera K, Bondoc A, Tennakoon A, Kuwamura M, et al. Depletion of Hepatic Macrophages Aggravates Liver Lesions Induced in Rats by Thioacetamide (TAA). Toxicol Pathol (2016) 44(2):246-58. doi: 10.1177/0192623315621191

88. Maes M, Vinken M, Jaeschke H. Experimental Models of Hepatotoxicity Related to Acute Liver Failure. Toxicol Appl Pharmacol (2016) 290:86-97. doi: 10.1016/j.taap.2015.11.016

89. Zigmond E, Samia-Grinberg S, Pasmanik-Chor M, Brazowski E, Shibolet O, Halpern Z, et al. Infiltrating Monocyte-Derived Macrophages and Resident Kupffer Cells Display Different Ontogeny and Functions in Acute Liver Injury. J Immunol (Baltimore Md. 1950) (2014) 193(1):344-53. doi: 10.4049/ jimmunol.1400574

90. Rahman N, Pervin M, Kuramochi M, Karim M, Izawa T, Kuwamura M, et al. M1/M2-Macrophage Polarization-Based Hepatotoxicity in D-GalactosamineInduced Acute Liver Injury in Rats. Toxicol Pathol (2018) 46(7):764-76. doi: 10.1177/0192623318801574

91. Ren A, Wang H, Zhu H, Ye G, Li K, Chen D, et al. Rabdosia Japonicaglycoproteins From Var. Regulate Macrophage Polarization and Alleviate Lipopolysaccharide-Induced Acute Lung Injury in Mice TLR4/ NF-kb Pathway. Front Pharmacol (2021) 12:693298. doi: 10.3389/ fphar.2021.693298

92. Xie J, Wu X, Zhou Q, Yang Y, Tian Y, Huang C, et al. PICK1 Confers AntiInflammatory Effects in Acute Liver Injury via Suppressing M1 Macrophage Polarization. Biochimie (2016) 127:121-32. doi: 10.1016/j.biochi.2016.05.002

93. Wang J, Liu Y, Ding H, Shi X, Ren H. Mesenchymal Stem Cell-Secreted Prostaglandin E Ameliorates Acute Liver Failure via Attenuation of Cell Death and Regulation of Macrophage Polarization. Stem Cell Res Ther (2021) 12 (1):15. doi: 10.1186/s13287-020-02070-2

94. Tomar S, Zumbrun E, Nagarkatti M, Nagarkatti P. Protective Role of Cannabinoid Receptor 2 Activation in Galactosamine/LipopolysaccharideInduced Acute Liver Failure Through Regulation of Macrophage Polarization and microRNAs. J Pharmacol Exp Ther (2015) 353(2):369-79. doi: 10.1124/ jpet.114.220368

95. Wang Q, Wei S, Zhou H, Shen G, Gan X, Zhou S, et al. Hyperglycemia Exacerbates Acetaminophen-Induced Acute Liver Injury by Promoting LiverResident Macrophage Proinflammatory Response via AMPK/PI3K/AKTMediated Oxidative Stress. Cell Death Discov (2019) 5:119. doi: 10.1038/ s41420-019-0198-y

96. Song B, Zhang C, Hu W, Guo C, Xia Z, Hu W, et al. Nano-Designed Carbon Monoxide Donor SMA/CORM2 Exhibits Protective Effect Against Acetaminophen Induced Liver Injury Through Macrophage Reprograming and Promoting Liver Regeneration. J Controlled Release (2021) 331:350-63. doi: 10.1016/j.jconrel.2021.01.025

97. Gong W, Zhu H, Lu L, Hou Y, Dou H. A Benzenediamine Analog FC-99 Drives M2 Macrophage Polarization and Alleviates Lipopolysaccharide- (LPS) Induced Liver Injury. Mediators Inflamm (2019) 2019:7823069. doi: 10.1155/ 2019/7823069

98. Li M, Sun X, Zhao J, Xia L, Li J, Xu M, et al. CCL5 Deficiency Promotes Liver Repair by Improving Inflammation Resolution and Liver Regeneration Through M2 Macrophage Polarization. Cell Mol Immunol (2020) 17 (7):753-64. doi: 10.1038/s41423-019-0279-0

99. Peng J, Li J, Huang J, Xu P, Huang H, Liu Y, et al. P300/CBP Inhibitor A-485 Alleviates Acute Liver Injury by Regulating Macrophage Activation and Polarization. Theranostics (2019) 9(26):8344-61. doi: 10.7150/thno.30707

100. Liu J, Zhang S, Cao H, Wang H, Sun C, Liu S, et al. Deficiency of P38 $\alpha$ in Macrophage Ameliorates D-Galactosamine/TNF- $\alpha$-Induced Acute Liver Injury in Mice. FEBS J (2017) 284(24):4200-15. doi: 10.1111/febs.14294
101. Tsuji Y, Kuramochi M, Golbar H, Izawa T, Kuwamura M, Yamate J. Acetaminophen-Induced Rat Hepatotoxicity Based on M1/M2Macrophage Polarization, in Possible Relation to Damage-Associated Molecular Patterns and Autophagy. Int J Mol Sci (2020) 21(23):8998. doi: 10.3390/ijms21238998

102. Zhou S, Gu J, Liu R, Wei S, Wang Q, Shen H, et al. Spermine Alleviates Acute Liver Injury by Inhibiting Liver-Resident Macrophage Pro-Inflammatory Response Through ATG5-Dependent Autophagy. Front Immunol (2018) 9:948. doi: 10.3389/fimmu.2018.00948

103. Hua D, Ju Z, Gan X, Wang Q, Luo C, Gu J, et al. Human Amniotic Mesenchymal Stromal Cells Alleviate Acute Liver Injury by Inhibiting the Pro-Inflammatory Response of Liver Resident Macrophage Through Autophagy. Ann Trans Med (2019) 7(16):392. doi: 10.21037/atm.2019.08.83

104. Zhao H, Han Q, Lu N, Xu D, Tian Z, Zhang J. HMBOX1 in Hepatocytes Attenuates LPS/D-GalN-Induced Liver Injury by Inhibiting Macrophage Infiltration and Activation. Mol Immunol (2018) 101:303-11. doi: 10.1016/ j.molimm.2018.07.021

105. Almeida P, Matielo C, Curvelo L, Rocco R, Felga G, Della Guardia B, et al. Update on the Management and Treatment of Viral Hepatitis. World J Gastroenterol (2021) 27(23):3249-61. doi: 10.3748/wjg.v27.i23.3249

106. Shin E, Sung P, Park S. Immune Responses and Immunopathology in Acute and Chronic Viral Hepatitis. Nat Rev Immunol (2016) 16(8):509-23. doi: 10.1038/nri.2016.69

107. Li Y, Li S, Duan X, Yang C, Xu M, Chen L. Macrophage Phenotypes and Hepatitis B Virus Infection. J Clin Trans Hepatol (2020) 8(4):424-31 doi: $10.14218 /$ jcth.2020.00046

108. Dai K, Huang L, Sun X, Yang L, Gong Z. Hepatic CD206-Positive Macrophages Express Amphiregulin to Promote the Immunosuppressive Activity of Regulatory T Cells in HBV Infection. J Leukoc Biol (2015) 98 (6):1071-80. doi: 10.1189/jlb.4A0415-152R

109. Yi H, Zhang Y, Yang X, Li M, Hu H, Xiong J, et al. Hepatitis B Core Antigen Impairs the Polarization While Promoting the Production of Inflammatory Cytokines of M2 Macrophages via the TLR2 Pathway. Front Immunol (2020) 11:535. doi: 10.3389/fimmu.2020.00535

110. Zhao X, Sun L, Mu T, Yi J, Ma C, Xie H, et al. An HBV-Encoded miRNA Activates Innate Immunity to Restrict HBV Replication. J Mol Cell Biol (2020) 12(4):263-76. doi: 10.1093/jmcb/mjz104

111. Hellard M, Schroeder S, Pedrana A, Doyle J, Aitken C. The Elimination of Hepatitis C as a Public Health Threat. Cold Spring Harbor Perspect Med (2020) 10(4):a036939. doi: 10.1101/cshperspect.a036939

112. Dultz G, Gerber L, Zeuzem S, Sarrazin C, Waidmann O. The Macrophage Activation Marker CD163 Is Associated With IL28B Genotype and Hepatic Inflammation in Chronic Hepatitis C Virus Infected Patients. J Viral Hepatitis (2016) 23(4):267-73. doi: 10.1111/jvh.12488

113. Ahmed F, Ibrahim A, Cooper C, Kumar A, Crawley A. Chronic Hepatitis C Virus Infection Impairs M1 Macrophage Differentiation and Contributes to CD8 T-Cell Dysfunction. Cells (2019) 8(4):374. doi: 10.3390/cells8040374

114. Saha B, Kodys K, Szabo G. Hepatitis C Virus-Induced Monocyte Differentiation Into Polarized M2 Macrophages Promotes Stellate Cell Activation via TGF- $\beta$. Cell Mol Gastroenterol Hepatol (2016) 2(3):30216.e308. doi: 10.1016/j.jcmgh.2015.12.005

115. Yao Z, Song X, Cao S, Liang W, Lu W, Yang L, et al. Role of the Exogenous $\mathrm{HCV}$ Core Protein in the Interaction of Human Hepatocyte Proliferation and Macrophage Sub-Populations. PLoS One (2014) 9(9):e108278. doi: 10.1371/journal.pone.0108278

116. Zhang Q, Wang Y, Zhai N, Song H, Li H, Yang Y, et al. HCV Core Protein Inhibits Polarization and Activity of Both M1 and M2 Macrophages Through the TLR2 Signaling Pathway. Sci Rep (2016) 6:36160. doi: $10.1038 /$ srep36160

117. Ohtsuki T, Kimura K, Tokunaga Y, Tsukiyama-Kohara K, Tateno C, Hayashi Y, et al. M2 Macrophages Play Critical Roles in Progression of Inflammatory Liver Disease in Hepatitis C Virus Transgenic Mice. J Virol (2016) 90(1):3007. doi: 10.1128/jvi.02293-15

118. Labonte A, Sung S, Jennelle L, Dandekar A, Hahn Y. Expression of Scavenger Receptor-AI Promotes Alternative Activation of Murine Macrophages to Limit Hepatic Inflammation and Fibrosis. Hepatol (Baltimore Md.) (2017) 65 (1):32-43. doi: 10.1002/hep.28873 
119. Fan C, Zhang Y, Zhou Y, Li B, He Y, Guo Y, et al. Up-Regulation of A20/ ABIN1 Contributes to Inefficient M1 Macrophage Polarization During Hepatitis C Virus Infection. Virol J (2015) 12:147. doi: 10.1186/s12985015-0379-0

120. Saha B, Kodys K, Adejumo A, Szabo G. Circulating and Exosome-Packaged Hepatitis C Single-Stranded RNA Induce Monocyte Differentiation via TLR7/8 to Polarized Macrophages and Fibrocytes. J Immunol (Baltimore Md. 1950) (2017) 198(5):1974-84. doi: 10.4049/jimmunol.1600797

121. Kwon Y, Meyer K, Peng G, Chatterjee S, Hoft D, Ray R. Hepatitis C Virus E2 Envelope Glycoprotein Induces an Immunoregulatory Phenotype in Macrophages. Hepatol (Baltimore Md.) (2019) 69(5):1873-84. doi: $10.1002 /$ hep. 29843

122. Liu Z, Jia W, Jiang T, Dai J, Shuai C, Lv X. Regulation of CD39 Expression in ATP-P2Y2R-Mediated Alcoholic Liver Steatosis and Inflammation. Int Immunopharmacol (2019) 77:105915. doi: 10.1016/j.intimp.2019.105915

123. Roh Y, Seki E. Toll-Like Receptors in Alcoholic Liver Disease, Non-Alcoholic Steatohepatitis and Carcinogenesis. J Gastroenterol Hepatol (2013) 28 (s1):38-42. doi: 10.1111/jgh.12019

124. Voican C, Njiké-Nakseu M, Boujedidi H, Barri-Ova N, Bouchet-Delbos L, Agostini $\mathrm{H}$, et al. Alcohol Withdrawal Alleviates Adipose Tissue Inflammation in Patients With Alcoholic Liver Disease. Liver Int (2015) 35 (3):967-78. doi: 10.1111/liv.12575

125. Wan J, Benkdane M, Alons E, Lotersztajn S, Pavoine C. M2 Kupffer Cells Promote Hepatocyte Senescence: An IL-6-Dependent Protective Mechanism Against Alcoholic Liver Disease. Am J Pathol (2014) 184(6):1763-72. doi: 10.1016/j.ajpath.2014.02.014

126. Wu X, Yang Y, Li W, Cheng Y, Li X, Huang C, et al. Telomerase Reverse Transcriptase Acts in a Feedback Loop With NF-kb Pathway to Regulate Macrophage Polarization in Alcoholic Liver Disease. Sci Rep (2016) 6:18685. doi: $10.1038 /$ srep 18685

127. Louvet A, Teixeira-Clerc F, Chobert M, Deveaux V, Pavoine C, Zimmer A, et al. Cannabinoid CB2 Receptors Protect Against Alcoholic Liver Disease by Regulating Kupffer Cell Polarization in Mice. Hepatol (Baltimore Md.) (2011) 54(4):1217-26. doi: 10.1002/hep.24524

128. Luo P, Wang F, Wong N, Lv Y, Li X, Li M, et al. Divergent Roles of Kupffer Cell TLR2/3 Signaling in Alcoholic Liver Disease and the Protective Role of EGCG. Cell Mol Gastroenterol Hepatol (2020) 9(1):145-60. doi: 10.1016/ j.jcmgh.2019.09.002

129. Isayama F, Moore S, Hines I, Wheeler M. Fas Regulates Macrophage Polarization and Fibrogenic Phenotype in a Model of Chronic EthanolInduced Hepatocellular Injury. Am J Pathol (2016) 186(6):1524-36. doi: 10.1016/j.ajpath.2016.02.006

130. Zhou Y, Wu M, Xu L, Cheng J, Shen J, Yang T, et al. Bmall Regulates Macrophage Polarize Through Glycolytic Pathway in Alcoholic Liver Disease. Front Pharmacol (2021) 12:640521. doi: 10.3389/fphar.2021.640521

131. Saha B, Bala S, Hosseini N, Kodys K, Szabo G. Krüppel-Like Factor 4 Is a Transcriptional Regulator of M1/M2 Macrophage Polarization in Alcoholic Liver Disease. J Leukoc Biol (2015) 97(5):963-73. doi: 10.1189/jlb.4A1014$485 \mathrm{R}$

132. van Niel G, D'Angelo G, Raposo G. Shedding Light on the Cell Biology of Extracellular Vesicles. Nat Rev Mol Cell Biol (2018) 19(4):213-28. doi: $10.1038 / \mathrm{nrm} .2017 .125$

133. Saha B, Momen-Heravi F, Furi I, Kodys K, Catalano D, Gangopadhyay A, et al. Extracellular Vesicles From Mice With Alcoholic Liver Disease Carry a Distinct Protein Cargo and Induce Macrophage Activation Through Heat Shock Protein 90. Hepatol (Baltimore Md.) (2018) 67(5):1986-2000. doi: $10.1002 /$ hep. 29732

134. Saha B, Momen-Heravi F, Kodys K, Szabo G. MicroRNA Cargo of Extracellular Vesicles From Alcohol-Exposed Monocytes Signals Naive Monocytes to Differentiate Into M2 Macrophages. J Biol Chem (2016) 291 (1):149-59. doi: 10.1074/jbc.M115.694133

135. Kim A, Saikia P, Nagy L. miRNAs Involved in M1/M2 Hyperpolarization Are Clustered and Coordinately Expressed in Alcoholic Hepatitis. Front Immunol (2019) 10:1295. doi: 10.3389/fimmu.2019.01295

136. Oh J, Riek A, Weng S, Petty M, Kim D, Colonna M, et al. Endoplasmic Reticulum Stress Controls M2 Macrophage Differentiation and Foam Cell Formation. J Biol Chem (2012) 287(15):11629-41. doi: 10.1074/jbc.M111.338673
137. Park J, Shao M, Kim M, Baik S, Cho M, Utsumi T, et al. An Endoplasmic Reticulum Protein, Nogo-B, Facilitates Alcoholic Liver Disease Through Regulation of Kupffer Cell Polarization. Hepatol (Baltimore Md.) (2017) 65 (5):1720-34. doi: 10.1002/hep.29051

138. Wang Z, Zhang X, Zhu L, Yang X, He F, Wang T, et al. Inulin Alleviates Inflammation of Alcoholic Liver Disease via SCFAs-Inducing Suppression of M1 and Facilitation of M2 Macrophages in Mice. Int Immunopharmacol (2020) 78:106062. doi: 10.1016/j.intimp.2019.106062

139. Patel F, Parwani K, Patel D, Mandal P. In VitroMetformin and Probiotics Interplay in Amelioration of Ethanol-Induced Oxidative Stress and Inflammatory Response in an and Model of Hepatic Injury. Mediators Inflamm (2021) 2021:6636152. doi: 10.1155/2021/6636152

140. Varga Z, Matyas C, Erdelyi K, Cinar R, Nieri D, Chicca A, et al. $\beta$ Caryophyllene Protects Against Alcoholic Steatohepatitis by Attenuating Inflammation and Metabolic Dysregulation in Mice. Br J Pharmacol (2018) 175(2):320-34. doi: 10.1111/bph.13722

141. Chen Y, Ouyang X, Hoque R, Garcia-Martinez I, Yousaf M, Tonack S, et al. $\beta$-Hydroxybutyrate Protects From Alcohol-Induced Liver Injury via a Hcar2-cAMP Dependent Pathway. J Hepatol (2018) 69(3):687-96. doi: 10.1016/j.jhep.2018.04.004

142. Li J, Fan L, Yuan M, Xing M. Salidroside Inhibits LipopolysaccharideEthanol-Induced Activation of Proinflammatory Macrophages via Notch Signaling Pathway. Curr Med Sci (2019) 39(4):526-33. doi: 10.1007/s11596019-2069-4

143. Bala S, Csak T, Saha B, Zatsiorsky J, Kodys K, Catalano D, et al. The ProInflammatory Effects of miR-155 Promote Liver Fibrosis and AlcoholInduced Steatohepatitis. J Hepatol (2016) 64(6):1378-87. doi: 10.1016/ j.jhep.2016.01.035

144. Eslam M, Sanyal A, George J. MAFLD: A Consensus-Driven Proposed Nomenclature for Metabolic Associated Fatty Liver Disease. Gastroenterology (2020) 158(7):1999-2014.e1991. doi: 10.1053/j.gastro.2019.11.312

145. Zhou H, Ma C, Wang C, Gong L, Zhang Y, Li Y. Research Progress in Use of Traditional Chinese Medicine Monomer for Treatment of Non-Alcoholic Fatty Liver Disease. Eur J Pharmacol (2021) 898:173976. doi: 10.1016/ j.ejphar.2021.173976

146. Pan X, Wang P, Luo J, Wang Z, Song Y, Ye J, et al. Adipogenic Changes of Hepatocytes in a High-Fat Diet-Induced Fatty Liver Mice Model and NonAlcoholic Fatty Liver Disease Patients. Endocrine (2015) 48(3):834-47. doi: 10.1007/s12020-014-0384-x

147. Sellmann C, Priebs J, Landmann M, Degen C, Engstler A, Jin C, et al. Diets Rich in Fructose, Fat or Fructose and Fat Alter Intestinal Barrier Function and Lead to the Development of Nonalcoholic Fatty Liver Disease Over Time. J Nutr Biochem (2015) 26(11):1183-92. doi: 10.1016/j.jnutbio. 2015.05.011

148. Fukushima H, Yamashina S, Arakawa A, Taniguchi G, Aoyama T, Uchiyama A, et al. Formation of P62-Positive Inclusion Body Is Associated With Macrophage Polarization in Non-Alcoholic Fatty Liver Disease. Hepatol Res (2018) 48(9):757-67. doi: 10.1111/hepr.13071

149. Yoshii D, Nakagawa T, Komohara Y, Kawaguchi H, Yamada S, Tanimoto A. Phenotypic Changes in Macrophage Activation in a Model of Nonalcoholic Fatty Liver Disease Using Microminipigs. J Atheroscl Thromb (2020) 28 (8):844-51. doi: 10.5551/jat.57703

150. Friedman S, Neuschwander-Tetri B, Rinella M, Sanyal A. Mechanisms of NAFLD Development and Therapeutic Strategies. Nat Med (2018) 24 (7):908-22. doi: 10.1038/s41591-018-0104-9

151. Nagata N, Xu L, Kohno S, Ushida Y, Aoki Y, Umeda R, et al. Glucoraphanin Ameliorates Obesity and Insulin Resistance Through Adipose Tissue Browning and Reduction of Metabolic Endotoxemia in Mice. Diabetes (2017) 66(5):1222-36. doi: 10.2337/db16-0662

152. Wang B, Li X, Hu W, Zhou Y, Din Y. Silencing of lncRNA SNHG20 Delays the Progression of Nonalcoholic Fatty Liver Disease to Hepatocellular Carcinoma via Regulating Liver Kupffer Cells Polarization. IUBMB Life (2019) 71(12):1952-61. doi: 10.1002/iub.2137

153. Sohn W, Jun D, Lee K, Lee H, Lee O, Choi H, et al. Lactobacillus Paracasei Induces M2-Dominant Kupffer Cell Polarization in a Mouse Model of Nonalcoholic Steatohepatitis. Dig Dis Sci (2015) 60(11):3340-50. doi: 10.1007/s10620-015-3770-1 
154. Zhang Y, Jiang W, Xu J, Wu N, Wang Y, Lin T, et al. E. Coli NF73-1 Isolated From NASH Patients Aggravates NAFLD in Mice by Translocating Into the Liver and Stimulating M1 Polarization. Front Cell Infect Microbiol (2020) 10:535940. doi: $10.3389 /$ fcimb.2020.535940

155. Wu H, Ni X, Xu Q, Wang Q, Li X, Hua J. Regulation of Lipid-Induced Macrophage Polarization Through Modulating Peroxisome ProliferatorActivated Receptor-Gamma Activity Affects Hepatic Lipid Metabolism via a Toll-Like Receptor 4/NF-kb Signaling Pathway. J Gastroenterol Hepatol (2020) 35(11):1998-2008. doi: 10.1111/jgh.15025

156. Li Z, Feng P, Zhao Z, Zhu W, Gong J, Du H. Liraglutide Protects Against Inflammatory Stress in Non-Alcoholic Fatty Liver by Modulating Kupffer Cells M2 Polarization via cAMP-PKA-STAT3 Signaling Pathway. Biochem Biophys Res Commun (2019) 510(1):20-6. doi: 10.1016/j.bbrc.2018.12.149

157. Yang Y, Lu Y, Han F, Chang Y, Li X, Han Z, et al. Saxagliptin Regulates M1/ M2 Macrophage Polarization via Camkk $\beta$ /AMPK Pathway to Attenuate NAFLD. Biochem Biophys Res Commun (2018) 503(3):1618-24. doi: 10.1016/j.bbrc.2018.07.090

158. Sanchez-Rangel E, Inzucchi S. Metformin: Clinical Use in Type 2 Diabetes. Diabetologia (2017) 60(9):1586-93. doi: 10.1007/s00125-017-4336-x

159. Zamani-Garmsiri F, Ghasempour G, Aliabadi M, Hashemnia S, Emamgholipour S, Meshkani R. Combination of Metformin and Chlorogenic Acid Attenuates Hepatic Steatosis and Inflammation in High-Fat Diet Fed Mice. IUBMB Life (2021) 73(1):252-63. doi: 10.1002/ iub. 2424

160. Zamani-Garmsiri F, Hashemnia S, Shabani M, Bagherieh M, Emamgholipour S, Meshkani R. Combination of Metformin and Genistein Alleviates Non-Alcoholic Fatty Liver Disease in High-Fat DietFed Mice. J Nutr Biochem (2021) 87:108505. doi: 10.1016/ j.jnutbio.2020.108505

161. Kolodziejczyk A, Zheng D, Shibolet O, Elinav E. The Role of the Microbiome in NAFLD and NASH. EMBO Mol Med (2019) 11(2):e9302. doi: 10.15252/ emmm.201809302

162. Zhong X, Liu H. Honokiol Attenuates Diet-Induced Non-Alcoholic Steatohepatitis by Regulating Macrophage Polarization Through Activating Peroxisome Proliferator-Activated Receptor $\gamma$. J Gastroenterol Hepatol (2018) 33(2):524-32. doi: 10.1111/jgh.13853

163. Kang J, Shin J, Koh E, Ryu H, Kim H, Lee S. Opuntia Ficus-Indica Seed Attenuates Hepatic Steatosis and Promotes M2 Macrophage Polarization in High-Fat Diet-Fed Mice. Nutr Res (New York N Y) (2016) 36(4):369-79. doi: 10.1016/j.nutres.2015.12.007

164. Yao Q, Li S, Li X, Wang F, Tu C. Myricetin Modulates Macrophage Polarization and Mitigates Liver Inflammation and Fibrosis in a Murine Model of Nonalcoholic Steatohepatitis. Front Med (2020) 7:71. doi: 10.3389/ fmed.2020.00071

165. Ni Y, Nagashimada M, Zhan L, Nagata N, Kobori M, Sugiura M, et al. Prevention and Reversal of Lipotoxicity-Induced Hepatic Insulin Resistance and Steatohepatitis in Mice by an Antioxidant Carotenoid, $\beta$-Cryptoxanthin. Endocrinology (2015) 156(3):987-99. doi: 10.1210/en.2014-1776

166. Ni Y, Nagashimada M, Zhuge F, Zhan L, Nagata N, Tsutsui A, et al. Astaxanthin Prevents and Reverses Diet-Induced Insulin Resistance and Steatohepatitis in Mice: A Comparison With Vitamin E. Sci Rep (2015) 5:17192. doi: 10.1038/srep 17192

167. Elsayed H, El-Nablaway M, Othman B, Abdalla A, El Nashar E, AbdElmonem M, et al. Can Dasatinib Ameliorate the Hepatic Changes, Induced by Long Term Western Diet, in Mice? Ann Anat = Anatomischer Anzeiger (2021) 234:151626. doi: 10.1016/j.aanat.2020.151626

168. Han Y, Kim H, Na H, Nam M, Kim J, Kim J, et al. Roro Induces KLF4Mediated M2 Polarization in the Liver Macrophages That Protect Against Nonalcoholic Steatohepatitis. Cell Rep (2017) 20(1):124-35. doi: 10.1016/ j.celrep.2017.06.017

169. Li Y, Huang B, Jiang X, Chen W, Zhang J, Wei Y, et al. Mucosal-Associated Invariant $\mathrm{T}$ Cells Improve Nonalcoholic Fatty Liver Disease Through Regulating Macrophage Polarization. Front Immunol (2018) 9:1994. doi: 10.3389/fimmu.2018.01994

170. Zheng $\mathrm{X}$, Wu J, Gong Y, Hong J, Xiao H, Zhong J, et al. IL-25 Protects Against High-Fat Diet-Induced Hepatic Steatosis in Mice by Inducing IL-25 and M2a Macrophage Production. Immunol Cell Biol (2019) 97(2):165-77. doi: $10.1111 /$ imcb.12207
171. Liu W, Ye C, Cheng Q, Zhang X, Yao L, Li Q, et al. Macrophage Raptor Deficiency-Induced Lysosome Dysfunction Exacerbates Nonalcoholic Steatohepatitis. Cell Mol Gastroenterol Hepatol (2019) 7(1):211-31. doi: 10.1016/j.jcmgh.2018.09.011

172. Lee Y, Pham T, Bae M, Hu S, O'Neill E, Chun O, et al. Blackcurrant (Ribes Nigrum) Prevents Obesity-Induced Nonalcoholic Steatohepatitis in Mice. Obes (Silver Spring Md.) (2019) 27(1):112-20. doi: 10.1002/oby.22353

173. Choi S, Park J, Shon C, Lee C, Ryu J, Son D, et al. Fermented Korean Red Ginseng Extract Enriched in Rd and Rg3 Protects Against Non-Alcoholic Fatty Liver Disease Through Regulation of Mtorc1. Nutrients (2019) 11 (12):2963. doi: 10.3390/nu11122963

174. Ai L, Luo W, Yuan P, Liu L, Zhou Y. Liver Macrophages Mediate Effects of Downhill Running and Caloric Restriction on Nonalcoholic Fatty Liver Disease of High Fat Diet-Fed Mice. Life Sci (2020) 256:117978. doi: 10.1016/ j.lfs. 2020.117978

175. Sakai Y, Chen G, Ni Y, Zhuge F, Xu L, Nagata N, et al. DPP-4 Inhibition With Anagliptin Reduces Lipotoxicity-Induced Insulin Resistance and Steatohepatitis in Male Mice. Endocrinology (2020) 161(10):bqaa139. doi: 10.1210/endocr/bqaa139

176. Zhou Z, Qi J, Lim C, Kim J, Kim B. Dual Tbk1/Ikke Inhibitor Amlexanox Mitigates Palmitic Acid-Induced Hepatotoxicity and Lipoapoptosis In Vitro. Toxicology (2020) 444:152579. doi: 10.1016/j.tox.2020.152579

177. Sun G, Zhao X, Li M, Zhang C, Jin H, Li C, et al. CD4 Derived Double Negative T Cells Prevent the Development and Progression of Nonalcoholic Steatohepatitis. Nat Commun (2021) 12(1):650. doi: 10.1038/s41467-021-20941-x

178. Shi Y, Su W, Zhang L, Shi C, Zhou J, Wang P, et al. TGR5 Regulates Macrophage Inflammation in Nonalcoholic Steatohepatitis by Modulating NLRP3 Inflammasome Activation. Front Immunol (2020) 11:609060. doi: 10.3389/fimmu.2020.609060

179. Fan Z, Li L, Li M, Zhang X, Hao C, Yu L, et al. The Histone Methyltransferase Suv39h2 Contributes to Nonalcoholic Steatohepatitis in Mice. Hepatol (Baltimore Md.) (2017) 65(6):1904-19. doi: 10.1002/hep.29127

180. Patouraux S, Rousseau D, Bonnafous S, Lebeaupin C, Luci C, Canivet C, et al. CD44 Is a Key Player in Non-Alcoholic Steatohepatitis. J Hepatol (2017) 67 (2):328-38. doi: 10.1016/j.jhep.2017.03.003

181. Tran M, Lee S, Shin D, Wang L. Loss of miR-141/200c Ameliorates Hepatic Steatosis and Inflammation by Reprogramming Multiple Signaling Pathways in NASH. JCI Insight (2017) 2(21):e96094. doi: 10.1172/jci.insight.96094

182. Kong Q, Li N, Cheng H, Zhang X, Cao X, Qi T, et al. HSPA12A Is a Novel Player in Nonalcoholic Steatohepatitis via Promoting Nuclear PKM2Mediated M1 Macrophage Polarization. Diabetes (2019) 68(2):361-76. doi: $10.2337 / \mathrm{db} 18-0035$

183. Handa P, Thomas S, Morgan-Stevenson V, Maliken B, Gochanour E, Boukhar S, et al. Iron Alters Macrophage Polarization Status and Leads to Steatohepatitis and Fibrogenesis. J Leukoc Biol (2019) 105(5):1015-26. doi: $10.1002 / j 1 b .3 \mathrm{a} 0318-108 \mathrm{r}$

184. Zhang X, Fan L, Wu J, Xu H, Leung W, Fu K, et al. Macrophage P38 Promotes Nutritional Steatohepatitis Through M1 Polarization. J Hepatol (2019) 71(1):163-74. doi: 10.1016/j.jhep.2019.03.014

185. Zhao Z, Zhong L, Li P, He K, Qiu C, Zhao L, et al. Cholesterol Impairs Hepatocyte Lysosomal Function Causing M1 Polarization of Macrophages via Exosomal miR-122-5p. Exp Cell Res (2020) 387(1):111738. doi: 10.1016/ j.yexcr.2019.111738

186. Liu X, Pan Q, Cao H, Xin F, Zhao Z, Yang R, et al. Lipotoxic HepatocyteDerived Exosomal MicroRNA 192-5p Activates Macrophages Through Rictor/Akt/Forkhead Box Transcription Factor O1 Signaling in Nonalcoholic Fatty Liver Disease. Hepatol (Baltimore Md.) (2020) 72 (2):454-69. doi: 10.1002/hep.31050

187. Aydın M, Akçalı K. Liver Fibrosis. Turkish J Gastroenterol (2018) 29(1):1421. doi: $10.5152 /$ tjg. 2018.17330

188. Rockey D. Translating an Understanding of the Pathogenesis of Hepatic Fibrosis to Novel Therapies. Clin Gastroenterol Hepatol (2013) 11(3):22431.e221-225. doi: 10.1016/j.cgh.2013.01.005

189. Dhar D, Baglieri J, Kisseleva T, Brenner D. Mechanisms of Liver Fibrosis and Its Role in Liver Cancer. Exp Biol Med (Maywood N.J.) (2020) 245(2):96-108. doi: $10.1177 / 1535370219898141$

190. Pradere J, Kluwe J, De Minicis S, Jiao J, Gwak G, Dapito D, et al. Hepatic Macrophages But Not Dendritic Cells Contribute to Liver Fibrosis by 
Promoting the Survival of Activated Hepatic Stellate Cells in Mice. Hepatol (Baltimore Md.) (2013) 58(4):1461-73. doi: 10.1002/hep.26429

191. Kisseleva T, Brenner D. Molecular and Cellular Mechanisms of Liver Fibrosis and Its Regression. Nat Rev Gastroenterol Hepatol (2021) 18(3):151-66. doi: 10.1038/s41575-020-00372-7

192. Beljaars L, Schippers M, Reker-Smit C, Martinez F, Helming L, Poelstra K, et al. Hepatic Localization of Macrophage Phenotypes During Fibrogenesis and Resolution of Fibrosis in Mice and Humans. Front Immunol (2014) 5:430. doi: 10.3389/fimmu.2014.00430

193. Xi S, Zheng X, Li X, Jiang Y, Wu Y, Gong J, et al. Viaactivated Hepatic Stellate Cells Induce Infiltration and Formation of CD163 Macrophages CCL2/ CCR2 Pathway. Front Med (2021) 8:627927. doi: 10.3389/fmed.2021.627927

194. Song L, Yin X, Mu S, Li J, Gao H, Zhang Y, et al. Schistosoma Japonicumthe Differential and Dynamic Progression of Hepatic Inflammation and Immune Responses During Liver Fibrosis Induced by or Carbon Tetrachloride in Mice. Front Immunol (2020) 11:570524. doi: 10.3389/fimmu.2020.570524

195. Wu B, Liu J, Li Y, Li J. Margatoxin Mitigates CCl4-induced Hepatic Fibrosis in Mice via Macrophage Polarization, Cytokine Secretion and STAT Signaling. Int J Mol Med (2020) 45(1):103-14. doi: 10.3892/ijmm.2019.4395

196. Li Y, Chen Y, Dang Y, Wang Y, Shang Z, Ma Q, et al. Corilagin Counteracts IL-13ro1 Signaling Pathway in Macrophages to Mitigate Schistosome EggInduced Hepatic Fibrosis. Front Cell Infect Microbiol (2017) 7:443. doi: $10.3389 /$ fcimb.2017.00443

197. Neamatallah T, Abdel-Naim A, Eid B, Hasan A. 2-Methoxyestradiol Attenuates Liver Fibrosis in Mice: Implications for M2 Macrophages. Naunyn-Schmiedeberg's Arch Pharmacol (2019) 392(3):381-91. doi: 10.1007/s00210-018-1577-2

198. Ni M, Wang Y, Wu W, Xia C, Zhang Y, Xu J, et al. Novel Insights on Notch Signaling Pathways in Liver Fibrosis. Eur J Pharmacol (2018) 826:66-74. doi: 10.1016/j.ejphar.2018.02.051

199. Bansal R, van Baarlen J, Storm G, Prakash J. The Interplay of the Notch Signaling in Hepatic Stellate Cells and Macrophages Determines the Fate of Liver Fibrogenesis. Sci Rep (2015) 5:18272. doi: 10.1038/srep18272

200. Li X, Jin Q, Yao Q, Xu B, Li L, Zhang S, et al. The Flavonoid Quercetin Ameliorates Liver Inflammation and Fibrosis by Regulating Hepatic Macrophages Activation and Polarization in Mice. Front Pharmacol (2018) 9:72. doi: 10.3389/fphar.2018.00072

201. Weng S, Wang X, Vijayan S, Tang Y, Kim Y, Padberg K, et al. IL-4 Receptor Alpha Signaling Through Macrophages Differentially Regulates Liver Fibrosis Progression and Reversal. EBioMedicine (2018) 29:92-103. doi: 10.1016/j.ebiom.2018.01.028

202. Eom Y, Shim K, Baik S. Mesenchymal Stem Cell Therapy for Liver Fibrosis. Korean J Internal Med (2015) 30(5):580-9. doi: 10.3904/kjim.2015.30.5.580

203. Watanabe Y, Tsuchiya A, Seino S, Kawata Y, Kojima Y, Ikarashi S, et al. Mesenchymal Stem Cells and Induced Bone Marrow-Derived Macrophages Synergistically Improve Liver Fibrosis in Mice. Stem Cells Trans Med (2019) 8(3):271-84. doi: 10.1002/sctm.18-0105

204. Luo X, Meng X, Cao D, Wang W, Zhou K, Li L, et al. Transplantation of Bone Marrow Mesenchymal Stromal Cells Attenuates Liver Fibrosis in Mice by Regulating Macrophage Subtypes. Stem Cell Res Ther (2019) 10(1):16. doi: 10.1186/s13287-018-1122-8

205. Wang M, Zhang M, Fu L, Lin J, Zhou X, Zhou P, et al. Liver-Targeted Delivery of TSG- 6 by Calcium Phosphate Nanoparticles for the Management of Liver Fibrosis. Theranostics (2020) 10(1):36-49. doi: 10.7150/thno.37301

206. Tosello-Trampont A, Krueger P, Narayanan S, Landes S, Leitinger N, Hahn Y. NKp46(+) Natural Killer Cells Attenuate Metabolism-Induced Hepatic Fibrosis by Regulating Macrophage Activation in Mice. Hepatol (Baltimore Md.) (2016) 63(3):799-812. doi: 10.1002/hep.28389

207. Xie Y, Wen H, Yan K, Wang S, Wang X, Chen J, et al. Toxoplasma Gondii GRA15 Effector-Induced M1 Cells Ameliorate Liver Fibrosis in Mice Infected With Schistosomiasis Japonica. Cell Mol Immunol (2018) 15 (2):120-34. doi: 10.1038/cmi.2016.21

208. Liu L, Jin M, Tao Q, Yu L, Du J, Wang C, et al. [Object Object]Effective Amelioration of Liver Fibrosis Through Lentiviral Vector Carrying in Murine Model. Front Immunol (2018) 9:1572. doi: 10.3389/ fimmu.2018.01572

209. Du P, Ma Q, Zhu Z, Li G, Wang Y, Li Q, et al. Mechanism of Corilagin Interference With IL-13/STAT6 Signaling Pathways in Hepatic Alternative
Activation Macrophages in Schistosomiasis-Induced Liver Fibrosis in Mouse Model. Eur J Pharmacol (2016) 793:119-26. doi: 10.1016/ j.ejphar.2016.11.018

210. Cheng Y, Tian Y, Xia J, Wu X, Yang Y, Li X, et al. The Role of PTEN in Regulation of Hepatic Macrophages Activation and Function in Progression and Reversal of Liver Fibrosis. Toxicol Appl Pharmacol (2017) 317:51-62. doi: 10.1016/j.taap.2017.01.005

211. Takemura S, Azuma H, Osada-Oka M, Kubo S, Shibata T, Minamiyama Y. SAllyl-Glutathione Improves Experimental Liver Fibrosis by Regulating Kupffer Cell Activation in Rats. Am J Physiol Gastrointest liver Physiol (2018) 314(2):G150-63. doi: 10.1152/ajpgi.00023.2017

212. Yang Y, Wu X, Li W, Huang H, Li H, Pan X, et al. PSTPIP2 Connects DNA Methylation to Macrophage Polarization in CCL4-Induced Mouse Model of Hepatic Fibrosis. Oncogene (2018) 37(47):6119-35. doi: 10.1038/s41388-0180383-0

213. Wang Y, Guo X, Jiao G, Luo L, Zhou L, Zhang J, et al. Splenectomy Promotes Macrophage Polarization in a Mouse Model of Concanavalin A- (ConA-) Induced Liver Fibrosis. BioMed Res Int (2019) 2019:5756189. doi: 10.1155/ 2019/5756189

214. Shen J, Wang L, Peng M, Liu Z, Zhang B, Zhou T, et al. Recombinant Sj16 Protein With Novel Activity Alleviates Hepatic Granulomatous Inflammation and Fibrosis Induced by Schistosoma Japonicum Associated With M2 Macrophages in a Mouse Model. Parasites Vectors (2019) 12 (1):457. doi: 10.1186/s13071-019-3697-z

215. Wang W, Xu X, Miao C. okupffer Cell-Derived TNF- Triggers the Apoptosis of Hepatic Stellate Cells Through TNF-R1/Caspase 8 Due to ER Stress. BioMed Res Int (2020) 2020:8035671. doi: 10.1155/2020/8035671

216. Su S, Qin S, Xian X, Huang F, Huang Q, ZhangDi H, et al. Interleukin-22 Regulating Kupffer Cell Polarization Through STAT3/Erk/Akt Crosstalk Pathways to Extenuate Liver Fibrosis. Life Sci (2021) 264:118677. doi: 10.1016/j.lfs.2020.118677

217. Guo Y, Xu C, Fang Y, Wang C, Gao N, Wen Q, et al. High CYP2E1 Activity Aggravates Hepatofibrosis by Limiting Macrophage Polarization Towards the M2 Phenotype. Mol Carcinog (2019) 58(8):1481-91. doi: 10.1002/ mc. 23029

218. She S, Wu X, Zheng D, Pei X, Ma J, Sun Y, et al. PSMP/MSMP Promotes Hepatic Fibrosis Through CCR2 and Represents a Novel Therapeutic Target. J Hepatol (2020) 72(3):506-18. doi: 10.1016/j.jhep.2019.09.033

219. Zhang K, Shi Z, Zhang M, Dong X, Zheng L, Li G, et al. Silencing IncRNA Lfar1 Alleviates the Classical Activation and Pyoptosis of Macrophage in Hepatic Fibrosis. Cell Death Dis (2020) 11(2):132. doi: 10.1038/s41419-020-2323-5

220. Baglieri J, Brenner D, Kisseleva T. The Role of Fibrosis and Liver-Associated Fibroblasts in the Pathogenesis of Hepatocellular Carcinoma. Int J Mol Sci (2019) 20(7):1723. doi: 10.3390/ijms20071723

221. Deng L, He K, Pan Y, Wang H, Luo Y, Xia Q. The Role of Tumor-Associated Macrophages in Primary Hepatocellular Carcinoma and Its Related Targeting Therapy. Int J Med Sci (2021) 18(10):2109-16. doi: 10.7150/ ijms.56003

222. Li Z, Wu T, Zheng B, Chen L. Individualized Precision Treatment: Targeting TAM in HCC. Cancer Lett (2019) 458:86-91. doi: 10.1016/j.canlet. 2019.05.019

223. Hou J, Han Z, Zhao N, Wei L. Autophagy and Tumour Metastasis. Adv Exp Med Biol (2020) 1207:315-38. doi: 10.1007/978-981-15-4272-5_22

224. Chang C, Su Y, Lee P, Lei H. Targeting NFKB by Autophagy to Polarize Hepatoma-Associated Macrophage Differentiation. Autophagy (2013) 9 (4):619-21. doi: 10.4161/auto.23546

225. Shiau D, Kuo W, Davuluri G, Shieh C, Tsai P, Chen C, et al. Hepatocellular Carcinoma-Derived High Mobility Group Box 1 Triggers M2 Macrophage Polarization via a TLR2/NOX2/autophagy Axis. Sci Rep (2020) 10(1):13582. doi: 10.1038/s41598-020-70137-4

226. Tan H, Wang N, Man K, Tsao S, Che C, Feng Y. Autophagy-Induced RelB/ p52 Activation Mediates Tumour-Associated Macrophage Repolarisation and Suppression of Hepatocellular Carcinoma by Natural Compound Baicalin. Cell Death Dis (2015) 6:e1942. doi: 10.1038/cddis.2015.271

227. Keating G. Sorafenib: A Review in Hepatocellular Carcinoma. Targeted Oncol (2017) 12(2):243-53. doi: 10.1007/s11523-017-0484-7

228. Wei F, Zong S, Zhou J, Fan M, Wang Y, Cheng X, et al. Tumor-Associated Macrophages Attenuate Apoptosis-Inducing Effect of Sorafenib in Hepatoma 
Cells by Increasing Autophagy. Nan fang yi ke da xue xue bao = J South Med Univ (2019) 39(3):264-70. doi: 10.12122/j.issn.1673-4254.2019.03.02

229. Huang Z, Zhou J, Peng Y, He W, Huang C. The Role of Long Noncoding RNAs in Hepatocellular Carcinoma. Mol Cancer (2020) 19(1):77. doi: 10.1186/s12943-020-01188-4

230. Chen J, Huang Z, Liao C, Hu X, Li S, Qi M, et al. LncRNA TP73-AS1/miR539/MMP-8 Axis Modulates M2 Macrophage Polarization in Hepatocellular Carcinoma via TGF- $\beta 1$ signaling. Cell Signal (2020) 75:109738. doi: 10.1016/ j.cellsig.2020.109738

231. Tian X, Wu Y, Yang Y, Wang J, Niu M, Gao S, et al. Long Noncoding RNA LINC00662 Promotes M2 Macrophage Polarization and Hepatocellular Carcinoma Progression via Activating Wnt/ $\beta$-Catenin Signaling. Mol Oncol (2020) 14(2):462-83. doi: 10.1002/1878-0261.12606

232. De Palma M, Biziato D, Petrova T. Microenvironmental Regulation of Tumour Angiogenesis. Nat Rev Cancer (2017) 17(8):457-74. doi: 10.1038/nrc.2017.51

233. Han C, Yang Y, Sheng Y, Wang J, Li W, Zhou X, et al. The Mechanism of IncRNA-CRNDE in Regulating Tumour-Associated Macrophage M2 Polarization and Promoting Tumour Angiogenesis. J Cell Mol Med (2021) 25(9):4235-47. doi: 10.1111/jcmm.16477

234. Hou Z, Xu X, Fu X, Zhou L, Liu S, Tan D. Long Non-Coding RNA MALAT1 Promotes Angiogenesis and Immunosuppressive Properties of HCC Cells by Sponging miR-140. Am J Physiol Cell Physiol (2020) 318(3):C649-63. doi: 10.1152/ajpcell.00510.2018

235. Zhang L, Yu D. Exosomes in Cancer Development, Metastasis, and Immunity. Biochim Biophys Acta Rev Cancer (2019) 1871(2):455-68. doi: 10.1016/j.bbcan.2019.04.004

236. Li X, Lei Y, Wu M, Li N. Regulation of Macrophage Activation and Polarization by HCC-Derived Exosomal IncRNA Tuc339. Int J Mol Sci (2018) 19(10):2958. doi: 10.3390/ijms19102958

237. Yin C, Han Q, Xu D, Zheng B, Zhao X, Zhang J. SALL4-Mediated Upregulation of Exosomal miR-146a-5p Drives T-Cell Exhaustion by M2 Tumor-Associated Macrophages in HCC. Oncoimmunology (2019) 8 (7):1601479. doi: 10.1080/2162402x.2019.1601479

238. Wu J, Gao W, Tang Q, Yu Y, You W, Wu Z, et al. M2 Macrophage-Derived Exosomes Facilitate HCC Metastasis by Transferring $\alpha \beta$ Integrin to Tumor Cells. Hepatol (Baltimore Md.) (2021) 73(4):1365-80. doi: 10.1002/hep.31432

239. Bai Z, Li H, Li C, Sheng C, Zhao X. M1 Macrophage-Derived Exosomal MicroRNA-326 Suppresses Hepatocellular Carcinoma Cell Progression Via Mediating NF-kb Signaling Pathway. Nanoscale Res Lett (2020) 15(1):221. doi: 10.1186/s11671-020-03432-8

240. Shu Q, Ge Y, Ma H, Gao X, Pan J, Liu D, et al. Prognostic Value of Polarized Macrophages in Patients With Hepatocellular Carcinoma After Curative Resection. J Cell Mol Med (2016) 20(6):1024-35. doi: 10.1111/jcmm.12787

241. Dong P, Ma L, Liu L, Zhao G, Zhang S, Dong L, et al. CD $86^{+} / \mathrm{CD} 206^{+}$, Diametrically Polarized Tumor-Associated Macrophages, Predict Hepatocellular Carcinoma Patient Prognosis. Int J Mol Sci (2016) 17 (3):320. doi: 10.3390/ijms17030320

242. Zhu F, Li X, Jiang Y, Zhu H, Zhang H, Zhang C, et al. GdCl3 Suppresses the Malignant Potential of Hepatocellular Carcinoma by Inhibiting the Expression of CD206 in Tumor-Associated Macrophages. Oncol Rep (2015) 34(5):2643-55. doi: 10.3892/or.2015.4268

243. Luo H, Chen J, Luo T, Wu F, Liu J, Wang H, et al. Downregulation of Macrophage-Derived T-UCR Uc.306 Associates With Poor Prognosis in Hepatocellular Carcinoma. Cell Physiol Biochem (2017) 42(4):1526-39. doi: $10.1159 / 000479269$

244. Li Q, Han L, Ruan S, Shen S, Cao Q, Cai X, et al. The Prognostic Value of Neuromedin U in Patients With Hepatocellular Carcinoma. BMC Cancer (2020) 20(1):95. doi: 10.1186/s12885-020-6532-1

245. Rao J, Wu X, Zhou X, Deng R, Ma Y. TMEM205 Is an Independent Prognostic Factor and Is Associated With Immune Cell Infiltrates in Hepatocellular Carcinoma. Front Genet (2020) 11:575776. doi: 10.3389/ fgene.2020.575776

246. Zhang Z, Zhang J, He P, Han J, Sun C. Interleukin-37 Suppresses Hepatocellular Carcinoma Growth Through Inhibiting M2 Polarization of Tumor-Associated Macrophages. Mol Immunol (2020) 122:13-20. doi: 10.1016/j.molimm.2020.03.012

247. Rodríguez M, Onorato A, Cantero M, Domínguez L, Bayo J, Fiore E, et al. 4Methylumbelliferone-Mediated Polarization of M1 Macrophages Correlate
With Decreased Hepatocellular Carcinoma Aggressiveness in Mice. Sci Rep (2021) 11(1):6310. doi: 10.1038/s41598-021-85491-0

248. Wang H, Wang X, Li X, Fan Y, Li G, Guo C, et al. CD68(+)HLA-DR(+) M1Like Macrophages Promote Motility of HCC Cells via NF-kb/FAK Pathway. Cancer Lett (2014) 345(1):91-9. doi: 10.1016/j.canlet.2013.11.013

249. Zong Z, Zou J, Mao R, Ma C, Li N, Wang J, et al. M1 Macrophages Induce PD-L1 Expression in Hepatocellular Carcinoma Cells Through IL-1 $\beta$ Signaling. Front Immunol (2019) 10:1643. doi: 10.3389/fimmu.2019.01643

250. Lu S, Gao Y, Huang X, Wang X. Cantharidin Exerts Anti-Hepatocellular Carcinoma by miR-214 Modulating Macrophage Polarization. Int J Biol Sci (2014) 10(4):415-25. doi: 10.7150/ijbs.8002

251. Wang Q, Cheng F, Ma T, Xiong H, Li Z, Xie C, et al. Interleukin-12 Inhibits the Hepatocellular Carcinoma Growth by Inducing Macrophage Polarization to the M1-Like Phenotype Through Downregulation of Stat-3. Mol Cell Biochem (2016) 415:157-68. doi: 10.1007/s11010-016-2687-0

252. Li Y, Poppoe F, Chen J, Yu L, Deng F, Luo Q, et al. Macrophages Polarized by Expression of ToxoGRA15 Inhibit Growth of Hepatic Carcinoma. Front Immunol (2017) 8:137. doi: 10.3389/fimmu.2017.00137

253. Ye Y, Xu Y, Lai Y, He W, Li Y, Wang R, et al. Long Non-Coding RNA Cox-2 Prevents Immune Evasion and Metastasis of Hepatocellular Carcinoma by Altering M1/M2 Macrophage Polarization. J Cell Biochem (2018) 119 (3):2951-63. doi: 10.1002/jcb.26509

254. Li L, Sun P, Zhang C, Li Z, Cui K, Zhou W. MiR-98 Modulates Macrophage Polarization and Suppresses the Effects of Tumor-Associated Macrophages on Promoting Invasion and Epithelial-Mesenchymal Transition of Hepatocellular Carcinoma. Cancer Cell Int (2018) 18:95. doi: 10.1186/ s12935-018-0590-3

255. Zhang Y, Li Q, Yang X, Fang F, Li J, Wang Y, et al. SPON2 Promotes M1Like Macrophage Recruitment and Inhibits Hepatocellular Carcinoma Metastasis by Distinct Integrin-Rho GTPase-Hippo Pathways. Cancer Res (2018) 78(9):2305-17. doi: 10.1158/0008-5472.Can-17-2867

256. Han Z, Liu S, Lin H, Trivett A, Hannifin S, Yang, et al. Inhibition of Murine Hepatoma Tumor Growth by Cryptotanshinone Involves TLR7-Dependent Activation of Macrophages and Induction of Adaptive Antitumor Immune Defenses. Cancer Immunol Immunother CII (2019) 68(7):1073-85. doi: 10.1007/s00262-019-02338-4

257. Zhou B, Yang Y, Li C. SIRT1 Inhibits Hepatocellular Carcinoma Metastasis by Promoting M1 Macrophage Polarization via NF- Kb Pathway. OncoTargets Ther (2019) 12:2519-29. doi: 10.2147/ott.S195234

258. Li Z, Li H, Zhao Z, Zhu W, Feng P, Zhu X, et al. SIRT4 Silencing in TumorAssociated Macrophages Promotes HCC Development via Ppard SignallingMediated Alternative Activation of Macrophages. J Exp Clin Cancer Res CR (2019) 38(1):469. doi: 10.1186/s13046-019-1456-9

259. Zhou B, Li C, Yang Y, Wang Z. RIG-I Promotes Cell Death in Hepatocellular Carcinoma by Inducing M1 Polarization of Perineal Macrophages Through the RIG-I/MAVS/NF- Kb Pathway. OncoTargets Ther (2020) 13:8783-94. doi: $10.2147 /$ ott.S258450

260. Song M, Li Z, Gu H, Tang R, Zhang R, Zhu Y, et al. Ganoderma Lucidum Spore Polysaccharide Inhibits the Growth of Hepatocellular Carcinoma Cells by Altering Macrophage Polarity and Induction of Apoptosis. J Immunol Res (2021) 2021:6696606. doi: 10.1155/2021/6696606

261. Zhao J, Li H, Zhao S, Wang E, Zhu J, Feng D, et al. Epigenetic Silencing of miR-144/451a Cluster Contributes to HCC Progression via Paracrine HGF/ MIF-Mediated TAM Remodeling. Mol Cancer (2021) 20(1):46. doi: 10.1186/ s12943-021-01343-5

262. Chen S, Zheng P, Wang W, Yi M, Chen P, Cai J, et al. Abberent Expression of NOR1 Protein in Tumor Associated Macrophages Contributes to the Development of DEN-Induced Hepatocellular Carcinoma. J Cell Physiol (2018) 233(6):5002-13. doi: 10.1002/jcp.26349

263. Li M, Lai X, Zhao Y, Zhang Y, Li M, Li D, et al. Loss of NDRG2 in Liver Microenvironment Inhibits Cancer Liver Metastasis by Regulating Tumor Associate Macrophages Polarization. Cell Death Dis (2018) 9(2):248. doi: 10.1038/s41419-018-0284-8

264. Xiao P, Long X, Zhang L, Ye Y, Guo J, Liu P, et al. Neurotensin/IL-8 Pathway Orchestrates Local Inflammatory Response and Tumor Invasion by Inducing M2 Polarization of Tumor-Associated Macrophages and EpithelialMesenchymal Transition of Hepatocellular Carcinoma Cells. Oncoimmunology (2018) 7(7):e1440166. doi: 10.1080/2162402x.2018.1440166 
265. Li Q, Ma L, Shen S, Guo Y, Cao Q, Cai X, et al. Intestinal DysbacteriosisInduced IL-25 Promotes Development of HCC via Alternative Activation of Macrophages in Tumor Microenvironment. J Exp Clin Cancer Res CR (2019) 38(1):303. doi: 10.1186/s13046-019-1271-3

266. Cai J, Zhang Q, Qian X, Li J, Qi Q, Sun R, et al. Extracellular Ubiquitin Promotes Hepatoma Metastasis by Mediating M2 Macrophage Polarization via the Activation of the CXCR4/ERK Signaling Pathway. Ann Trans Med (2020) 8(15):929. doi: 10.21037/atm-20-1054

267. Zhao X, Wang X, You Y, Wen D, Feng Z, Zhou Y, et al. Nogo-B Fosters HCC Progression by Enhancing Yap/Taz-Mediated Tumor-Associated Macrophages M2 Polarization. Exp Cell Res (2020) 391(1):111979. doi: 10.1016/j.yexcr.2020.111979

268. Li J, Xue J, Ling M, Sun J, Xiao T, Dai X, et al. MicroRNA-15b in Extracellular Vesicles From Arsenite-Treated Macrophages Promotes the Progression of Hepatocellular Carcinomas by Blocking the LATS1-Mediated Hippo Pathway. Cancer Lett (2021) 497:137-53. doi: 10.1016/j.canlet.2020.10.023

269. Chen S, Morine Y, Tokuda K, Yamada S, Saito Y, Nishi M, et al. Cancer -associated Fibroblast-Induced M2-polarized Macrophages Promote Hepatocellular Carcinoma Progression via the Plasminogen Activator Inhibitor-1 Pathway. Int J Oncol (2021) 59(2):59. doi: 10.3892/ijo.2021.5239

270. Xun X, Zhang C, Wang S, Hu S, Xiang X, Cheng Q, et al. Cyclooxygenase-2 Expressed Hepatocellular Carcinoma Induces Cytotoxic T Lymphocytes Exhaustion Through M2 Macrophage Polarization. Am J Trans Res (2021) 13(5):4360-75

271. Xu D, Wang Y, Wu J, Zhang Z, Chen J, Xie M, et al. ECT2 Overexpression Promotes the Polarization of Tumor-Associated Macrophages in Hepatocellular Carcinoma via the ECT2/PLK1/PTEN Pathway. Cell Death Dis (2021) 12(2):162. doi: 10.1038/s41419-021-03450-z

272. Wang L, Lin J, Ma X, Xu D, Shi C, Wang W, et al. Exosomal DLX6-AS1 From Hepatocellular Carcinoma Cells Induces M2 Macrophage Polarization to Promote Migration and Invasion in Hepatocellular Carcinoma Through microRNA-15a-5p/CXCL17 Axis. J Exp Clin Cancer Res CR (2021) 40 (1):177. doi: 10.1186/s13046-021-01973-Z

273. Dou L, Shi X, He X, Gao Y. Macrophage Phenotype and Function in Liver Disorder. Front Immunol (2019) 10:3112. doi: 10.3389/fimmu.2019.03112

274. Faure-Dupuy S, Delphin M, Aillot L, Dimier L, Lebossé F, Fresquet J, et al. Hepatitis B Virus-Induced Modulation of Liver Macrophage Function Promotes Hepatocyte Infection. J Hepatol (2019) 71(6):1086-98. doi: 10.1016/ j.jhep. 2019.06 .032

275. Lee J, French B, Morgan T, French S. The Liver Is Populated by a Broad Spectrum of Markers for Macrophages. In Alcoholic Hepatitis the Macrophages Are M1 and M2. Exp Mol Pathol (2014) 96(1):118-25. doi: 10.1016/j.yexmp.2013.09.004

276. Zhu L, Liu C, Li Z, Niu C, Wu J. NLRP3 Deficiency did Not Attenuate NASH Development Under High Fat Calorie Diet Plus High Fructose and Glucose in Drinking Water. Lab Invest (2021) 101(5):588-99. doi: 10.1038/s41374021-00535-3

277. Wan J, Benkdane M, Teixeira-Clerc F, Bonnafous S, Louvet A, Lafdil F, et al. M2 Kupffer Cells Promote M1 Kupffer Cell Apoptosis: A Protective Mechanism Against Alcoholic and Nonalcoholic Fatty Liver Disease. Hepatol (Baltimore Md.) (2014) 59(1):130-42. doi: 10.1002/hep.26607

278. Tan Z, Sun H, Xue T, Gan C, Liu H, Xie Y, et al. Liver Fibrosis: Therapeutic Targets and Advances in Drug Therapy. Front Cell Dev Biol (2021) 9:730176. doi: $10.3389 /$ fcell.2021.730176

279. Liu J, Kong D, Qiu J, Xie Y, Lu Z, Zhou C, et al. Praziquantel Ameliorates CCl -Induced Liver Fibrosis in Mice by Inhibiting TGF- $\beta /$ Smad Signalling via Up-Regulating Smad7 in Hepatic Stellate Cells. Br J Pharmacol (2019) 176 (24):4666-80. doi: 10.1111/bph.14831

280. Wu K, Lin K, Li X, Yuan X, Xu P, Ni P, et al. Redefining Tumor-Associated Macrophage Subpopulations and Functions in the Tumor Microenvironment. Front Immunol (2020) 11:1731. doi: 10.3389/fimmu.2020.01731

281. Zhang Y, Kong D, Wang H. Mucosal-Associated Invariant T Cell in Liver Diseases. Int J Biol Sci (2020) 16(3):460-70. doi: 10.7150/ijbs.39016

282. Grønbaek H, Kreutzfeldt M, Kazankov K, Jessen N, Sandahl T, HamiltonDutoit S, et al. Single-Centre Experience of the Macrophage Activation Marker Soluble (s)CD163 - Associations With Disease Activity and Treatment Response in Patients With Autoimmune Hepatitis. Aliment Pharmacol Ther (2016) 44(10):1062-70. doi: 10.1111/apt.13801
283. Bossen L, Rebora P, Bernuzzi F, Jepsen P, Gerussi A, Andreone P, et al. Soluble CD163 and Mannose Receptor as Markers of Liver Disease Severity and Prognosis in Patients With Primary Biliary Cholangitis. Liver Int (2020) 40(6):1408-14. doi: 10.1111/liv.14466

284. Bossen L, Vesterhus M, Hov J, Färkkilä M, Rosenberg W, Møller H, et al. Circulating Macrophage Activation Markers Predict Transplant-Free Survival in Patients With Primary Sclerosing Cholangitis. Clin Trans Gastroenterol (2021) 12(3):e00315. doi: 10.14309/ctg.0000000000000315

285. Guicciardi M, Trussoni C, Krishnan A, Bronk S, Lorenzo Pisarello M, O'Hara S, et al. Macrophages Contribute to the Pathogenesis of Sclerosing Cholangitis in Mice. J Hepatol (2018) 69(3):676-86. doi: 10.1016/j.jhep.2018.05.018

286. Li H, Sun S, Lei Q, Lei P, Cai X, Wan C, et al. M1-Polarized Macrophages Promote Self-Renewing Phenotype of Hepatic Progenitor Cells With Jagged1Notch Signalling Involved: Relevance in Primary Sclerosing Cholangitis. $J$ Immunol Res (2018) 2018:4807145. doi: 10.1155/2018/4807145

287. Jiang A, Okabe H, Popovic B, Preziosi M, Pradhan-Sundd T, Poddar M, et al. Loss of Wnt Secretion by Macrophages Promotes Hepatobiliary Injury After Administration of 3,5-Diethoxycarbonyl-1, 4-Dihydrocollidine Diet. Am J Pathol (2019) 189(3):590-603. doi: 10.1016/j.ajpath.2018.11.010

288. Li X, Liu R, Wang Y, Zhu W, Zhao D, Wang X, et al. Cholangiocyte-Derived Exosomal lncRNA H19 Promotes Macrophage Activation and Hepatic Inflammation Under Cholestatic Conditions. Cells (2020) 9(1):190. doi: 10.3390/cells9010190

289. Liu Y, Liu H, Zhu J, Bian Z. Interleukin-34 Drives Macrophage Polarization to the M2 Phenotype in Autoimmune Hepatitis. Pathol Res Pract (2019) 215 (8):152493. doi: 10.1016/j.prp.2019.152493

290. Li X, Wang H. Multiple Organs Involved in the Pathogenesis of NonAlcoholic Fatty Liver Disease. Cell Biosci (2020) 10(1):140. doi: 10.1186/ s13578-020-00507-y

291. Shim Y, Jeong W. Recent Advances of Sterile Inflammation and Inter-Organ Cross-Talk in Alcoholic Liver Disease. Exp Mol Med (2020) 52(5):772-80. doi: 10.1038/s12276-020-0438-5

292. Zhang X, Ji X, Wang Q, Li J. New Insight Into Inter-Organ Crosstalk Contributing to the Pathogenesis of Non-Alcoholic Fatty Liver Disease (NAFLD). Protein Cell (2018) 9(2):164-77. doi: 10.1007/s13238-017-0436-0

293. Mandal P, Pritchard M, Nagy L. Anti-Inflammatory Pathways and Alcoholic Liver Disease: Role of an Adiponectin/Interleukin-10/Heme Oxygenase-1 Pathway. World J Gastroenterol (2010) 16(11):1330-6. doi: 10.3748/ wjg.v16.i11.1330

294. Fang T, Lv H, Lv G, Li T, Wang C, Han Q, et al. Tumor-Derived Exosomal miR-1247-3p Induces Cancer-Associated Fibroblast Activation to Foster Lung Metastasis of Liver Cancer. Nat Commun (2018) 9(1):191. doi: 10.1038/s41467-017-02583-0

295. Gastaldi G, Gomes D, Schneiter P, Montet X, Tappy L, Clément S, et al. Treatment With Direct-Acting Antivirals Improves Peripheral Insulin Sensitivity in Non-Diabetic, Lean Chronic Hepatitis C Patients. PLoS One (2019) 14(6):e0217751. doi: 10.1371/journal.pone.0217751

296. Zheng Y, Cui B, Sun W, Wang S, Huang X, Gao H, et al. Potential Crosstalk Between Liver and Extra-Liver Organs in Mouse Models of Acute Liver Injury. Int J Biol Sci (2020) 16(7):1166-79. doi: 10.7150/ijbs.41293

Conflict of Interest: The authors declare that the research was conducted in the absence of any commercial or financial relationships that could be construed as a potential conflict of interest.

Publisher's Note: All claims expressed in this article are solely those of the authors and do not necessarily represent those of their affiliated organizations, or those of the publisher, the editors and the reviewers. Any product that may be evaluated in this article, or claim that may be made by its manufacturer, is not guaranteed or endorsed by the publisher.

Copyright (๑) 2021 Wang, Ma, Gong, Guo, Fu, Zhang, Zhou and Li. This is an openaccess article distributed under the terms of the Creative Commons Attribution License (CC BY). The use, distribution or reproduction in other forums is permitted, provided the original author(s) and the copyright owner(s) are credited and that the original publication in this journal is cited, in accordance with accepted academic practice. No use, distribution or reproduction is permitted which does not comply with these terms. 